\title{
Evaluation of the CRREL Permafrost Tunnel
}

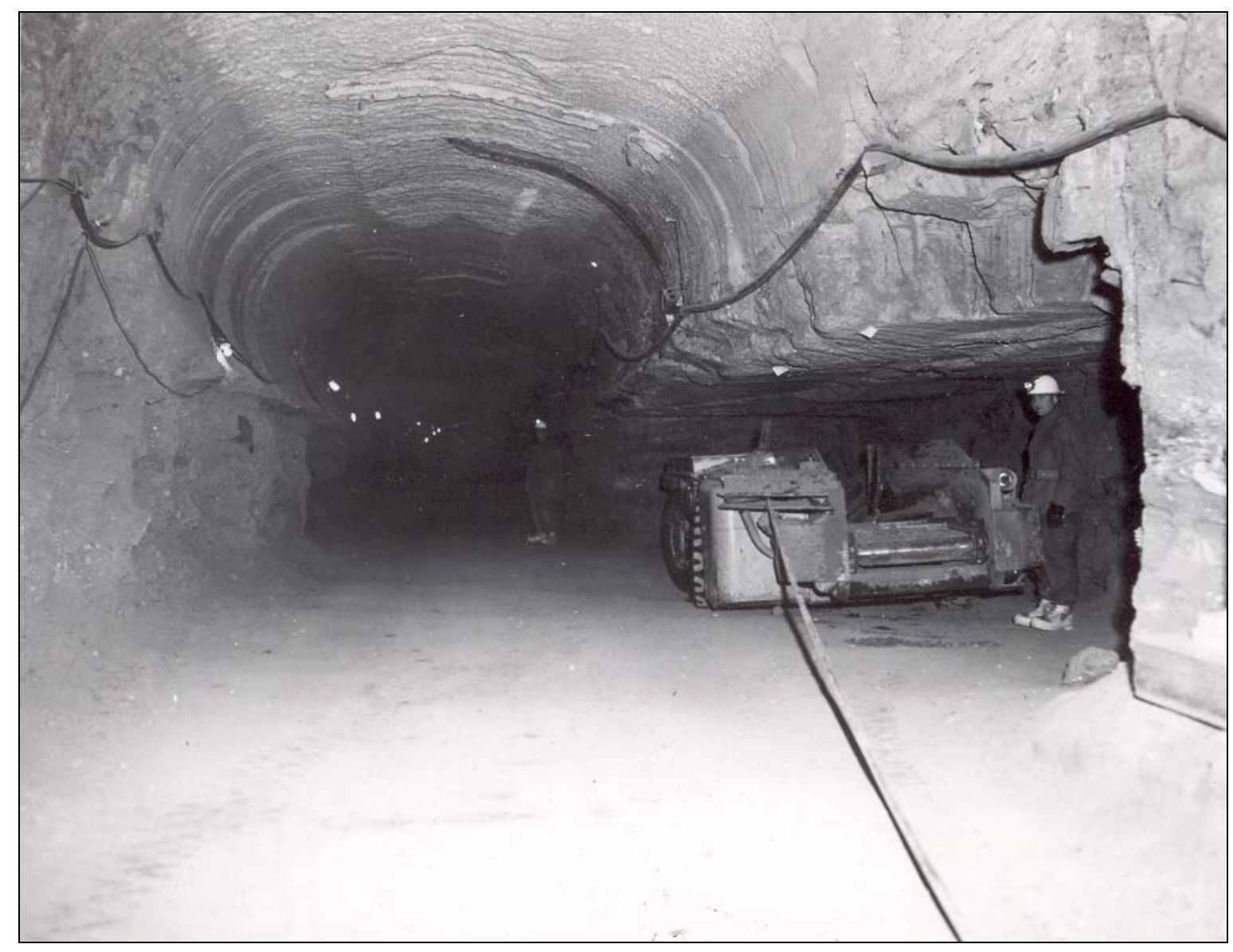


COVER: The CRREL Permafrost Tunnel shortly after completion of the adit. 


\section{Evaluation of the CRREL Permafrost Tunnel}

Kevin Bjella, Thomas Tantillo, Jason Weale, and James Lever

US Army Engineer Research and Development Center

Cold Regions Research and Engineering Laboratory

72 Lyme Road

Hanover, NH 03755-1290

Approved for public release; distribution is unlimited. 


\begin{abstract}
The Permafrost Tunnel was excavated in frozen silt and consists of a 110-m-long horizontal adit and a 45-m-long winze that extends down to the underlying gravel. Some change has occurred since the excavation was conducted in the mid-1960s, so a team was assembled in the spring of 2006 to assess these changes. Frozen silt deformation was noted in the rear of the adit, and a roof fall of the gravel layer was noted in the room at the bottom of the winze. Both of these were found to be attributable to thermal forcing events and the raising of the overall facility temperature to near-freezing temperatures. Sublimation was also noted throughout the tunnel, but this does not pose a problem for the structural integrity of the facility. The team recommends that the facility temperature be lowered to approximately $-5^{\circ} \mathrm{C}$, which will decrease creep rates and the weakening of lithologic bonds between soil units. Overall, the facility is safe for continued use by researchers and others.
\end{abstract}

DISCLAIMER: The contents of this report are not to be used for advertising, publication, or promotional purposes. Citation of trade names does not constitute an official endorsement or approval of the use of such commercial products. All product names and trademarks cited are the property of their respective owners. The findings of this report are not to be construed as an official Department of the Army position unless so designated by other authorized documents. 


\section{Contents}

PREFACE

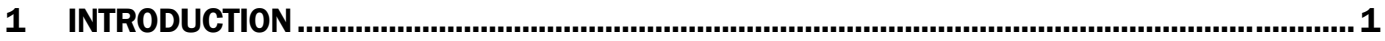

2 BACKGROUND

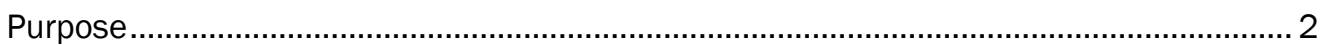

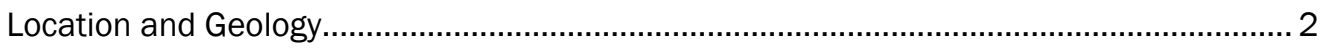

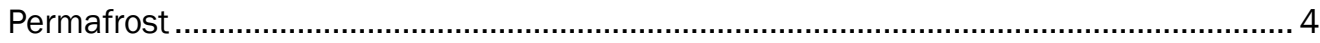

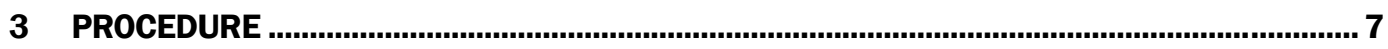

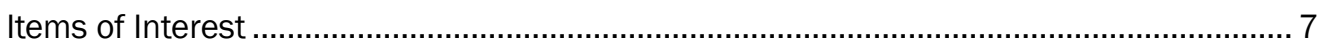

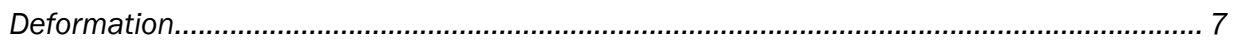

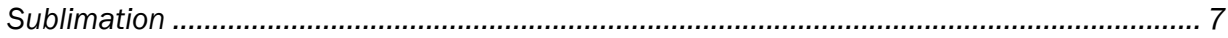

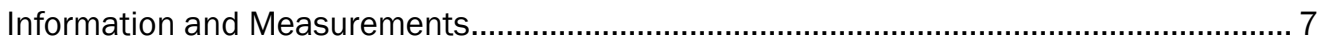

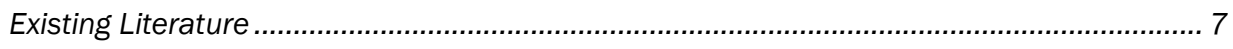

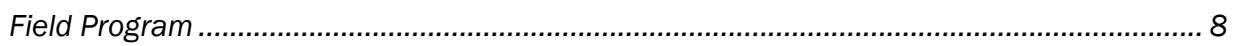

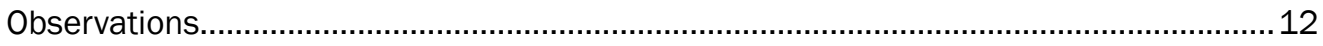

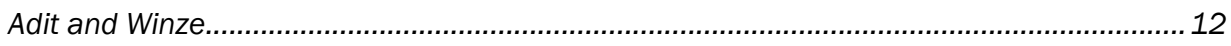

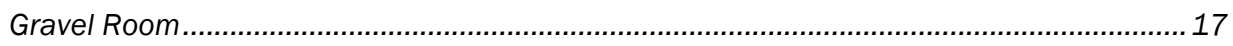

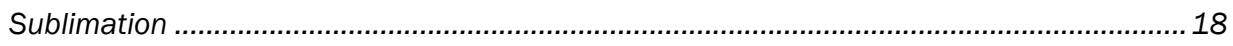

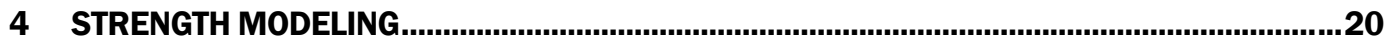

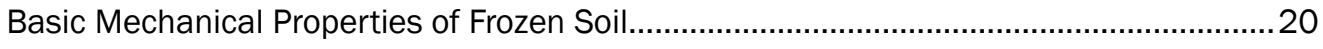

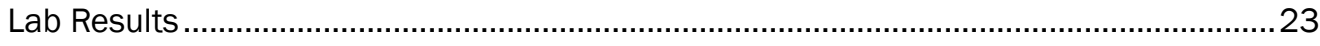

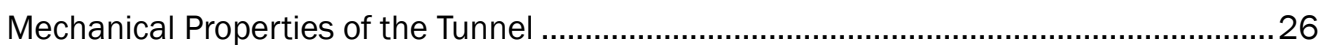

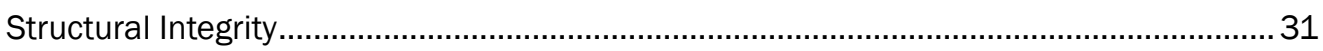

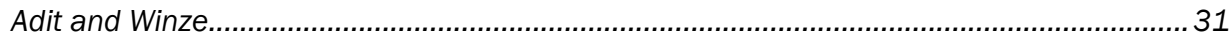

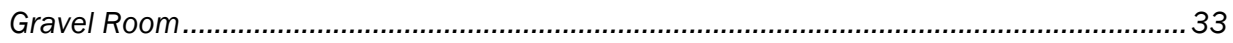

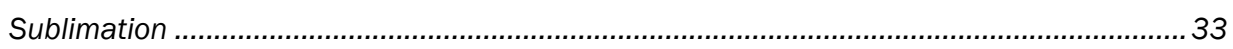

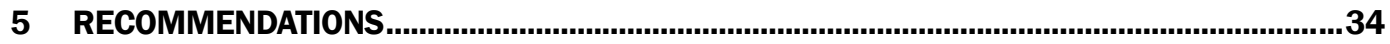

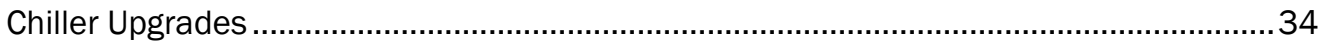

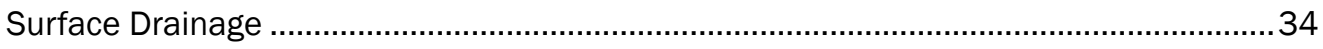

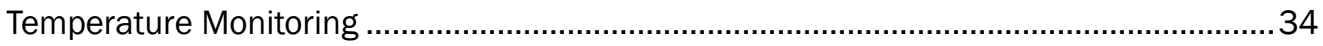

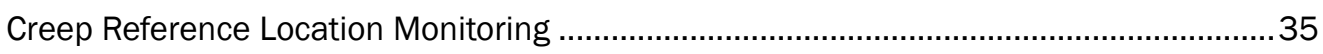

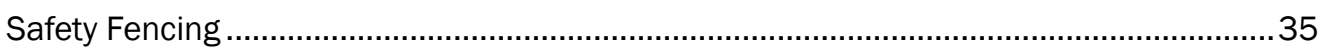

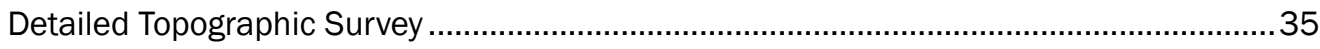

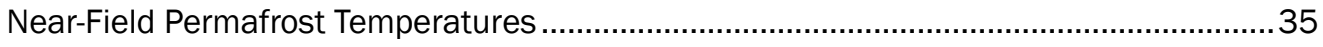

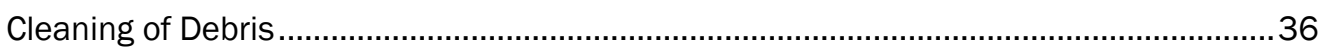

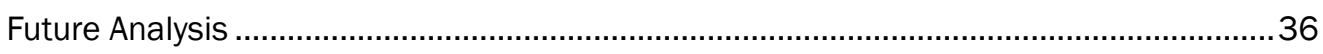

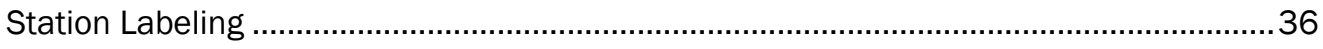

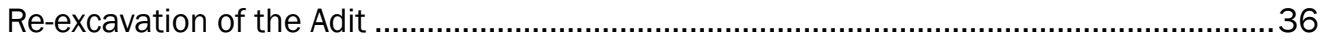

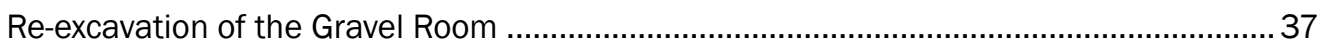




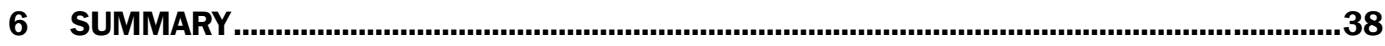

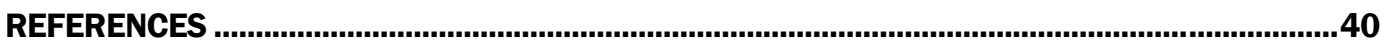

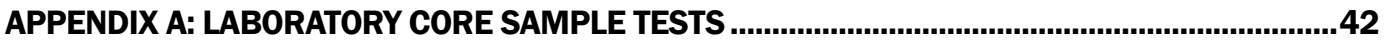

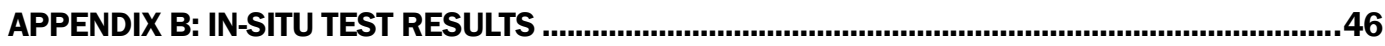

APPENDIX C: CALIBRATION OF LOAD CELL........................................................................

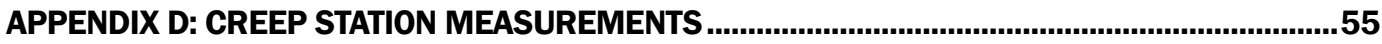

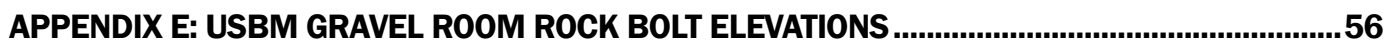

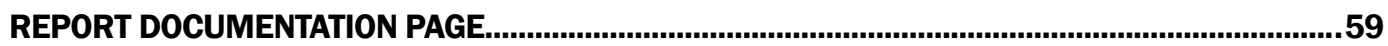




\section{Figures and Tables}

\section{Figures}

Figure 1. Location of the CRREL Permafrost Tunnel and surface topography...

Figure 2. Cross section of the Permafrost Tunnel showing the lithology and the locations

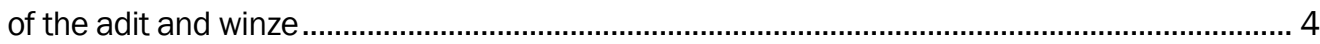

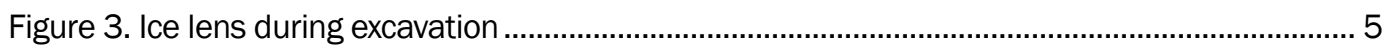

Figure 4. Ice wedge in the adit wall ............................................................................................... 5

Figure 5. Periglacial features in the Permafrost Tunnel.................................................................. 6

Figure 6. Detailed topographic survey conducted in 1969 by USBM .............................................. 10

Figure 7. Typical creep reference location numbering scheme, looking up-station toward

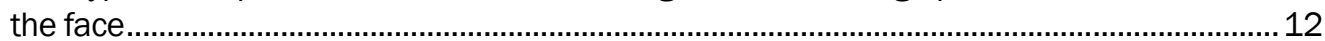

Figure 8. Rear of adit at approximately 85+00 ......................................................................... 14

Figure 9. Roof over the area shown in Figure 8, where a layer has delaminated, sagged,

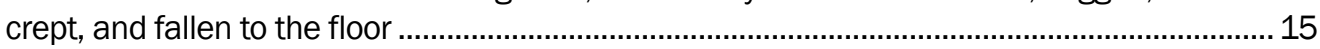

Figure 10. Third vent installed from the surface to the rear of the adit, with a louvered pipe to close off the vent during the summer...................................................................... 17

Figure 11. USBM Gravel Room located at the bottom of the winze ................................................ 19

Figure 12. Classic creep curves resulting from constant stress testing ........................................... 21

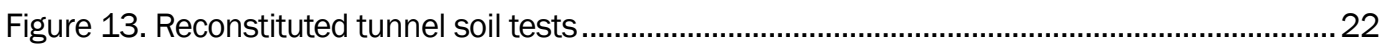

Figure 14. Simple rectangular beam in pure bending, showing the distribution of compression and tension stresses................................................................................ 27

Figure 15. Core \#1-H unconfined constant strain rate test at a strain rate of $1 \times 10^{-3} / \mathrm{s}$

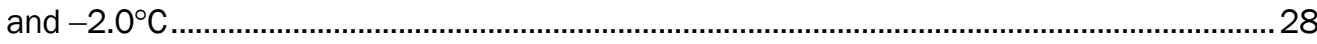

Figure 16. Vertical and horizontal boundary stresses determined by geometry and field stress

\section{Tables}

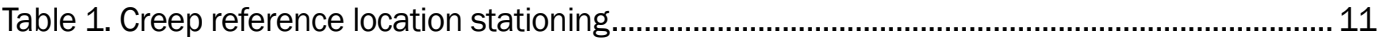

Table 2. Results of constant strain rate testing of tunnel cores ....................................................25

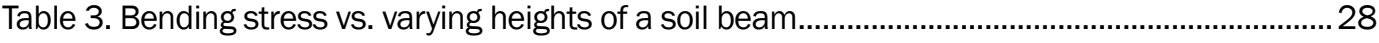

Table 4. Strength indexes normalized to $1.8 \mathrm{MPa}$ and tested at $1 \times 10^{-3} / \mathrm{s}$ strain rate...................29 


\section{Preface}

This report was prepared by Kevin Bjella, Applied and Military Engineering Branch; Thomas Tantillo, Engineering Resources Branch; Jason Weale, Applied and Military Engineering Branch; and Dr. James Lever, Applied and Military Engineering Branch, Cold Regions Research and Engineering Laboratory (CRREL), US Army Engineer Research and Development Center (ERDC), Hanover, New Hampshire.

The authors thank Charles Collins, Dr. Jerome Johnson, and Dr. Matthew Sturm for their review and comments. Funding for this report was supplied by CRREL Special Programs and Initiatives.

This report was prepared under the general supervision of Dr. Lance D. Hansen, Deputy Director, CRREL; and Dr. Robert E. Davis, Director, CRREL.

At the time this report was published, Colonel Gary E. Johnston was Commander and Executive Director of ERDC. Dr. James R. Houston was Director. 


\section{INTRODUCTION}

The Cold Regions Research and Engineering Laboratory (CRREL) operates a subsurface tunnel constructed in permanently frozen soil in Fox, Alaska. During the spring of 2006, a team from CRREL was assembled to examine the state of the tunnel and assess the possibilities for upgrades and expansion. This included a literature review, a tunnel site visit with soil sample collection and climatic measurements, on-site and laboratory soil strength evaluation, and presentation of results with recommendations. 


\section{BACKGROUND}

\section{Purpose}

Over the years, the tunnel has proved to be an invaluable tool for the insitu study of warm, fine-grained permafrost and associated periglacial features. The tunnel also serves as a portal to the past, as flora and fauna of the Pleistocene Era are preserved in the walls for scientists to study and non-scientists to view. As one moves from the portal to the lower reaches of the winze, one passes through more than 40,000 years of time. Bison and mammoth bones, willow roots and branches, and various grasses can be found preserved in the frozen ground.

Because of the age of the tunnel, areas and items have fallen into disrepair; there has been a general degradation and it is in need of upgrade or reconditioning. To best determine the current operational limits and what could be done to upgrade the tunnel for access to further study and outreach, a team was assembled to inspect all areas of the facility and recommend a course of action to facilitate its longevity. This is the report of findings and recommendations from that investigation.

\section{Location and Geology}

The tunnel is located $16 \mathrm{~km}$ north of Fairbanks in Fox, Alaska. It was driven into a nearly vertical silt escarpment that lies at the margin of Goldstream Creek Valley. The valley was historically mined for placer gold, and the escarpment was created by this activity. The geology at the tunnel consists of silt deposits that are Wisconsin to recent in age and eolian (wind blown) in nature and are derived from the glaciers of the Alaska Range. The silts overlie gravels of Nebraskan age that are derived from the surrounding hills of the Yukon-Tanana Upland terrain, and they in turn overlie Pre-Cambrian metamorphic schist bedrock (Sellman 1967). The natural surface over the axis of the tunnel rises gently from the top of the 10-m escarpment and preferentially drains toward Goldstream Creek to the west and Glenn Creek to the north (Fig. 1). 


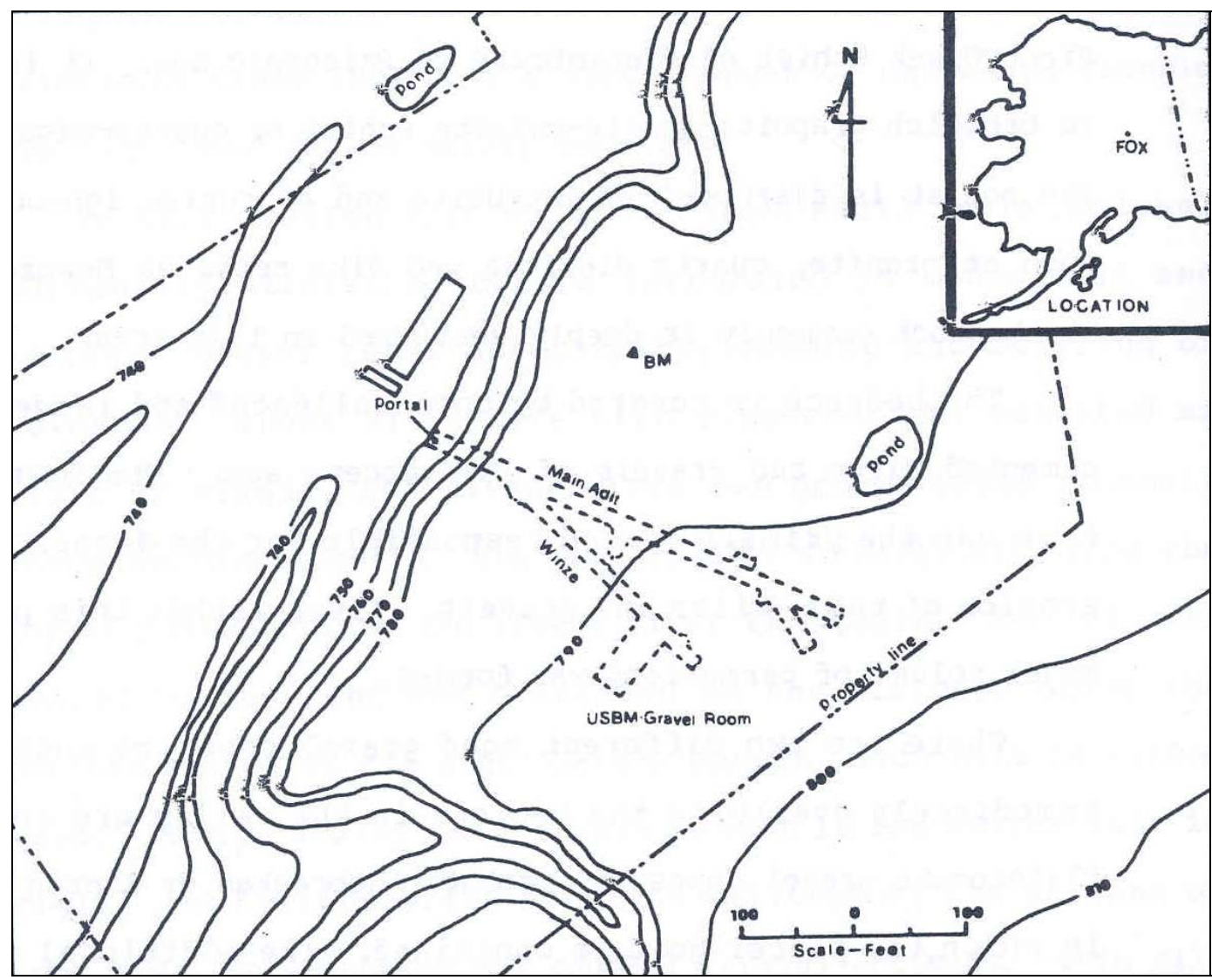

Figure 1. Location of the CRREL Permafrost Tunnel and surface topography.* (From Pettibone and Waddell 1969.)

This tunnel is composed of two portions: the adit (a nearly horizontal passage from the surface into a mine), which was driven by the US Army Corps of Engineers using continuous mining methods in the winters of 1963-64, 1964-65, and 1965-66 (Sellman 1967), and the winze (an inclined adit), which was driven by the US Bureau of Mines (USBM) from 1968 to 1969 using drill and blast, thermal relaxation, and hydraulic relaxation methods (Chester and Frank 1969). The adit extends into the scarp $110 \mathrm{~m}$ and is predominantly located in the silt unit (Fig. 2). The winze begins approximately $30 \mathrm{~m}$ into the adit and drops obliquely at an incline of $14 \%$ for $45 \mathrm{~m}$, passing into the gravel unit and ultimately into the weathered bedrock, where a Gravel Room was excavated (Pettibone 1973). At the time of excavation, portions of the Gravel Room roof consisted of a gravel layer up to $2 \mathrm{~m}$ thick below the overlying silt unit (Garbeil 1983). After the winze levels out adjacent to the Gravel Room, it continues for another $10 \mathrm{~m}$ as a drift into what is known as the CRREL Room. The silt overburden at the thickest point is approximately $14 \mathrm{~m}$ over the adit and $18 \mathrm{~m}$ over the Gravel Room.

\footnotetext{
* Some older figures use feet instead of meters. To convert, multiply feet by 0.3048 to obtain meters.
} 


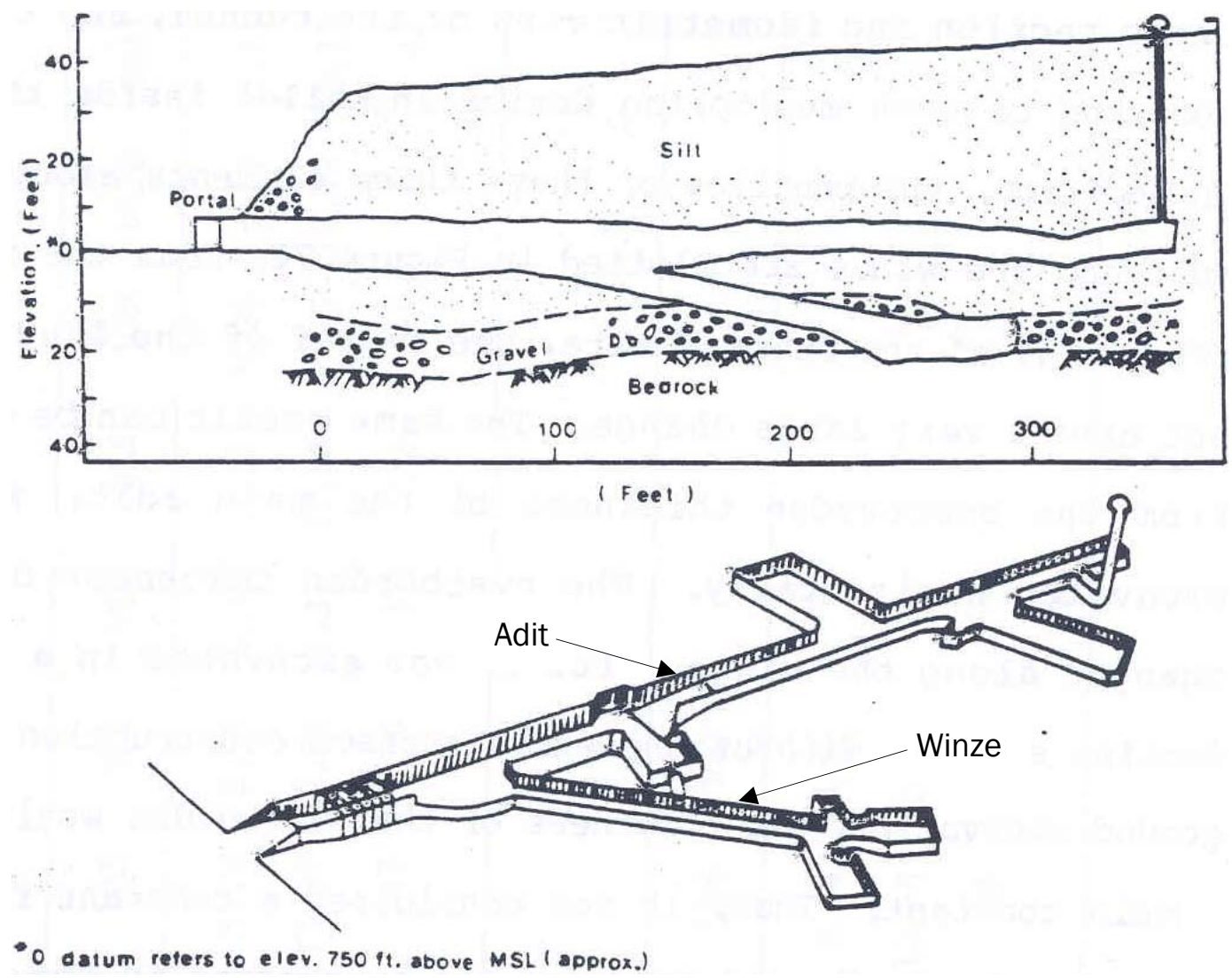

Figure 2. Cross section of the Permafrost Tunnel showing the lithology and the locations of the adit and winze. (From Wu 1985.)

\section{Permafrost}

The Fairbanks area lies in a region of discontinuous permafrost, and the temperature of this ground is generally warm $\left(-5.0^{\circ} \mathrm{C}\right.$ to $\left.-0.5^{\circ} \mathrm{C}\right)$. Hilltops, south-facing slopes, and well-drained areas are usually permafrost free. The permafrost layer extends approximately $30-50 \mathrm{~m}$ below the surface, but it can exceed a thickness of 100 m (Péwé 1993).

The Permafrost Tunnel is driven completely into frozen ground and is overlain at the surface by a 0.7- to 1.0-m-deep active layer typical of the Fairbanks area. The active layer soils that are directly above the portal and extend to the surface are cooled by a mechanical liquid cooling system and loops of piping during the months when ambient temperatures are above $\mathrm{O}^{\circ} \mathrm{C}$. The tunnel contains many periglacial features found in fine-grained permafrost, such as segregated ice (ice lenses, Fig. 3), massive ice (ice wedges and thaw ponds, Fig. 4), and erosional and climate change boundaries marking depositional events, all of which are readily seen in the walls and roof of the adit and winze. The mode of permafrost formation was generally syngenetic (frozen during emplacement), while the lower end 


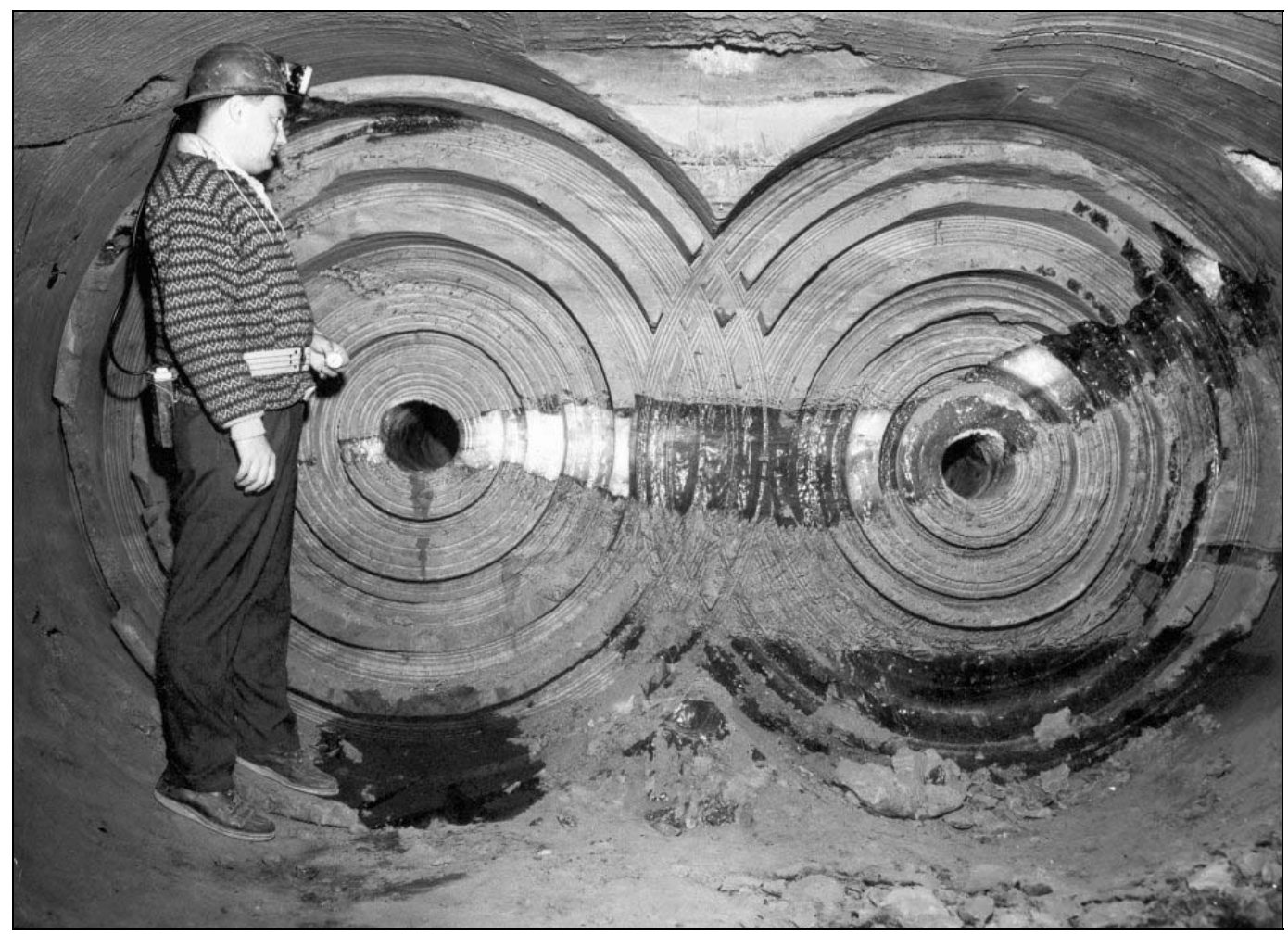

Figure 3. Ice lens during excavation. These features are abundant in the fine-grained soils of the Fairbanks region and are visible in the tunnel. This is one pass of the Alkirk mining machine that excavated the adit.

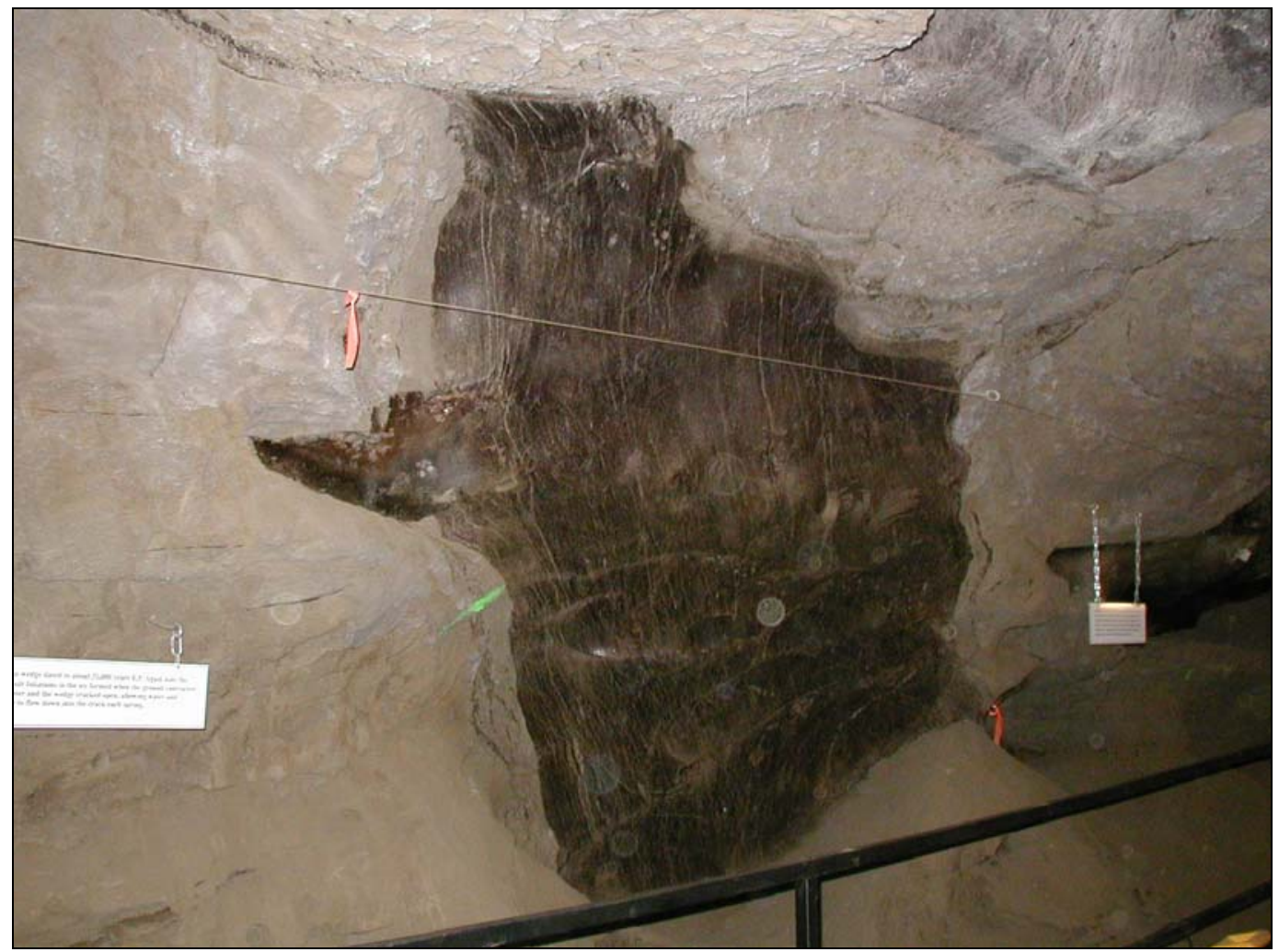

Figure 4. Ice wedge in the adit wall. 
of the ice wedge features must have been epigenetic (frozen after emplacement). The ice wedges are probably segments of larger ice-wedge polygon complexes. Sellman (1967) suggested that two major silt units with separate ice wedge development exist in the adit. The major features are illustrated in Figure 5; note the gravel in the rear of the adit.
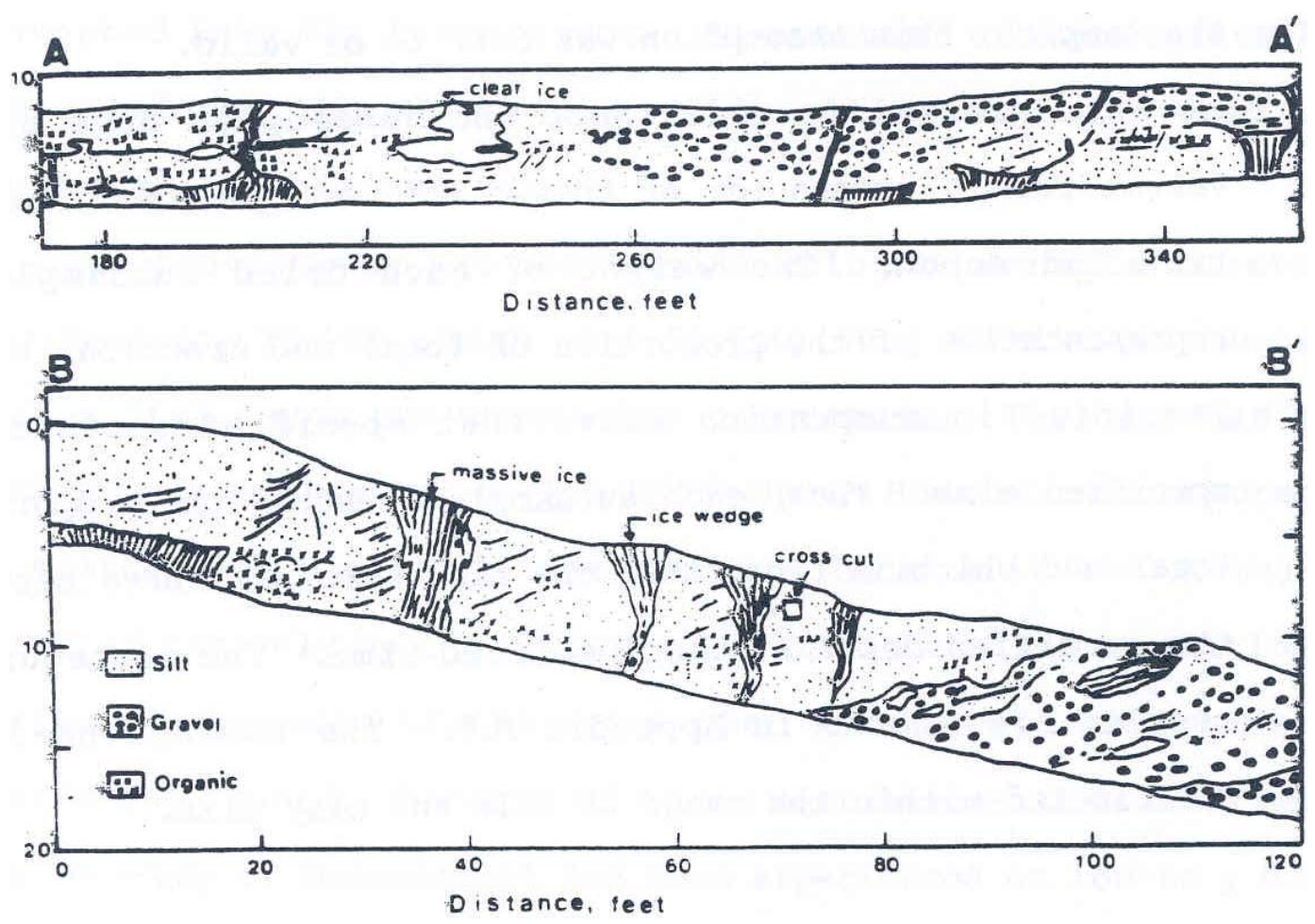

Figure 5. Periglacial features in the Permafrost Tunnel. The rear portion of the adit is the upper diagram, and the winze is the lower diagram. (From Sellman 1967.) 


\section{PROCEDURE}

\section{Items of Interest}

Two items that required assessment were 1) the strength of the deforming soils and closure rate at the end of the adit and the USBM Gravel Room, and 2) the sublimation of ice within the soil matrix, which has caused slow ablation of the tunnel walls and roof.

\section{Deformation}

The deformation has led to altered use of portions of the tunnel and has prompted concerns for longevity and safety. Specifically, the rear $20 \mathrm{~m}$ of the adit is inaccessible because of roof deformation, where the roof has crept to floor level over the last 10-15 years. The roof of the USBM Gravel Room fell to the floor, presumably after a 6.2 magnitude earthquake in October 1995. The portion that fell was the remaining gravel that extended up to the overlying silt unit.

\section{Sublimation}

Because of sublimation, the ice matrix cementing the soil grains is slowly lost, causing silt to mask periglacial features and ultimately fall from the walls and roof and accumulate on the floor as a fine powder. This has caused the ice features to recede into the walls, resulting in obscured exposure. As visitors move through, the powder is disturbed and particles are suspended in the air. This has required extensive cleanings in the past and the installation of a metal catwalk that keeps foot traffic out of the dust. Sublimation of the ice matrix in the coarser soils causes gravels to fall to the floor, resulting in a thick layer of loose gravel overlying the bedrock.

\section{Information and Measurements}

\section{Existing Literature}

The literature review revealed studies conducted in the tunnel to determine the creep rate of the facility, both in the adit and in the Gravel Room. Other studies were conducted that are applicable to the soils of the tunnel, such as Sayles and Carbee (1981), who investigated the strength of frozen silt as a function of ice content; Sayles and Haines (1974), who investigated 
the creep of frozen silt and clay; and a very comprehensive CRREL report by Zhu and Carbee (1987a), who investigated the creep and strength of reconstituted tunnel silt.

\section{Field Program}

The lack of knowledge about the state of the tunnel and the mechanics of its frozen soil warranted a field program to measure current parameters that affect the tunnel integrity.

\section{Temperature}

A Campbell Scientific datalogger was wired with seven thermistors and a relative humidity sensor. Two of the thermistors consisted of 30-m lengths of wire, two were 20-m lengths, and two were 10-m lengths, with the remaining thermistor in the datalogger box and the relative humidity sensor attached to a $3-\mathrm{m}$ length of wire. This array was deployed with the datalogger box located at the center of the span to be measured. The thermistors were either hung in ambient air or a drill was used to emplace them at depth in the soil. A $0.6-\mathrm{cm}$-diameter by 91-cm-long drill bit was used to drill into the permafrost, and the thermistors were placed at the depth for measurement and allowed to equilibrate, usually overnight. Measurements were taken at various depths into the wall of the tunnel to obtain temperature gradients perpendicular to the axis at various stations.

\section{Soil Strength}

A modified Shelby tube was manufactured to obtain 5-cm-diameter core samples by installing 5 -mm carbide teeth onto the leading edge of the original Shelby tube. Seventeen samples were tested in the tunnel by the use of a hand-operated Soiltest press used in the unconfined, constantstrain-rate mode. Strain rates of $1 \%$ per minute were used for the majority of the in-situ core tests in the tunnel. The tested samples were then sent to the Hanover, New Hampshire, laboratory for moisture content determination. Untested cores were shipped to Hanover to validate the tunnel tests by conducting uni-axial and confined constant-strain-rate tests. The complete results are shown in Appendices A and B, and the calibration of the load cell is discussed in Appendix C. 
Surveys

A topographic survey was conducted to locate areas of interest and establish a baseline profile of the tunnel. Two control points were located outside of the portal in the parking area by differential GPS. This control was then brought into the tunnel via an optical total station. Another control point was needed (away from the portal) to capture points of interest in that area. The centerlines of the adit and winze and the vent locations were located on the surface (above ground). A very detailed survey conducted in 1969 is shown in Figure 6; unfortunately the original data are not available. Four rock bolts that were installed in the Gravel Room in 1969 (Appendix E, Fig. E2) were used for reference. The elevations of the bottom of these rods that hang from the roof and are placed into or near the silt unit were measured. Also, a survey was conducted to gather lithological and structural information in association with areas of interest and, to a lesser extent, throughout the facility. This consisted of visual examination of the soil and soil strata, the orientations and types of excess and massive ice features, the dimensional characteristics of the tunnel and rooms, the extent of the deformation, and other structural information (broken timbers and deformed lumber). 


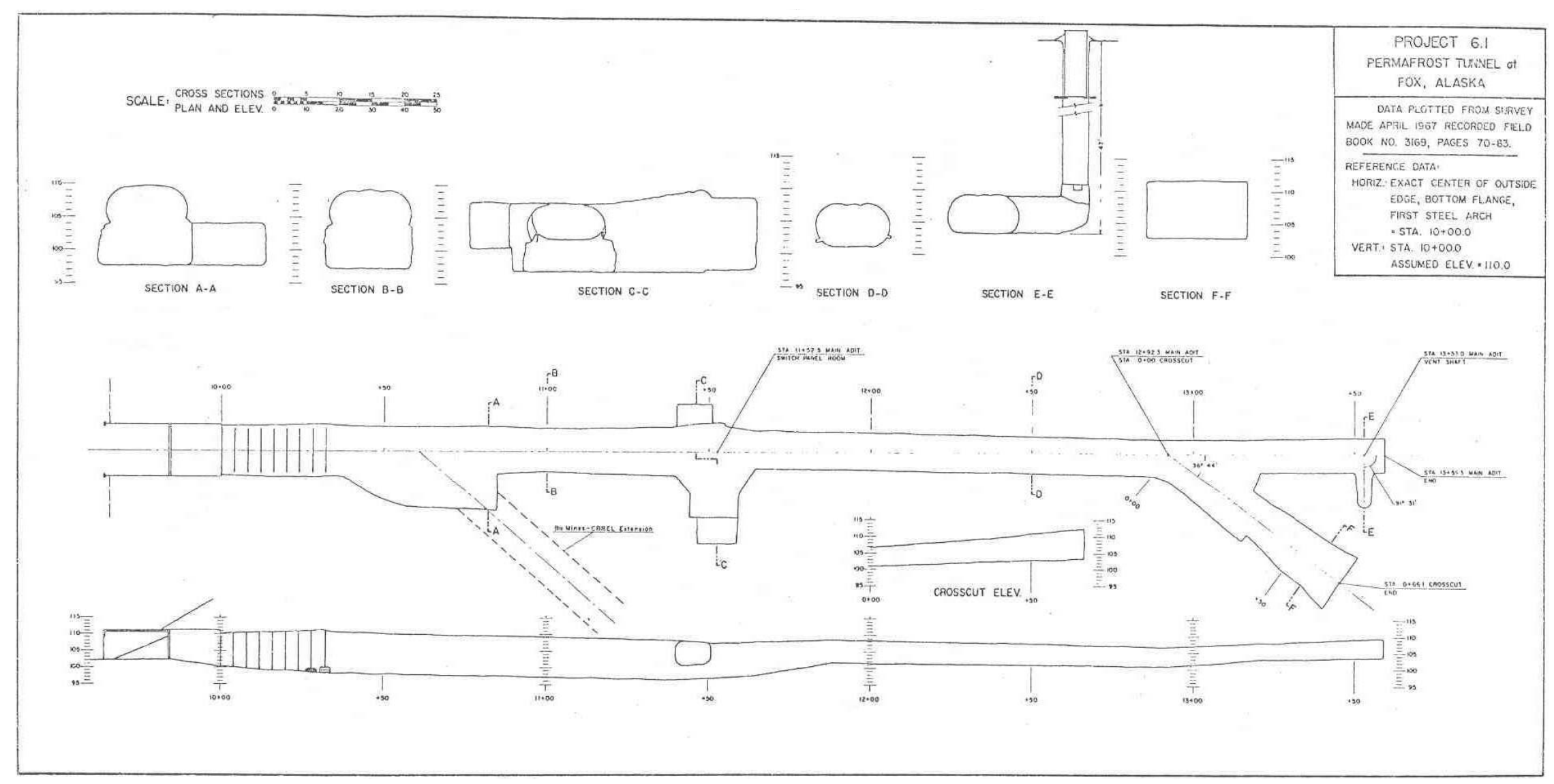

Figure 6. Detailed topographic survey conducted in 1969 by USBM. (From Chester and Frank 1969.) 


\section{Monitoring Locations}

Seven creep reference locations were established in the adit, and two more were established in the winze, to specifically measure the change in dimension of selected areas in the tunnel. Each location consisted of four points, which were 0.95 -cm-diameter $\times 20$-cm-long lag eye-bolts screwed into the soil. Two of the points were located at mid-height of opposing walls, approximately perpendicular to the axis of the tunnel and approximately across from each other. The other two were located in the roof and floor in the same plane as the wall points, and they were approximately middistance across the width of the adit or winze.

The locations are numbered starting with 1 and continuing up-station and are prefixed with $\mathrm{A}$ for adit or $\mathrm{W}$ for winze. Four points at each location are indicated as follows: the floor point is A, the left wall point (as viewed looking up-station) is B, and so forth. For example, the floor point of the first location in the adit is labeled A1-A, and the right wall point of the second location in the winze is labeled W2-D (Fig. 7). Adit location number 3 consists of only floor and roof points, which are labeled A3-A and A3-C, respectively. The creep reference locations are listed in Table 1.

Table 1. Creep reference location stationing.

\begin{tabular}{|c|c|}
\hline Location ID & Stationing $(\mathrm{m})$ \\
\hline $\mathrm{A}-1$ & $16+5$ \\
\hline A-2 & $40+00$ \\
\hline A-3 & $54+00$ \\
\hline A-4 & $63+00$ \\
\hline$A-5$ & $75+00$ \\
\hline A-6 & $80+00$ \\
\hline$A-7$ & $85+00$ \\
\hline$* \mathrm{~W}-1$ & $30+00$ \\
\hline$* \mathrm{~W}-2$ & $42+00$ \\
\hline \multicolumn{2}{|c|}{$\begin{array}{l}\text { * Measured from A1-A in adit. From A1-A to } \\
\text { beginning of winze }=15 \mathrm{~m} \text {. }\end{array}$} \\
\hline
\end{tabular}




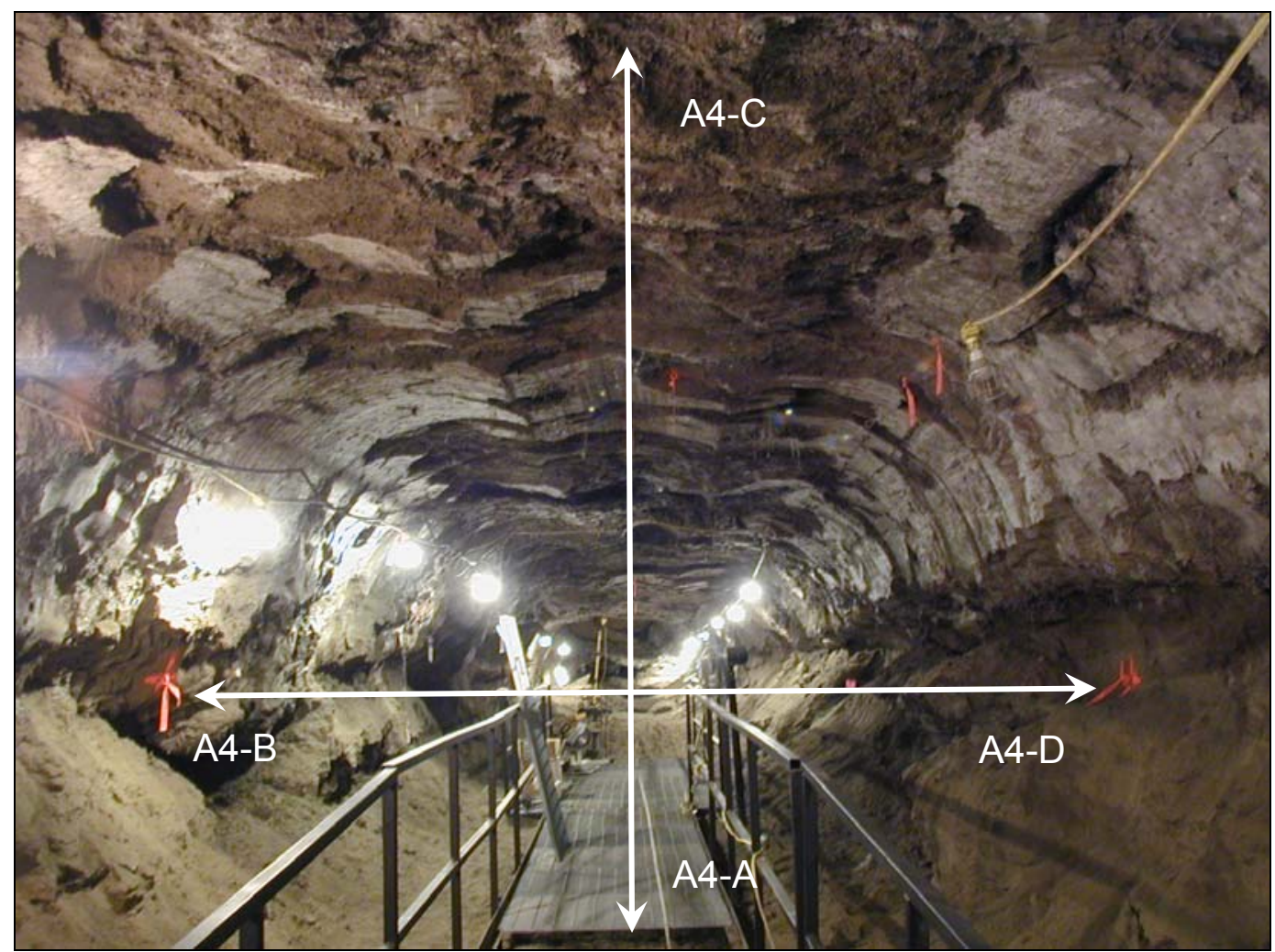

Figure 7. Typical creep reference location numbering scheme, looking up-station toward the face. Alkirk mining machine contours are still visible in the roof of the adit.

The reference locations were designed to be measured with a metal tape extensometer, which measures the relative distance to the nearest 0.001 $\mathrm{mm}$. Tape readings are eliminated in the calculation of changes, so the actual length of the tape is not relevant. Since absolute measurements were not required, it was not necessary to consider the tape catenary or the stickout of reference points. A permanent extensometer reference location was established at the portal bulkhead to verify continued accuracy of the tape extensometer. On either side wall near the bulkhead are $0.95-\mathrm{cm} \mathrm{lag}$ bolts located in vertical $10-\times 10-\mathrm{cm}$ timber posts. The results of the measurements are located in Appendix D, along with instructions for using the tape extensometer.

\section{Observations}

\section{Adit and Winze}

The adit was excavated using an Alkirk continuous mining machine, which simultaneously cut two, 2-m circular arcs, side by side. After this pass was complete to the end of the adit at $110 \mathrm{~m}(110+00)$, a portion of the floor was lowered using a Joy $10 \mathrm{RU}$ coal cutter, which resembles a large, multi- 
angle chainsaw. This started near the bulkhead and continued to approximately midway at 50+00, where the floor begins to incline noticeably to meet the elevation of the Alkirk pass at $62+0.5$ (Fig. 6). Beginning at the portal and moving toward the rear, it is apparent that the original geometry of the adit is still intact. An examination of the portion near the portal reveals that this location has not experienced any appreciable deformation, probably because of the proximity of the portal doors during winter cooling and the proximity to the air cooler unit during summer cooling.

At 50+0o the "switch room," measuring $6 \times 6 \mathrm{~m}$, was excavated on the south" side of the adit. It appears that the roof in this area may have dropped some amount corresponding to the 12-m roof span. A northsouth-oriented crack, about $4 \mathrm{~cm}$ wide, crosses the roof within this area. It is ice filled, thereby suggesting a cyrostructural origin and not a tension crack from deformation. A vertical creep station was installed at this location to monitor creep. Otherwise, from the portal to approximately $75^{+00}$, there is no perceptible deformation to suggest structural instability. In fact, for most of this portion of the adit, the Alkirk Miner profile is still visible in the roof, suggesting that the material is relatively stable and has not moved or fallen since the time of excavation.

There is no evidence of deformation until approximately $75+00$, where the roof is perceptibly and progressively sagging; the adit is almost completely blocked by low-hanging and fallen soil layers at 94+oo (Fig. 8). At this location, overhead layers of soil have delaminated from the bedded sediments above and have crept down toward the floor and eventually detached from the roof. This is a slow, non-catastrophic process. This portion of the adit has evidence of paleo-alluvial deposition and erosion (Sellman 1967), and these laminations contain interbedded layers of gravelly sandy silt, millimeters to centimeters in thickness. These laminations are the preferential locations of the detachment. This slow deformation of the layer apparently can then give way to an abrupt release of portions up to $4 \mathrm{~m}^{2}$ when the tensile strength of the soil is exceeded on either end of the catenary. From $94+00$ it was possible to negotiate a path for another 5 $\mathrm{m}$ through the blocked area and view an additional $10 \mathrm{~m}$ of low-hanging and dropped soil layers.

\footnotetext{
* For simplification in describing orientation, the tunnel axis will be assumed to run west to east.
} 


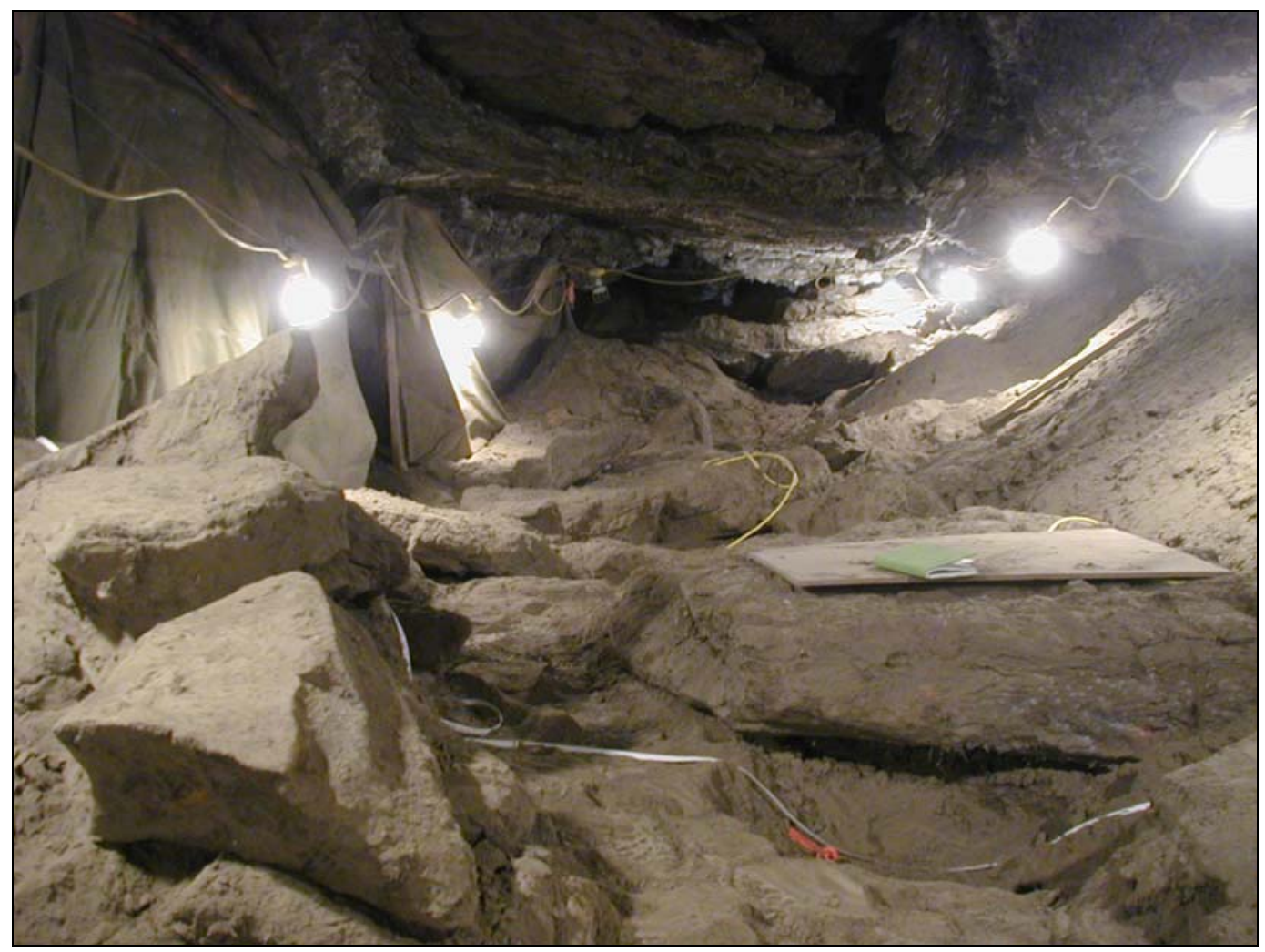

Figure 8. Rear of the adit at approximately $85+00$. Bedded layers are delaminating from the roof, and previous fallen layers are lying on the floor. The tarp to Sayles's Room is visible at the left.

Immediately adjacent on the north side of $80+00$ is a $5^{-} \times 5^{-m}$ side area referred to as Sayles's Room (also called the Crystal Room). It is divided from the adit by a lumber frame and a heavy tarpaulin (Fig. 9). This area is still accessible, and inspection revealed a large ice wedge on the western wall that widens where it meets the roof and then spreads out to almost room-width across the roof toward the adit. The adit at this station is overlain by massive ice, but to what degree is uncertain. The roof in Sayles's Room is supported by a 3-m-long steel beam resting on $15^{-} \times 15^{-}$ $\mathrm{cm}$ timbers. One of these timbers has apparently yielded from the stress of the creeping roof, but otherwise the roof has remained stable with very little creep.

Opposite Sayles's Room on the south side of the adit, at approximately $90+00$, a $16-\times 6-\mathrm{m}$ crosscut exists that departs at a $36^{\circ}$ angle. This room is now inaccessible because of the deformation in the adit, and anecdotal information* implies that an ice wedge feature is exposed in the southwest

\footnotetext{
* Charles Collins, personal communication.
} 


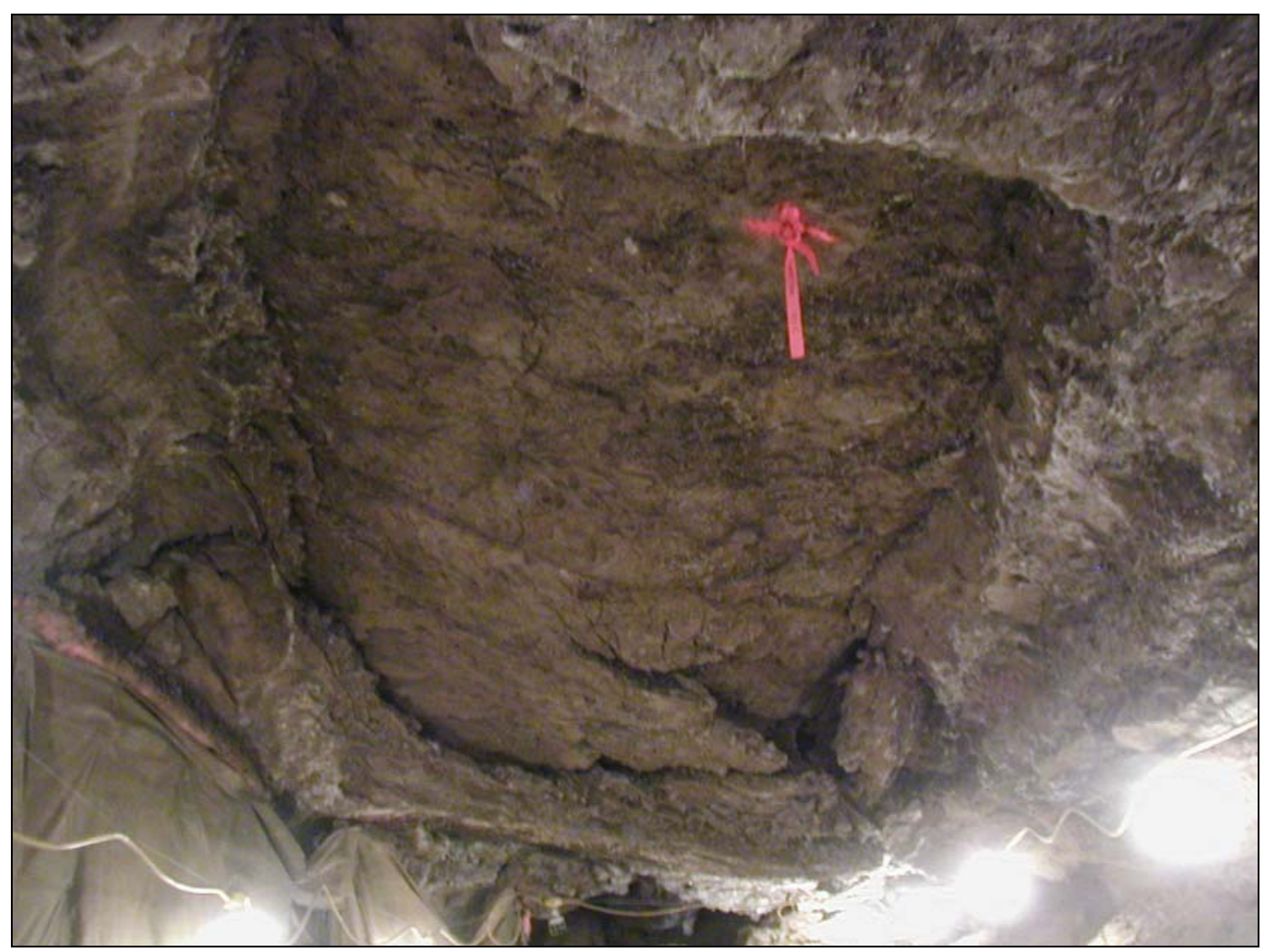

Figure 9. Roof over the area shown in Figure 8, where a layer has delaminated, sagged, crept, and fallen to the floor. The tarp is visible on the left.

wall of this room adjacent to the adit. Also, in the north wall of the adit at $75^{+00}$, there is a complex configuration of massive ice consisting of ice wedges, buried pond ice, and 5- to 15-cm-thick ice lenses. Because of the polygonal nature of ice wedge complexes (Williams and Smith 1989, Murton and French 1994) and the close proximity of the adit deformation, the Sayles's Room ice wedge, the cross-cut ice wedge, and the massive ice complex in the adit, this intersection may be coincident with the center of an ice wedge polygon.

Temperature measurements taken in the adit revealed that the mechanical cooling unit was delivering approximately $-5.0^{\circ} \mathrm{C}$ air. The tunnel air near the portal was approximately $-3^{\circ} \mathrm{C}$, and the rear adit air was approximately -2.0 to $-1.8^{\circ} \mathrm{C}$. The temperature gradient near the portal was $5.6^{\circ} \mathrm{C} / \mathrm{m}$ with depth into the wall, with the ambient air colder than the wall. The gradient at $83+00$ was $0.42^{\circ} \mathrm{C} / \mathrm{m}$, with the ambient air warmer than the wall. The crossover $\left(0^{\circ} \mathrm{C} / \mathrm{m}\right)$ where the temperature of the ambient air is the same as the wall temperature takes place at approximately $75^{+00}$, where the deformation begins. This warmer air regime then continues to the blockage of the adit, where the gradient at $92+0.5$ is 
$0.98^{\circ} \mathrm{C} / \mathrm{m}$. It is unknown at what depth the soil temperature reaches equilibrium with the local permafrost at any point along the adit. Previous studies (Wu 1985, Law 1987) have shown considerable seasonal and even hourly temperature variations; this was confirmed by our measurements.

A video recording (Johansen 1993) discussed temperatures at the rear of the adit as being very near $\mathrm{o}^{\circ} \mathrm{C}$. This was taken approximately one week after the dropping of a bedded soil layer was observed at the nowdeformed section. References in the video, and in another video made by Collins* (date unknown), indicate that the extremely heavy snow season of 1992-1993 produced unusually high surface-water runoff. The spring snowmelt overwhelmed the tunnel entrance and flooded the adit with 6$10 \mathrm{~cm}$ of water. This thermal event delivered heat through storage and latent heat of fusion to warm the adit to $0^{\circ} \mathrm{C}$ or above, for some unknown amount of time. Also coincident with this event was the failure of the air cooler for an unknown amount of time. ${ }^{\dagger}$

Now inaccessible at the end of the adit are three, approximately 1-mdiameter ventilation shafts that were augured down from the surface to the tunnel. These were designed to aid in natural convection cooling in the winter while the portal doors were opened. Apparently these were problematic to maintain, as surface water would migrate along the shaft, melt the permafrost, and form a conduit for surface water to travel to the tunnel, eventually icing in the vent and causing permafrost degradation problems (Fig. 10). Subsequent vents were installed after the failure of the previous. Currently the evidence on the surface consists of one ice-filled pipe extending above the surface with insulation debris around it, a vent pipe with a louver located in an uncovered insulated box, and a vent pipe located in an insulated box with a screened cover. Jim Buska of CRREL provided photos of the installation of the box for the vent pipe with the louver taken in June 1978. Sometime after the 1993 flooding event, the last of the three vents froze shut with surface water and has not been operable since. To aid in cooling the rear of the adit since that time, fans have been used to circulate the winter air after opening the portal doors, but with little efficacy.

\footnotetext{
* Charles Collins, personal communication.

† Also Charles Collins, personal communication.
} 


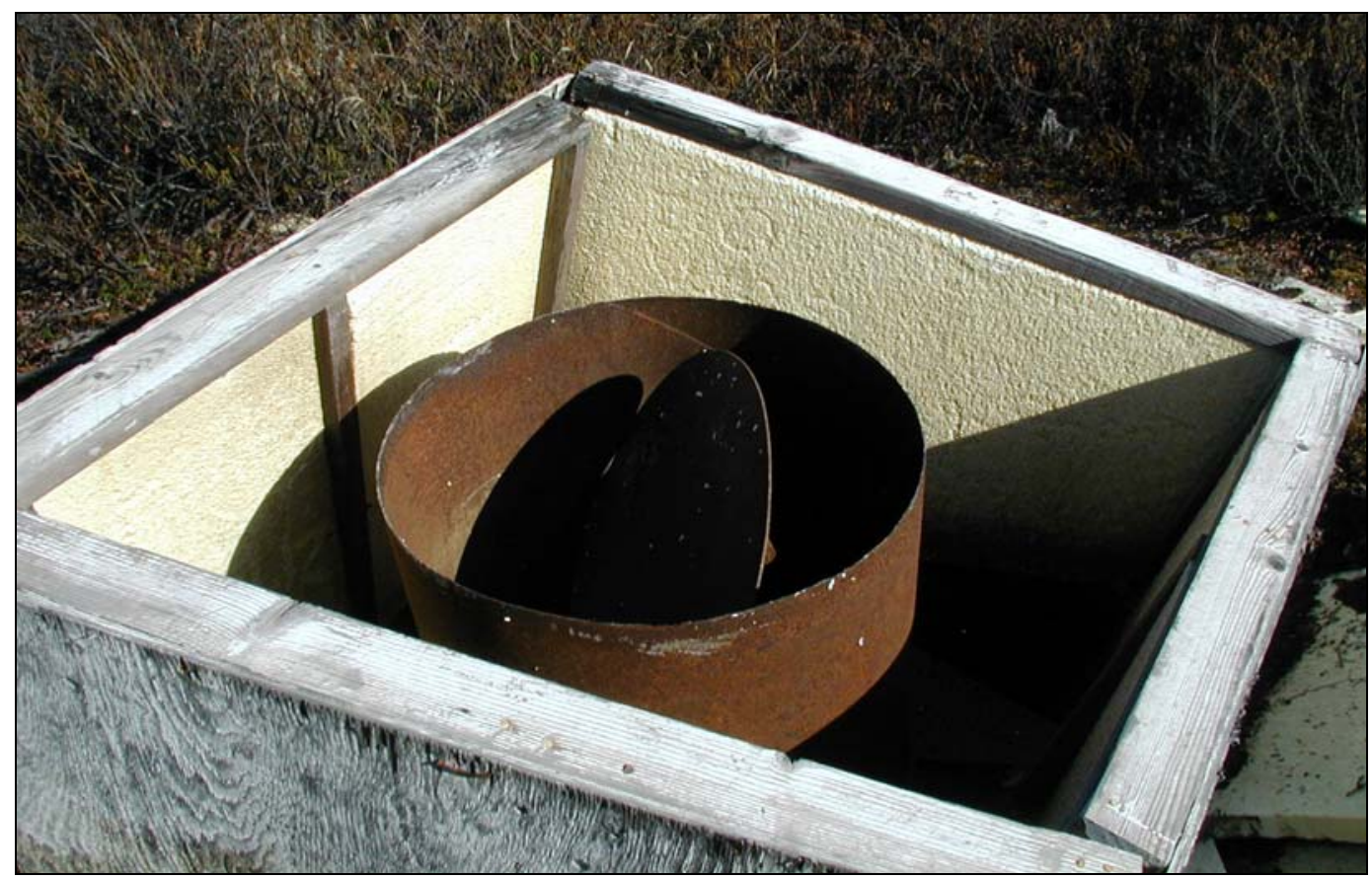

Figure 10. Third vent installed from the surface to the rear of the adit, with a louvered pipe to close off the vent during the summer. The pipe is now ice-filled and inoperative.

The winze was excavated using drill and blast methods starting at a lowhanging ledge at $30+00$. This ledge was the pullout location for the shuttle car used to move waste material out of the adit from the Alkirk machine (see cover photo). Because of the excavation method, the winze retains a much rougher appearance than the adit and is shallower in geometry. There is no evidence through the entire length that this ramp has undergone deformation to any significant degree. There is a thick layer of sublimated material on the floor, $30-35 \mathrm{~cm}$ deep, and approximately midway down the 45-m excavation, there is an extremely large ice wedge feature that encompasses both walls and extends through the entire span of the roof.

\section{Gravel Room}

The USBM Gravel Room, which is located at the foot of the winze and extends to the south, was the focus of subsurface mining studies in the late 1960s. The room is $9 \times 21 \mathrm{~m}$ and was excavated in the gravel and bedrock below the overlying silt unit. This lithology change at the time of excavation was approximately $2 \mathrm{~m}$ above the level of the roof of the Gravel Room. It was recognized that this gravel material, with its much higher unit weight than the silt unit to which it is bonded $\left(2080 \mathrm{~kg} / \mathrm{m}^{3}\right.$ for the gravel vs. $1600 \mathrm{~kg} / \mathrm{m}^{3}$ for the silt), would separate and fall in rooms of large roof 
span. Investigators have repeatedly studied this parting potential through the years, with two investigations warming it to study the temperature dependence on creep and separation of the gravels (Pettibone 1973, Garbeil 1983, Huang 1985 and 1986).

Two multiple-position borehole extensometers (MPBX) were installed during the 1983 study, with one end anchored in the silt unit and the other anchored in the gravel roof. Specific parting was noted between the silt and gravel units $(0.0084 \mathrm{~mm} /$ day) when temperatures achieved their highest readings $\left(-1.9^{\circ} \mathrm{C}\right)$ during the study. Overall vertical closure rates for the room during April 1983 at $-3.7^{\circ} \mathrm{C}$ were $0.010 \mathrm{~mm} /$ day, and in July 1983 at $-1.9^{\circ} \mathrm{C}$ the closure accelerated to $0.053 \mathrm{~mm} /$ day.

The Gravel Room roof fell to the floor (approximately $25 \mathrm{~m}^{3}$ ) after a 6.2 Richter magnitude earthquake struck the Fairbanks region in October 1995. The boundary of the dropped material is coincident with the wall that was installed to facilitate warming of the roof in 1983 (Fig. 11). It is unknown if creeping or deformation was noticed prior to this event.

As a side note, another study researched the possibility of monitoring the parting separation by acoustic emission, but that was not successful (Pettibone 1973).

\section{Sublimation}

Sublimation of the ice matrix that binds the soil grains has been ongoing since the initial construction of the tunnel and winze. It is believed these high rates were due to very low ambient temperatures, with associated low relative humidity, of the air used for cooling during the winter months. Current rates appear to not be as high, with the tunnel temperature maintained near $0^{\circ} \mathrm{C}$. No current measurements are available, but in just a few weeks following the cleaning of a wall surface, there will be a few millimeters of loose silt grains adhering to the wall. 


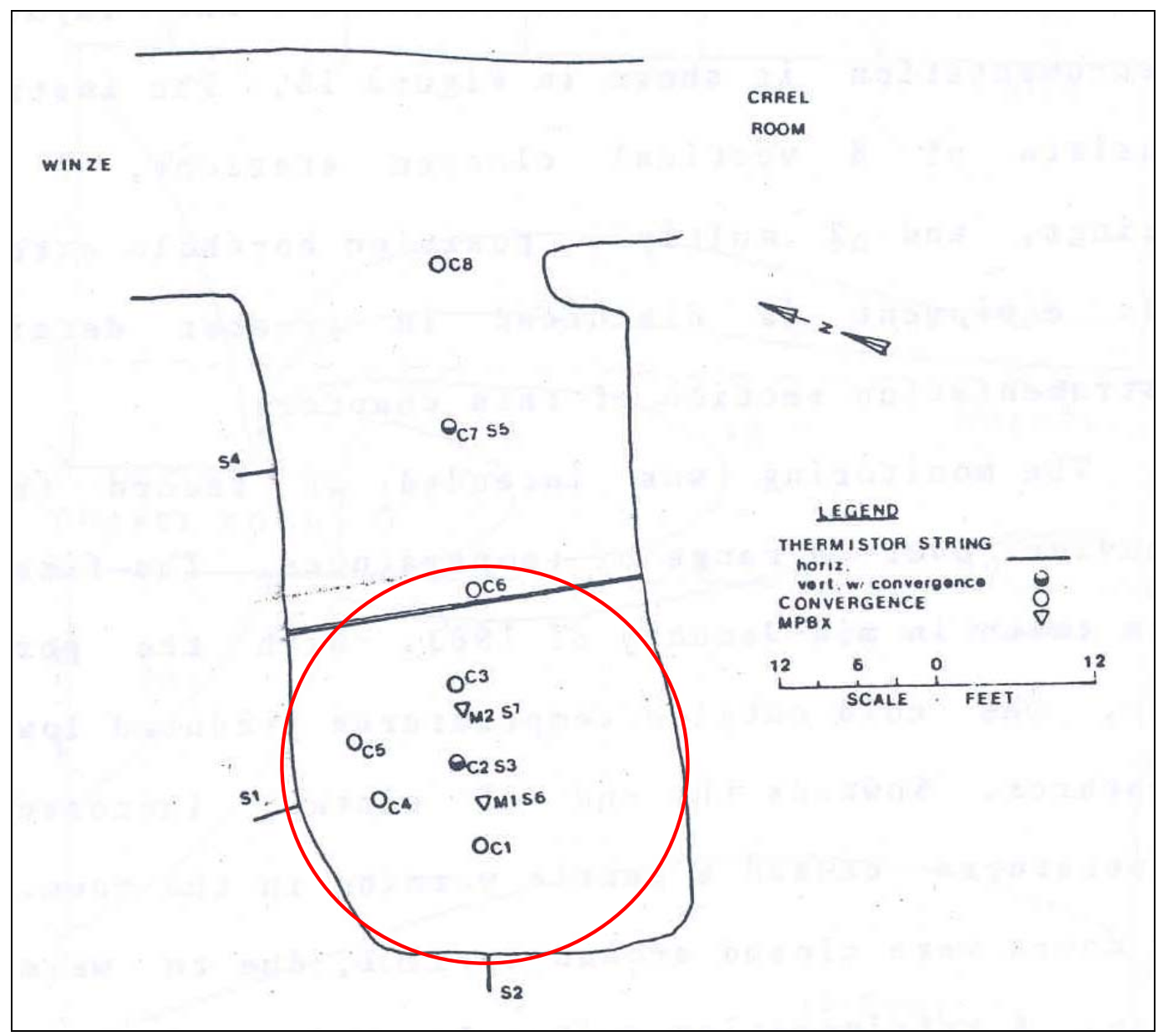

Figure 11. USBM Gravel Room located at the bottom of the winze. The bulkhead that was installed to thermally isolate the room is seen in the drawing, and the red circle indicates the area where the roof slab fell, parting from the overlying silt unit.

The relative humidity measured during this site visit ranged from 85 to $90 \%$ in the adit and from 89 to $92 \%$ in the winze and Gravel Room. The silt grains maintain some inter-particle adhesion after the loss of the ice matrix and do not immediately fall to the floor, but there is a thick dust cover of $10 \mathrm{~cm}$ or more on the floor throughout the tunnel from this process, obscuring periglacial features. The rates immediately after excavation in the silt were $14 \mathrm{~cm}$ in 65 days, whereupon the sublimation slowed to an imperceptible rate as the thickness of the soil residue increased (Swinzow 1970). In the lower winze and Gravel Room the gravels have a much lower moisture (ice) content, and the size and weight of the grains are much greater, so the material readily falls to the floor with the loss of the matrix. It is common to hear gravel falling from the wall and roof while in these areas. 


\section{STRENGTH MODELING}

\section{Basic Mechanical Properties of Frozen Soil}

Pore ice (matrix ice) exists in all frozen soil, with varying amounts of excess ice (segregated) and/or massive ice. Ice strength is strongly temperature-dependent, where lower temperatures produce higher strengths and decreased creep rates. Temperatures approaching $0^{\circ} \mathrm{C}$ show marked decreases in strength and accelerated creep rates. It has been shown that an increasing moisture content (ice content) has a strengthening effect on soil to a certain point, above which the strength begins to decrease with continued increasing ice content (Sayles and Carbee 1981). Therefore, the soil/ice composition is critical to the instantaneous and long-term loading performance of frozen soil as an engineering material. The tunnel has an extremely varying amount of ice from one location to another, from non-visible pore ice, to ice lenses $9 \mathrm{~cm}$ in thickness, to ice wedges $2 \mathrm{~m}$ wide by $3 \mathrm{~m}$ high.

Plotting strain vs. time for a frozen soil sample that has undergone constant stress testing reveals the classic creep curve shown in Figure 12a. With loading, there will be an instantaneous deformation, the amount of which is determined by the magnitude of the load. If the load does not induce instant failure, then after this initial loading, the rate of deformation decreases until it reaches a theoretical constant value. This first stage is defined as primary creep. If the applied load exceeds the critical stress of the frozen soil, deformation will increase with time and will reach a second inflection point, resulting in secondary creep or steady state creep. If the applied load is high enough, or the variables affecting the strength of the soil are changed (i.e., temperature), the steady state creep will accelerate into failure, resulting in tertiary creep.

Zhu and Carbee (1987a) discussed the relationship between constant stress (creep) and constant strain rate (strength) tests. They reported that for the same soil, temperature, and strain rate, the applied stress in a creep test approximates the peak strength in a strength test. Figure 13 illustrates determination of peak strength and initial yield strength. 


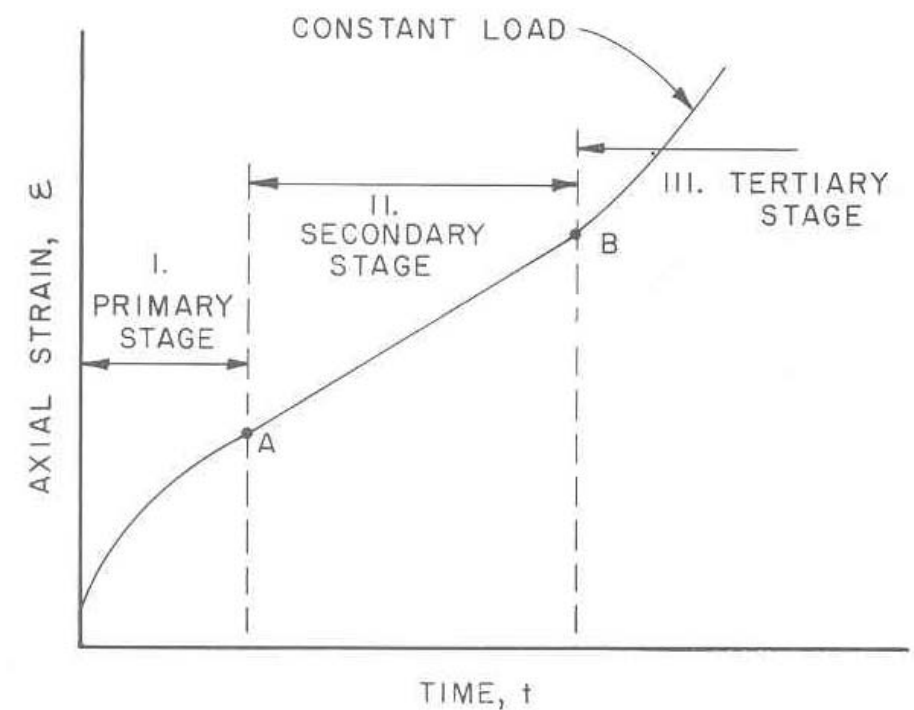

a. Stages of creep.

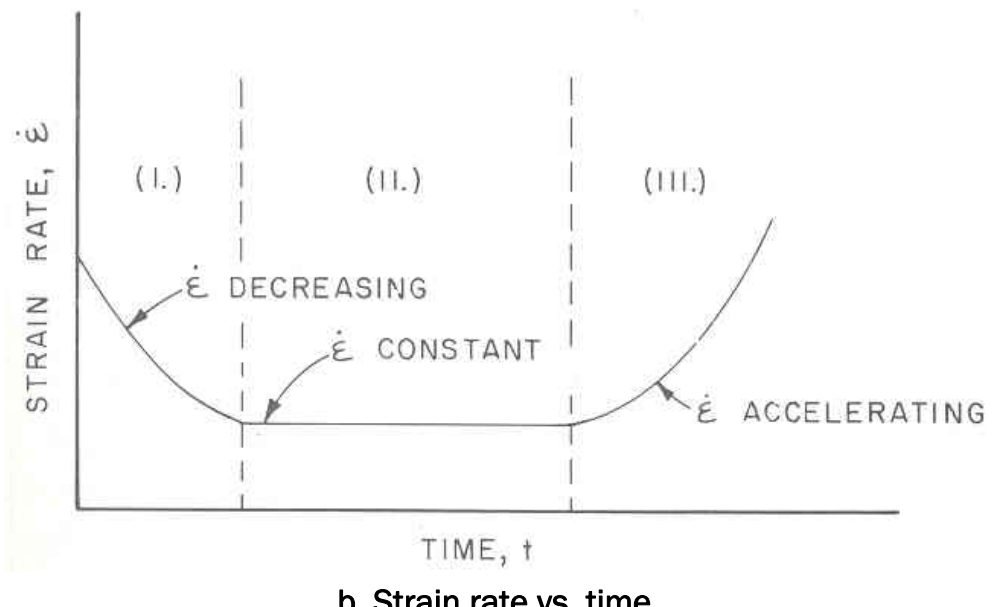

b. Strain rate vs. time.

Figure 12. Classic creep curves resulting from constant stress testing. (From Phukan 1985.) 


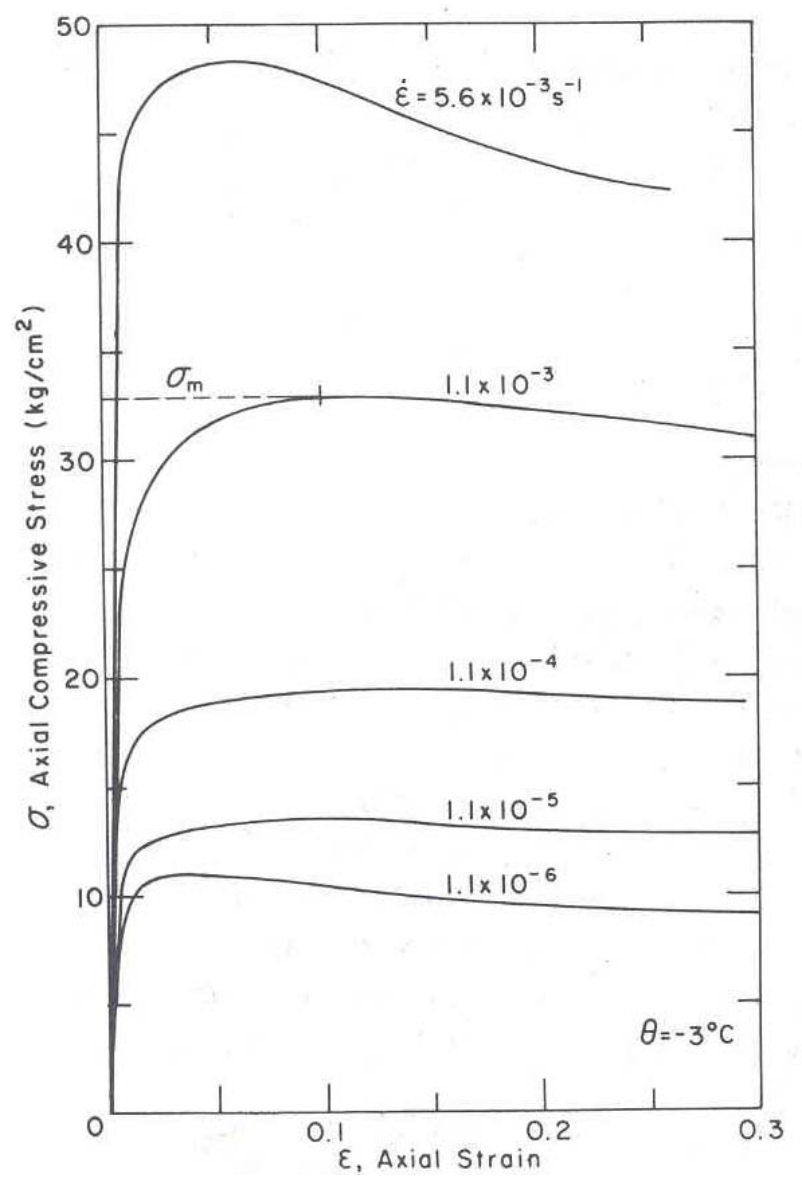

a. Constant strain rate test showing determination of peak strength $\sigma_{\mathrm{m}}$.

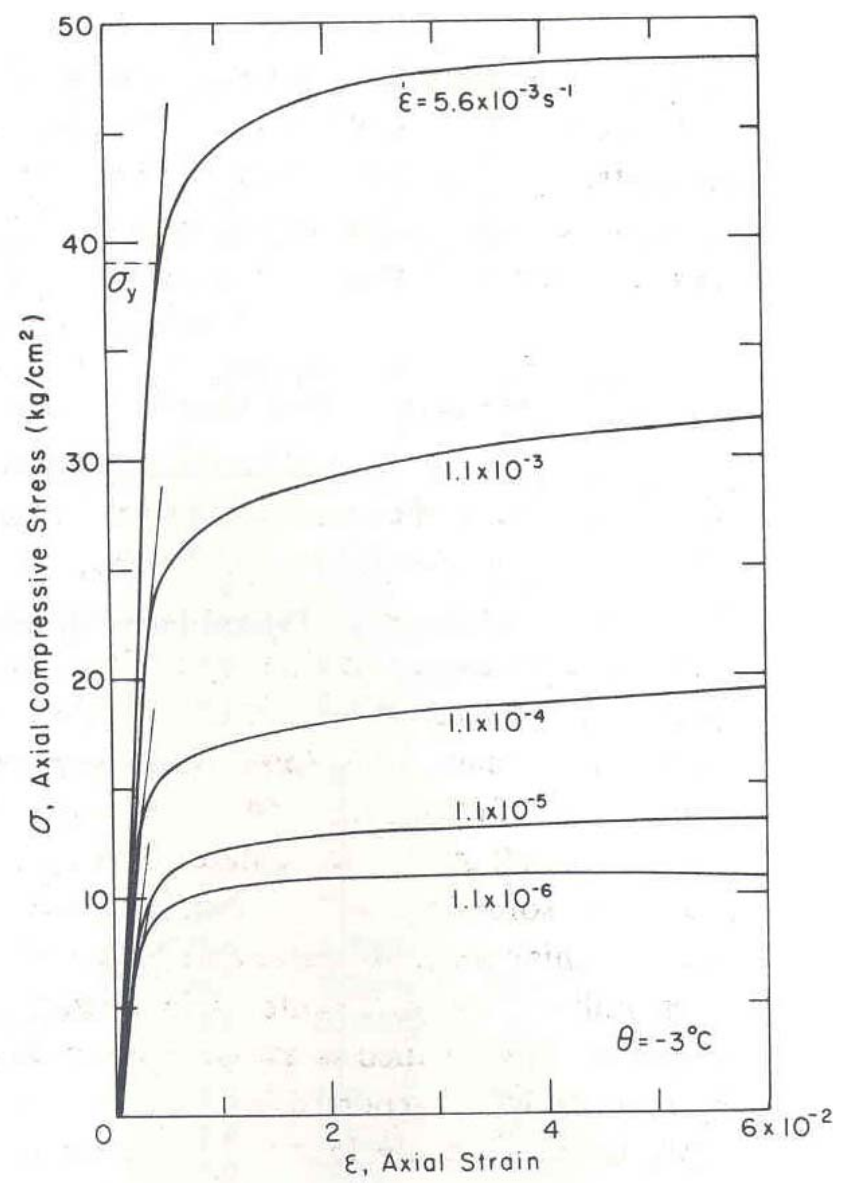

b. Determination of initial yield strength $\sigma_{\mathrm{y}}$.

Figure 13. Reconstituted tunnel soil tests. (From Zhu and Carbee 1987a and b.)

The creep process can be described using a model proposed by Hult (1966):

$$
\varepsilon=\varepsilon^{\mathrm{i}}+\dot{\varepsilon}^{\mathrm{c}} t
$$

where

$$
\begin{aligned}
\varepsilon^{\mathrm{i}} & =\text { instantaneous strain (primary creep) } \\
\dot{\varepsilon}^{\mathrm{c}} & =\text { constant strain rate (secondary creep). }
\end{aligned}
$$

We can further describe the frozen soil by $\varepsilon^{i}$ as the pseudo-instantaneous strain consisting of both elastic and plastic strains: 


$$
\varepsilon^{\mathrm{i}}=\varepsilon^{\mathrm{ie}}+\varepsilon^{\mathrm{ip}}=\frac{\sigma}{E}+\varepsilon_{\mathrm{k}}\left(\frac{\sigma}{\sigma_{\mathrm{k}}}\right)^{\mathrm{k}}
$$

where

$$
\begin{aligned}
\mathrm{E} & =\text { Young's Modulus } \\
\varepsilon_{\mathrm{k}} & =\text { small strain for normalization } \\
\sigma_{\mathrm{k}} & =\text { temperature-dependent deformation modulus. }
\end{aligned}
$$

The summed terms in eq 1 determine the long-term creep strength of a frozen soil. For engineering calculations the first term can be neglected, as it makes up approximately 10\% of the total deformation (Phukan 1985). This visco-elastic model, or others like it, are useful for determining longterm stresses and deformation prior to loading. This illustrates the complex nature of frozen soil, without considering the additional complexities of massive and segregated ice features, complex lithologies, and varying temperatures that also may be found in soils of this type.

\section{Lab Results}

A total of 25 intact cores measuring $5 \mathrm{~cm}$ in diameter were taken from the walls and roof of the tunnel. The lengths ranged from 10 to over $13 \mathrm{~cm}$, with the majority averaging $12.5 \mathrm{~cm}$. The samples were generally taken in clusters to determine testing repeatability, with adjoining samples taken only a few centimeters apart from one another. The areas located to take cores were to be free of ice lenses, massive ice, and clear ice and did not contain visible traces of gravel or organic material. Samples containing visible ice lenses ( $>1 \mathrm{~mm}$ ) or ice inclusions were discarded.

The object of our testing was to assess the validity of the extensive test results available from Zhu and Carbee (1987 a and b). They performed strength tests, long-term creep tests, and tension tests, with enough samples to eliminate outliers and plot well-developed trends that varied with temperature and strain rate. To eliminate the uncertainty that would be found in situ, they reconstituted silt from the tunnel, saturated it, and slowly froze it to prevent extensive ice lensing, with moisture contents averaging 40\%. If the highly variable character of our in-situ samples revealed mechanical properties reasonably close to those of $\mathrm{Zhu}$ and Carbee's data, we then would have considerable strength information on hand for this analysis. 
Of the 25 samples taken, 17 of the cores were tested in the tunnel (labeled with a T) utilizing a hand-crank Soiltest press and performing a constant strain rate test. The desired rate was $1 \% /$ minute $\left(1 \times 10^{-3} / \mathrm{s}\right)$, and this would be performed until the initial yield strength $\left(\sigma_{y}\right)$ was passed and the strength output became nearly constant or peaked $\left(\sigma_{\mathrm{m}}\right)$. For some of the samples, the stress continued to increase, so the test was terminated after 15 minutes or so. The samples were taken from different locations in the tunnel, generally in the $36+00$ to $84+00$ region, and $-2^{\circ} \mathrm{C}$ was used as the average core temperature. The tested cores were shipped back to our Hanover, NH, laboratory for moisture content determination.

The remaining eight cores were tested on a motorized compression testing machine at the Hanover lab (labeled with an $\mathrm{H}$ ) to further test at varying temperatures and to validate the tunnel testing. Four of these unconfined tests were conducted under varying strain rates at $-2^{\circ} \mathrm{C}$, while the remaining three were conducted utilizing a strain rate of $1 \times 10^{-3} / \mathrm{s}$ with differing temperatures $\left(-0.5,-1.0\right.$, and $\left.-5.0^{\circ} \mathrm{C}\right)$. The results of our tests, both in the tunnel and in the laboratory, demonstrate the strength variability of the eolian silts, even when the cores are taken within a few centimeters of each other. This is probably most attributable to the amount and orientation of pore ice and micro-lensing in each core. In Table 2 we categorized each core by the cryostructure format proposed by Shur et al. (2004) and Bray et al. (2006).

There were no discernable trends in our data regarding cryostructure and strength, though there appears to be a relationship between the orientation of the core and the nature of the peak stress curve. This is likely the result of the preferential orientation for the bedding planes as the windblown silt came to rest. These bedding planes are probably parallel to the freezing front, and the micro-lenses and ice lenses exploited this weakness and grew between the planes. The horizontal cores (at high strain rates) achieved a definitive yield point, and the peak stress became more or less constant for continued strain, while the vertical cores reached yield strength and the resistance continued to rise, requiring increased stress to compress these planes. With regard to samples tested in the tunnel at $1 \times$ $10^{-3} / \mathrm{s}$, the yield strength of the horizontal cores varied by a factor of two or more, which is approximately equal to the variation of yield strength between horizontal and vertical. The results of testing are listed in Table 2, and the complete curves for each sample are listed in Appendices A and B. 
Table 2. Results of constant strain rate testing of tunnel cores.

\begin{tabular}{|c|c|c|c|c|c|c|c|c|c|c|}
\hline $\begin{array}{l}\text { Sample } \\
\#\end{array}$ & $\begin{array}{l}\text { Strain } \\
\text { rate } \bar{\varepsilon} \\
\left(\mathrm{s}^{-1}\right)\end{array}$ & $\begin{array}{c}\text { Yield } \\
\text { strength } \\
\sigma_{\mathrm{y}} \\
(\mathrm{MPa})\end{array}$ & \begin{tabular}{|c|} 
Peak \\
strength \\
$\sigma_{\mathrm{m}}$ \\
$(\mathrm{MPa})$
\end{tabular} & $\begin{array}{l}\text { Time } \\
\text { to } \sigma_{m} \\
t_{m}(s)\end{array}$ & $\begin{array}{c}\text { Strain } \\
\text { at } \sigma_{m} \\
\varepsilon_{m}\end{array}$ & $\begin{array}{c}\text { Moisture } \\
(\%)\end{array}$ & $\begin{array}{l}\text { Temp } \\
\left({ }^{\circ} \mathrm{C}\right)\end{array}$ & $\begin{array}{c}\text { Cryo- } \\
\text { lithostratigraphic } \\
\text { unit }\end{array}$ & $\begin{array}{l}\text { Stationing } \\
\text { and wall }{ }^{\dagger}\end{array}$ & $\begin{array}{c}\text { Core } \\
\text { orientation }\end{array}$ \\
\hline 1- & $1 \times 10^{-3}$ & 1.83 & 2.06 & 200 & 0.037 & 84.7 & -2.0 & Micro-lenticular & $75+00 \mathrm{Rt}$ & Horizontal \\
\hline $2-T$ & $1 \times 10^{-3}$ & 2.40 & 3.08 & 120 & 0.022 & 104 & -2.0 & Lenticular-layered & $75+00 \mathrm{Rt}$ & Horizontal \\
\hline 3-T & $1 \times 10^{-3}$ & 1.63 & 2.09 & 136 & 0.028 & 63.3 & -2.0 & Micro-lenticular & $75+00 \mathrm{Rt}$ & Horizontal \\
\hline $4-T$ & $1 \times 10^{-3}$ & 1.80 & 2.09 & 104 & 0.021 & 52.0 & -2.0 & Massive & $69+0.7 \mathrm{Rt}$ & Horizontal \\
\hline 5-T & $1 \times 10^{-3}$ & 0.910 & - & - & - & 60.2 & -2.0 & Micro-lenticular & $54+00 \mathrm{Rf}$ & Vertical \\
\hline 6-T & $1 \times 10^{-3}$ & 1.83 & 2.52 & 96.0 & 0.018 & 191 & -2.0 & Lenticular-layered & $55+00 \mathrm{Lt}$ & Horizontal \\
\hline $7-T$ & $1 \times 10^{-3}$ & 0.780 & - & - & - & 82.8 & -2.0 & Micro-lenticular & $54+00 \mathrm{Rf}$ & Vertical \\
\hline 8-T & $1 \times 10^{-3}$ & 1.29 & - & - & - & 114 & -2.0 & Lenticular-layered & $58+00 \mathrm{Lt}$ & Vertical \\
\hline $9-\mathrm{T}$ & $1 \times 10^{-3}$ & 1.65 & - & - & - & 119 & -2.0 & Lenticular-layered & $58+00 \mathrm{Lt}$ & Vertical \\
\hline $10-\mathrm{T}$ & $1 \times 10^{-3}$ & 1.59 & 1.71 & 152 & 0.029 & 92.9 & -2.0 & Micro-lenticular & $36+00 \mathrm{Rt}$ & Horizontal \\
\hline $11-\mathrm{T}$ & $1 \times 10^{-3}$ & 1.83 & 2.10 & 120 & 0.024 & 86.5 & -2.0 & Micro-lenticular & $36+00 \mathrm{Rt}$ & Horizontal \\
\hline 12-T & $1 \times 10^{-3}$ & 1.34 & 1.68 & 192 & 0.046 & 92.6 & -2.0 & Lenticular-layered & $84+0.5 \mathrm{Rt}$ & Horizontal \\
\hline 13-T & $1 \times 10^{-3}$ & 0.975 & - & - & - & 123 & -2.0 & Lenticular-layered & $84+0.5 \mathrm{Rt}$ & Horizontal \\
\hline 14- & $.5 \times 10^{-3}$ & 0.745 & 0.905 & 352 & 0.036 & 78.8 & -2.0 & Massive & $57+00 \mathrm{Rt}$ & Horizontal \\
\hline 15-T & $1 \times 10^{-3}$ & 0.843 & 0.939 & 184 & 0.036 & 55.3 & -2.0 & Massive & $57+0.5 \mathrm{Rt}$ & Horizontal \\
\hline 16- & $2 \times 10^{-3}$ & 1.28 & - & - & - & 68.3 & -2.0 & Massive & $57+0.5 \mathrm{Rt}$ & Horizontal \\
\hline $17-\mathrm{T}$ & $2 \times 10^{-3}$ & 2.06 & 2.32 & 96.0 & 0.040 & 95.0 & -2.0 & Micro-lenticular & $55+0.5 \mathrm{Lt}$ & Horizontal \\
\hline $1-\mathrm{H}$ & $1 \times 10^{-3}$ & 1.40 & 1.85 & 35.0 & 0.034 & 94.0 & -2.0 & Massive & $57+00 \mathrm{Rt}$ & Horizontal \\
\hline $2-\mathrm{H}$ & $1 \times 10^{-4}$ & 0.505 & - & - & - & 92.0 & -2.0 & Micro-lenticular & $57+00 \mathrm{Rt}$ & Horizontal \\
\hline $3-\mathrm{H}$ & $1 \times 10^{-2}$ & 2.18 & 2.71 & 1.90 & 0.022 & 128 & -2.0 & Micro-lenticular & $57+00 \mathrm{Rt}$ & Horizontal \\
\hline $4-\mathrm{H}$ & $1 \times 10^{-5}$ & 0.197 & - & - & - & 99.5 & -2.0 & Micro-lenticular & $57+00 \mathrm{Rt}$ & Horizontal \\
\hline $5-\mathrm{H}$ & $1 \times 10^{-3}$ & 2.13 & 2.17 & 13.0 & 0.014 & 104 & -0.5 & Micro-lenticular & $57+00 \mathrm{Rt}$ & Horizontal \\
\hline $6-\mathrm{H}$ & $1 \times 10^{-3}$ & 1.66 & 1.84 & 19.2 & 0.019 & 103 & -1.0 & Micro-lenticular & $57+00 \mathrm{Rt}$ & Horizontal \\
\hline $7-\mathrm{H}$ & $1 \times 10^{-3}$ & 2.52 & - & - & - & 70.0 & -5.0 & Massive & $57+0.5 \mathrm{Rt}$ & Horizontal \\
\hline$\star 8-\mathrm{H}$ & $1 \times 10^{-3}$ & 1.29 & - & - & - & 68.0 & -2.0 & Massive & $57+0.5 \mathrm{Rt}$ & Horizontal \\
\hline
\end{tabular}

${ }^{\dagger} \mathrm{Rt}=$ Right Wall, Lt $=$ Left Wall, $\mathrm{Rf}=$ Roof

* Triaxial with confining pressure of $0.08 \mathrm{MPa}$

The varying temperature tests at $1 \times 10^{-3} / \mathrm{s}$ agreed with Zhu and Carbee (1987a) for the lower temperatures, but the data are inconclusive for the near-freezing temperatures (Table 2). More samples would likely need to be run to assure repeatability of these results. For the purpose of our analysis, the general nature of the stress vs. strain curves and the magnitude of the strengths are in close agreement with Zhu and Carbee (1987a), within a factor of two. A single confined strength test was performed utiliz- 
ing $0.08 \mathrm{MPa}$ and a strain rate of $1 \times 10^{-3} / \mathrm{s}$. The confining stress was based on the best estimate for the $\mathrm{K}$ factor, which is used to normalize the overburden stress in the horizontal direction, in this case 0.3.

\section{Mechanical Properties of the Tunnel}

For the first 130 days after excavation, closure rates in the adit were 0.78 and $1.17 \mathrm{~mm} /$ day at 50+00 and 106+00, respectively (Swinzow 1970). Twenty years later, the closure rates were 0.014 and $0.08 \mathrm{~mm} /$ day, respectively, for the same stations (Wu 1985). This deceleration of deformation over 20 years suggests that immediately after the excavation of the tunnel, the frozen soil experienced "instantaneous deformation" followed by a decrease in deformation rate, indicative of the primary creep stage. There is no appreciable visible deformation from the portal to $75^{+00}$, and also down the winze, so we assume that this portion of the facility has not yet accelerated into tertiary creep. We also assume that the continual loading due to overburden stresses and, to a very minor extent, lateral earth pressure stresses are continually relaxing around the excavation and have nearly come into equilibrium with the strength of the soil.

Because of the complex structure and strength of all the tunnel features acting collectively (such as the ice content, ice formation, soil density, inter-granular bonding due to the ice matrix, unfrozen water content, and depositional character of the soil), modeling this facility would require an in-depth computational solution that is beyond the scope of this project. However, this near-equilibrium condition allows us to use an alternative approach to determine approximately when the soil will deform. Utilizing engineering criteria for stresses on geometric elements, and assuming that the behavior of the soil can be modeled using instantaneous elastic strain $\varepsilon^{\text {ie }}$, we can equate those geometric stresses to the strength of the tunnel materials as taken from Zhu and Carbee (1987a) and validated by the insitu and laboratory tests. Elastic theory is straightforward to apply and can give guidance to reserve strength for sudden loads or change in soil parameters (such as temperature), and will define the sensitivity of the tunnel materials to deformation.

Consider the inter-bedded layering of the soil in the deforming portion of the adit as elastic, uniform in dimension, and isotropic. From field measurements we found most layers to be $0.2-0.3 \mathrm{~m}$ thick. Applying beam theory (Fig. 14) to model these layers, using a 0.2-m-high $\times 0.3$-m-wide $\times$ 
3 -m-long rectangular cross section and $1600 \mathrm{~kg} / \mathrm{m}^{3}$ for the unit weight of the soil, yields 1.2 MPa for the maximum bending stress, $\sigma_{\max }$ :

$$
\sigma_{\max }=\frac{M y}{I}
$$

and

$$
I=\frac{b h^{3}}{12}
$$

where

$\mathrm{M}=$ maximum bending moment

$\mathrm{y}=$ distance from the centroid to the outer boundary of the beam

$\mathrm{I}=$ moment of inertia

$\mathrm{b}=$ base dimension

$\mathrm{h}=$ height dimension.

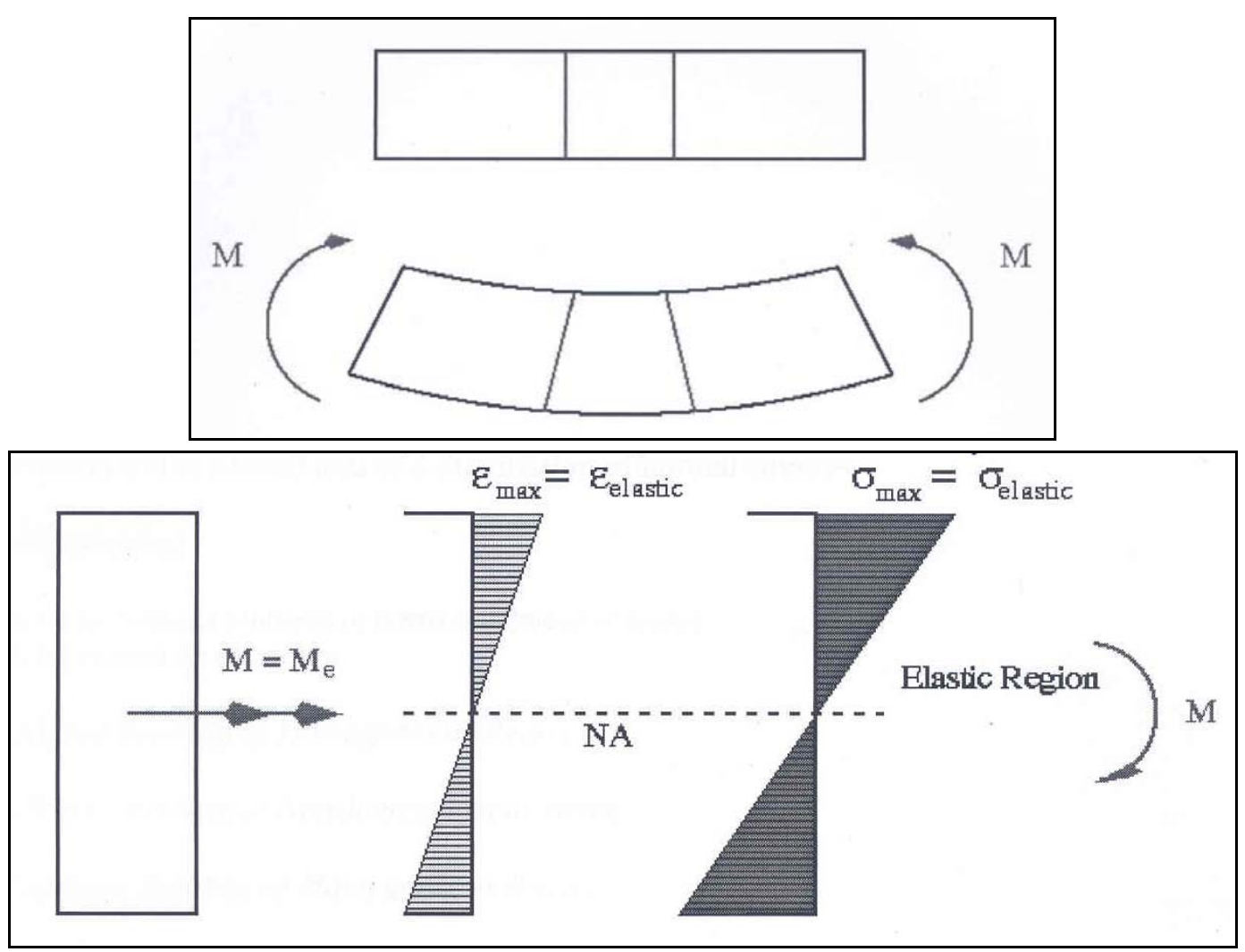

Figure 14. Simple rectangular beam in pure bending, showing the distribution of compression and tension stresses. 
This is the maximum stress found on either the upper boundary (compression) or lower boundary (tension) immediately after the layer has delaminated from the bedding above. This analysis assumes that the load is uniformly distributed and is extremely sensitive to the thickness of the beam, where a $1 / 3$ reduction in height results in an over two-fold increase in the stress (Table 3).

Table 3. Bending stress vs. varying heights of a soil beam.

\begin{tabular}{|c|c|c|c|}
\hline Height $(\mathrm{m})$ & 0.30 & 0.20 & 0.15 \\
\hline Bending stress (MPa) & 0.50 & 1.2 & 2.1 \\
\hline
\end{tabular}

Utilizing the initial yield strengths from the tested cores from the tunnel, determined as in Figure $13 \mathrm{~b}$, we see that at $-2.0^{\circ} \mathrm{C}$ and a strain rate of $1 \times$ $10^{-3} / \mathrm{s}$, the initial yield begins at approximately 1.4 MPa (Fig. 15). This is slightly lower than the value of 1.8 MPa that Zhu and Carbee (1987a) reported for initial yield strength at approximately the same strain rate and temperature. This is understandable, as the moistures for their remolded specimens were $40 \%$, compared to our tested "undisturbed" tunnel cores of 50-190\%. Higher moistures will yield lower strengths because of the increased ice volume, and the reconstituted samples would provide more uniform grain-to-grain contact than for a naturally deposited sample.

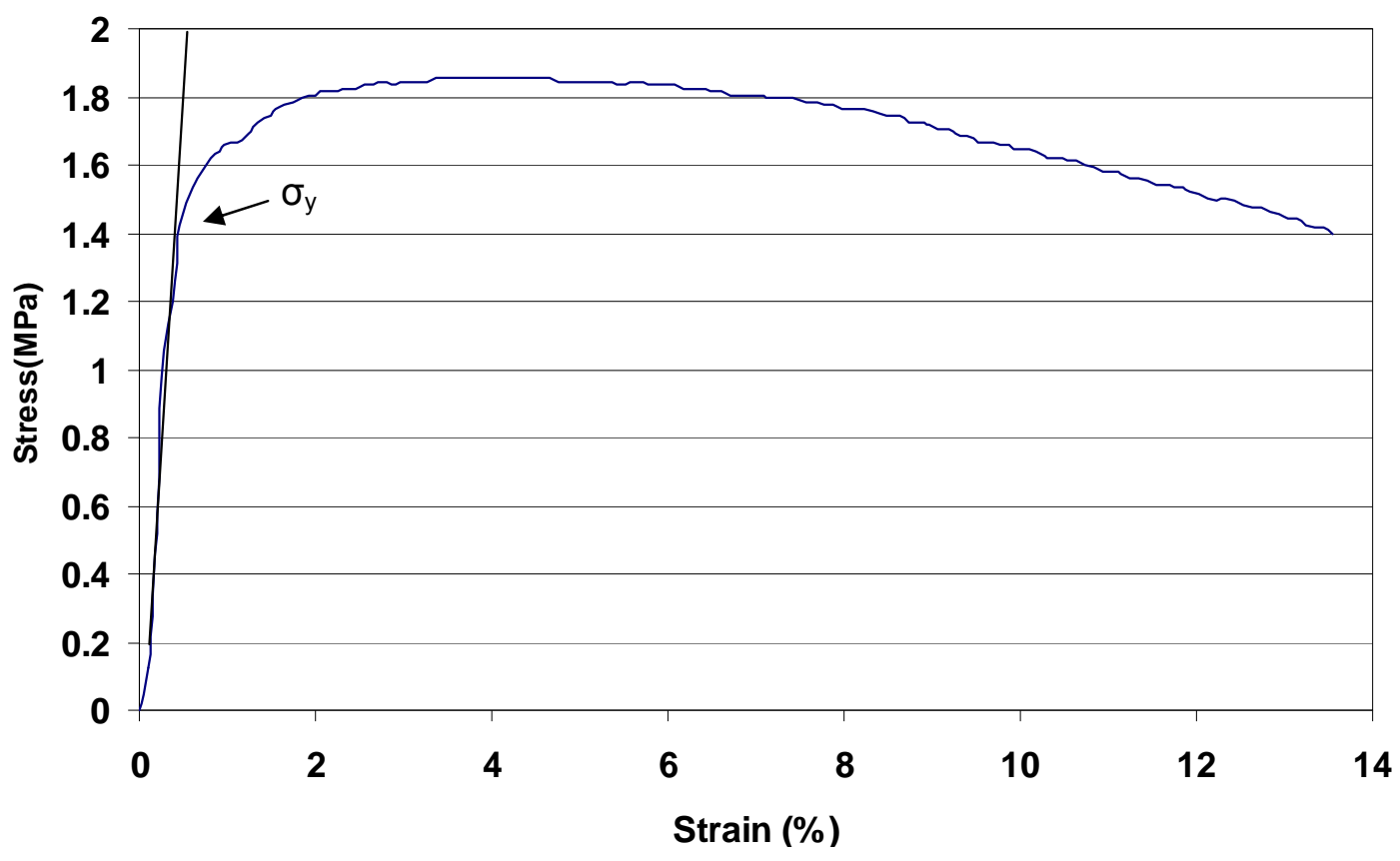

Figure 15. Core \#1-H unconfined constant strain rate test at a strain rate of $1 \times 10^{-3} / \mathrm{s}$ and $-2.0^{\circ} \mathrm{C}$. The moisture content was $84.7 \%$. 
Utilizing initial yield strengths from Zhu and Carbee (1987a) tested at $-0.5,-1.0$, and $-5.0^{\circ} \mathrm{C}$, and normalizing to a strength index using the 1.8 MPa as a reference, gives the values listed in Table 4, which show decreased strengths at near-zero temperatures and increased strengths as the temperature decreases to $-5.0^{\circ} \mathrm{C}$. In comparison to a strength index of 0.67 calculated from beam theory, the stresses developed are very close to the strength of the soil for the warmer, near-zero temperatures. Many simplifying assumptions have been made in this analysis, and the strain rates used in the Zhu and Carbee tests are not necessarily the strain rates currently in the tunnel, so the strength of the tunnel soil is not exactly duplicated. But it is possible to see that temperature greatly affects creep rate and soil strength. Therefore, the increasing amount of deformation as one moves toward the face of the tunnel can easily be attributed to both an increase in temperature and a non-uniform material.

Table 4. Strength indexes normalized to $1.8 \mathrm{MPa}$ and tested at $1 \times$ $10^{-3} / \mathrm{s}$ strain rate.

\begin{tabular}{|c|c|c|c|c|c|}
\hline & $-0.5^{\circ} \mathrm{C}$ & $-1.0^{\circ} \mathrm{C}$ & $-2.0^{\circ} \mathrm{C}$ & $-3.0^{\circ} \mathrm{C}$ & $-5.0^{\circ} \mathrm{C}$ \\
\hline Zhu and Carbee & 0.60 & 0.66 & 1.0 & 1.3 & 1.7 \\
\hline In situ & 1.2 & 0.94 & 0.70 & - & 1.4 \\
\hline
\end{tabular}

We now compare theoretical boundary stresses found around the perimeter of an elliptical opening in an elastic isotropic body. This is applicable to the front of the adit, where deformation has not occurred and the geometry is intact from the time of initial excavation. For the opening shown in Figure 16, we can compute the stresses found at the top (or bottom) of the opening and those found at the walls.

From Brady and Brown (1983),

$$
\sigma_{\mathrm{A}}=p\left(1-K+\sqrt{\frac{2 W}{\rho_{\mathrm{A}}}}\right)
$$

and

$$
\sigma_{\mathrm{B}}=p\left(K-1+K \sqrt{\frac{2 H}{\rho_{\mathrm{B}}}}\right)
$$




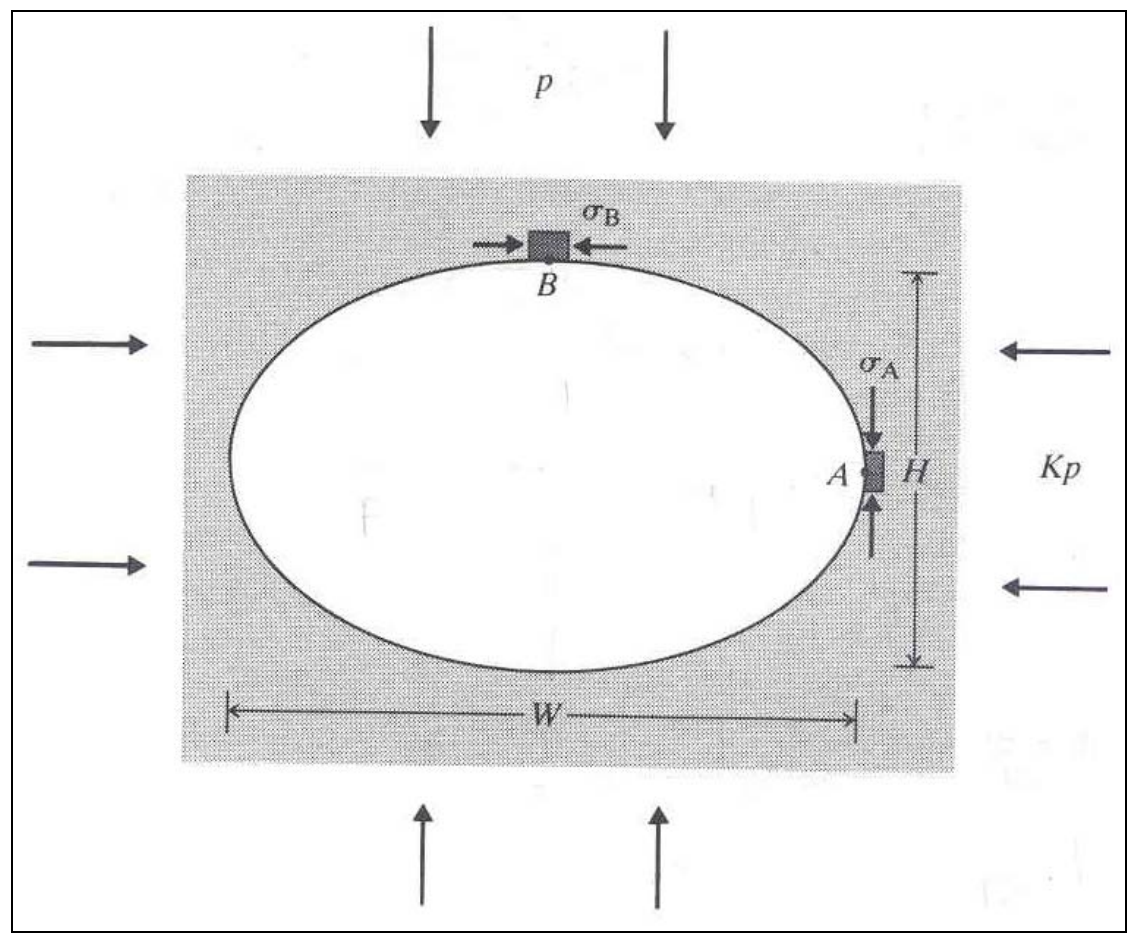

Figure 16. Vertical and horizontal boundary stresses determined by geometry and field stress. (From Brady and Brown 1993.)

and the radius of curvature is

$$
\rho_{A}=\frac{b^{2}}{a} \text { and } \rho_{B}=\frac{a^{2}}{b}
$$

where

$$
\begin{aligned}
& \mathrm{p}=\text { field stress (overburden stress) } \\
& \mathrm{K}=\text { stress equilibrium factor } \\
& \mathrm{a}=\text { major axis } \\
& \mathrm{b}=\text { minor axis }
\end{aligned}
$$

With an overburden stress of $0.22 \mathrm{MPa}$, a ratio of width to height of 1.0, and a $\mathrm{K}$ factor of 0.3 , eq 5 and 6 result in values of $0.6 \mathrm{MPa}$ for $\sigma_{\mathrm{A}}$ and $-0.02 \mathrm{MPa}$ (tension) for $\sigma_{\mathrm{B}}$. These values are within the strength range for $-3.0^{\circ} \mathrm{C}$ soil of $2.3 \mathrm{MPa}$ with a factor of safety of $2.3 / 0.6$, or 3.8 . This probably explains why the front portion of the adit exhibits little or no deformation. It can also be shown that lowering the temperature to $-5.0^{\circ} \mathrm{C}$ would increase the factor of safety to 5 . Regarding tension strength, Zhu and Carbee (1987b) demonstrated that for low strain rates up to the brittleductile transition point, the tension strength equals the compressive 
strength for these frozen silts. After the brittle-ductile transition, the compressive strength continues to increase while tensional strength begins to decrease.

\section{Structural Integrity}

\section{Adit and Winze}

Because of the creep behavior of the ice-rich silt where the overburden stress is continually relaxing around the cavity, there has not been catastrophic failure with unexpected slab falls, as would be encountered in highly jointed or faulted rock. Because the overburden depth does not significantly change between about $50+00$ and the face, the stress applied to the soil should be nearly constant, so it is not a variable affecting the deformation.

Therefore, looking at the complete adit from portal to face, and taking into account the evidence for particular defining events, we can see that temperature is a factor contributing to the collapse of the roof near the face. The early literature suggested that after construction, the overall temperature of the tunnel was maintained from around $-6.0^{\circ} \mathrm{C}$ to $-3.0^{\circ} \mathrm{C}$. Since that time the closing of the rear vent(s) and the timing of the thermal flooding in 1993 have accelerated the deformation and creep of the silt unit in the back of the adit. These abrupt changes in temperature have had compounded effects with the massive ice features and bedded lithology; most importantly, the yield strength of the soil is very near the stresses induced on a detached layer of soil. Based on field measurements, the temperature increases from the portal (non-deforming) to the face (deformed), pushing this yield strength threshold to the point where noticeable deformation begins. The steady-state creep of the secondary stage is pushed into the accelerating creep of the tertiary stage.

The sequence for deformation is as follows:

- Excavation of the tunnel, with initial stress redistribution and low overall tunnel temperatures, gives a stable excavation that does not exceed the threshold of failure strength. The deformation rate is initially high but decreases with time.

- With an increase of tunnel temperature toward the face, the warming soil begins to experience higher creep rates and lower bonding strength between the interbedded layers of gravel, sand, and silt, which have an 
inherently lower failure strength than the layers of silt alone. As a result, silt slabs slowly separate at the layers and begin to preferentially detach along this boundary.

- Once this detachment is complete, the silt layer hangs freely and creeps in bending under its own weight in the warmer temperatures. The layer slowly moves toward the floor and either breaks under tensional forces or creeps to meet the floor.

- As this layer is moving downward, the layers above repeat the process of detachment and begin to move as well. From a tunnel engineering perspective, the overall strength of the shallow overburden adit geometry is not compromised by delamination and removal, and the adit is safe for continued operation. The sudden release of low, hanging layers, if allowed to continue to creep, is a safety concern that must be avoided by preventing access to this area until stabilized.

For a frozen silt soil column $12.2 \mathrm{~m}$ in height (from the top of the adit to the surface), it would be expected that $2.0 \mathrm{~m}$ of downward movement at the base of this column would result in a depression at the surface, but there is no surface reflection of any subsidence. If a replacement process were under way in which surface or subsurface water were replenishing these voids and freezing, then interbedded layers of ice would most probably have been noticed in the most recent delaminations, and subsequent thermokarst would be seen at the surface, but this is not the case.

Based on visual examination of the walls and roof, the deformation scenario described probably does not apply near the portal or in the silt unit down the winze. The almost negligible deformation in these areas has not revealed the exact nature of how this soil structure would perform with rising temperatures. We speculate that a similar type of delamination would occur, but the layers would probably be irregular with unknown thickness because of the lack of alluvial sediments and the depositional nature of the wind-blown silt. The structure of the soil very near the portal, consisting of wind-blown silt, colluvium, alluvium, and large plant material, would almost certainly delaminate in very irregular, odd-shaped prisms. This material is so close to the portal doors and air cooler unit that critical temperatures should never occur unless mechanical problems force the issue. 


\section{Gravel Room}

The problem with this area is the overlying, heavier material that is weakly bonded to the silt unit above, and this is temperature-dependent. The large fall from the roof of the Gravel Room triggered by the seismic event also can be attributed to the investigational studies, although this is likely not the only reason, as general temperature fluctuations in the tunnel over the years have likely contributed as well. The fall happened without the advance warning that would come from creeping fine-grained soils; the gravel slab pulled away and came to the floor in one rapid event, which most certainly would have been deadly if this had happened while the space below had been occupied. Mitigation measures are required for this area.

\section{Sublimation}

The amount of loose material that can be found on the floor and scraped from the walls may seem excessive. The increase in roof span would be the only consequence of this process, but the resulting change has been minimal in the last 40 years, based on the near-portal geometry. Calculating the boundary stress for the geometry near the portal and increasing the roof span by $0.3 \mathrm{~m}$ results in a $5.0 \%$ increase in vertical stress at the wall, from 0.58 to $0.61 \mathrm{MPa}$, and a $29 \%$ increase in horizontal stress in the roof, from -0.020 to $-0.028 \mathrm{MPa}$. This relatively large change in stress in the roof is negligible compared to the strength of the frozen soil. Sublimation is a nuisance for the maintenance of the tunnel, but it does not affect the strength or stability.

The addition of moisture to the chilled air would decrease the scavenging of moisture from the ice. One consequence of too much moisture is the potential for hoarfrost growth, which might obscure periglacial features. The ability to adjust the amount of moisture addition would be required to find the level that minimizes sublimation without producing hoarfrost growth. A cost-benefit analysis has not been conducted regarding the addition of moisture compared to the periodic cleaning of sublimated material. 


\section{RECOMMENDATIONS}

The following are analysis team recommendations to ensure longevity of the tunnel.

\section{Chiller Upgrades}

Our analysis has shown that the soils are in delicate equilibrium with the field stresses produced by the overburden. The sensitivity of this equilibrium is profound when temperatures of the soil approach near $\mathrm{o}^{\circ} \mathrm{C}$. Therefore, to immediately decelerate and nearly stop the deformation, we recommend that chiller upgrades be performed to maintain the entire tunnel at a maximum of $-3.0^{\circ} \mathrm{C}$ and also to incorporate the addition of moisture to raise the relative humidity to reduce sublimation. A unit cooler with an attached duct trunk placed along the axis of the tunnel toward the face should be installed. Refrigerated and humidified air would be used to cool the tunnel to a target of $-5^{\circ} \mathrm{C}$ with an average relative humidity of 90$95 \%$.

\section{Surface Drainage}

According to information provided by personnel, the addition of surface water from poorly routed drainage outside of the portal has contributed in the past to the rapid thermal events. We recommend that this surface water be adequately channeled away from the portal using a drainage system designed for the most extreme flooding problems from melting snow or extremely heavy rain.

\section{Temperature Monitoring}

Installation of air and soil temperature datalogging is imperative for the entire adit, winze, and Gravel Room. We recommend that near-roof air temperature and near-surface soil thermistors ( $0.3 \mathrm{~m}$ deep) be installed every $10 \mathrm{~m}$ adjacent to the creep reference locations. This should include a sensor to monitor the air chiller and soil freeze pipe temperatures, as well as a relative humidity sensor for the adit and winze. These should be installed with datalogging capability where the readings could be taken every $2-3$ hours. 


\section{Creep Reference Location Monitoring}

Because of the lack of closure measurements, and to determine if any portion of the tunnel facility is accelerating in deformation, we recommend routine creep reference monitoring at least bi-annually. This will require the purchase of a metal tape extensometer; the measurements can be performed by one person in approximately two hours. An underground, warm, frozen fine-grained soil tunnel such as this requires this monitoring, as it will be easy to detect if a portion is beginning to yield to stresses. We installed nine stations to be monitored in the vertical and horizontal orientation, and we also established an extensometer reference location at the bulkhead.

\section{Safety Fencing}

Chain link fencing should be installed at the end of the catwalk in the adit and at the bottom of the winze to prevent entrance into the unstable area and yet allow air movement. A gate should be supplied on each fence bulkhead. This barrier may be removed once lower temperatures have stabilized, continued monitoring shows deceleration of deformation, and structural support has been installed.

\section{Detailed Topographic Survey}

We recommend that a topographic survey of the tunnel and surface be conducted every two years to monitor all fixed points in the tunnel relative to a fixed location outside the portal. This will determine how the creep reference locations and other points are moving relative to each other, and it will monitor any surface subsidence.

\section{Near-Field Permafrost Temperatures}

Installation of a near-field permafrost temperature measurement borehole is recommended to monitor the overall permafrost temperature from surface to bedrock. The thermistor string could be configured to capture active layer measurements at that location and permafrost temperatures at 3-m intervals. This should be installed with datalogging capability. This also would serve as baseline measurements for climate change effects on the tunnel. 


\section{Cleaning of Debris}

Cleaning of the sublimated debris from all floors and installation of a catwalk down the winze to eliminate dust would allow a clear view of all the tunnel features and eliminate the nuisance of suspended particles in the air.

\section{Future Analysis}

After stabilization of temperature, periodic measurements should be recorded to establish long-term creep rates vs. temperature. This will establish the rate of deformation and determine if the deformation rate of any portion of the tunnel is continuing to accelerate.

A cost-benefit analysis should be conducted regarding the addition of moisture compared to periodic cleaning of sublimated material.

Drilling should be conducted into the roof at the location of the most extreme delamination to determine the extent of the voids between the layers and to look for intrusive ice. This will help determine the amount of barring down that will be required to open the adit to the face once temperatures have stabilized at a lower level.

\section{Station Labeling}

We recommend labeling stationing on the walls, railings, or catwalk to allow quick determination during viewing and to aid research. For our report, stationing began at the bulkhead and was measured in meters. This will ensure that any future items or problems noticed by researchers or CRREL personnel will be correctly identified and noted. This also will help all future research by referencing from the same location with easy-to-read placards or paint.

\section{Re-excavation of the Adit}

After sufficient stabilization of temperature to a maximum of $-3.0^{\circ} \mathrm{C}$ and determination that creep has decelerated to an acceptable level, we recommend that the crept material at the end of the adit be barred down and that the fallen slabs lying on the floor be removed to gain access to the periglacial features at the back of the tunnel. In conjunction, we recommend the installation of structural supports at key locations of previous significant deformation and large roof spans. End-supported steel col- 
umns with steel or timber beams can be installed at four specific locations to react against any future deformation. Details for this support can be provided by these investigators upon request.

\section{Re-excavation of the Gravel Room}

After sufficient stabilization of the temperature, we recommend removing the remaining overlying gravel layer in the lower winze and Gravel Room and installing structural support as detailed above under large spans. This support would be founded on bedrock and would find excellent footing in the schist. It also would be possible to install structural support under the remaining gravel, if this is deemed worthy of the investment, and to monitor its performance. Sublimation of the ice matrix binding the gravels will eventually require the barring down of material and repositioning of the support if this option is chosen. Details for this support can be provided by these investigators upon request. 


\section{SUMMARY}

The CRREL Permafrost Tunnel is safe for continued use and recommendations are made that will ensure the safe and continued use for decades to come. It is apparent the original geometry of the adit is still intact. From the portal to approximately $75^{+00}$, there is no perceptible deformation to suggest structural instability. In fact, for most of this portion of the adit, the Alkirk Miner profile is still visible in the roof, suggesting the material is relatively stable and has not moved or fallen since the time of excavation.

To immediately decelerate and nearly stop the deformation, we recommend that chiller upgrades be performed to maintain the entire tunnel at a maximum of $-3.0^{\circ} \mathrm{C}$, giving a factor of safety of 3.8 . Lowering the temperature to $-5.0^{\circ} \mathrm{C}$ would increase the factor of safety to 5 . Also, moisture should be added to raise the relative humidity to counter sublimation. Sublimation is a nuisance for the maintenance of the tunnel, but it does not affect the strength or stability.

We recommend that chain link fencing be installed at the end of the catwalk in the adit and at the bottom of the winze to prevent entrance into unstable areas and yet allow air movement. A gate should be supplied on each fence bulkhead. This fencing could be removed if the temperature reduction proved to make the rear of the tunnel and the lower winze stable.

We recommend that surface drainage be adequately channeled away from the portal and designed for the most extreme flooding problems from melting snow or extremely heavy rain. This will prevent the repeat of past thermal events that have initiated and accelerated the deformation at the rear of the adit and added to the lithological weakness in the Gravel Room.

Because of the lack of closure measurements and to determine if any portion of the tunnel facility is accelerating in deformation, we recommend creep reference location monitoring at least bi-annually. We also recommend that near-roof air temperatures and near-surface soil thermistors ( $0.3 \mathrm{~m}$ deep) be installed every $10 \mathrm{~m}$ and adjacent to the creep reference locations. This should include a sensor to monitor the air chiller and soil freeze pipe temperatures, as well as a relative humidity sensor for the adit 
and winze. These should be installed with datalogging capability where the readings could be taken every $2-3$ hours. 


\section{REFERENCES}

Brady, B.H.G., and E.T. Brown (1993) Rock Mechanics for Underground Mining. Second Edition. London, England: Chapman Hall.

Bray, M.T., H.M. French, and Y. Shur (2006) Further cryostratigraphic observations in the CRREL Permafrost Tunnel, Fox, Alaska. Permafrost and Periglacial Processes, 17(3): 233.

Chester, J.W., and J.N. Frank (1969) Fairbanks placers fragmentation research final report. Minneapolis: Twin Cities Mining Research Center, US Bureau of Mines, Heavy Metals Program, 52 p.

Garbeil, H.M. (1983) Temperature effects upon the closure of a gravel room in permafrost. MS thesis, University of Alaska Fairbanks.

Huang, S.L. (1985) Temperature and time effects on the closure of a gravel room in permafrost. Bulletin of Association of Engineering Geologists 22(2): 53-65.

Huang, S.L., and N.B. Aughenbaugh (1986) Stability study of CRREL Permafrost Tunnel. ASCE J ournal of Geotechnical Engineering 112(8): 777-790.

Hult, J.A.H. (1966) Creep in engineering structures. Waltham, MA: Blaisdell.

Johansen, N.I. (1993) CRREL Permafrost Tunnel after event video.

Law, K.H. (1987) Time-dependent bearing capacity of frozen ground. MS thesis, University of Alaska Fairbanks.

Murton, J. B., and H.M. French (1994) Cryostructures in permafrost, Tuktoyaktuk coastlands, western arctic Canada. Canadian J ournal of Earth Sciences 31: 737747.

Pettibone, H.C. (1973) Stability of an underground room in frozen gravel. In Permafrost: North American Contribution to the Second International Conference, Washington: National Academy of Sciences, p. 699-706.

Pettibone, H.C., and G.G. Waddell (1969) Stability of an underground room in frozen, gold-bearing strata, Fairbanks, Alaska. In Seventh Annual Northwest Mining Association Convention, Spokane, Washington, US Bureau of Mines Heavy Metals Program, $14 \mathrm{p}$.

Péwé, T.L. (1993) Geologic hazards of the Fairbanks area, Alaska. Special Report 15, State of Alaska Division of Geological and Geophysical Surveys.

Phukan, A. (1985) Frozen Ground Engineering. Englewood Cliffs, NJ: Prentice-Hall, Inc.

Sayles, F.H., and Carbee, D.L. (1981) Strength of frozen silt as a function of ice content and dry unit weight. Engineering Geology 18: 55-66. 
Sayles, F.H., and D. Haines (1974) Creep of frozen silt and clay. Technical Report 252. Hanover, NH: Cold Regions Research and Engineering Laboratory.

Sellmann, P.V. (1967) Geology of the USA CRREL Permafrost Tunnel in Fairbanks, Alaska. Technical Report 199. Hanover, NH: Cold Regions Research and Engineering Laboratory.

Shur, Y., H.M. French, M.T. Bray, and D.A. Anderson (2004) Syngenetic permafrost growth: Cryostratigraphic observations from the CRREL Tunnel near Fairbanks, Alaska. Permafrost and Periglacial Processes 15: 339-347.

Swinzow, G.K. (1970) Permafrost tunneling by a continuous mechanical method. Technical Report 221. Hanover, NH: Cold Regions Research and Engineering Laboratory.

Williams, P.J., and M.W. Smith (1989) The Frozen Earth: Fundamentals in Geocryology. Cambridge, U.K.: Cambridge University Press.

Wu, M.C. (1985) The temperature and geometry influences on an underground opening in the frozen ground. MS thesis, University of Alaska Fairbanks.

Zhu, Y., and D.L. Carbee (1987a) Creep and strength behavior of frozen silt in uniaxial compression. CRREL Report 87-10. Hanover, NH: Cold Regions Research and Engineering Laboratory.

Zhu, Y., and D.L. Carbee (1987b) Tensile strength of frozen silt. CRREL Report 87-15. Hanover, NH: Cold Regions Research and Engineering Laboratory. 


\section{APPENDIX A: Laboratory Core Sample Tests}

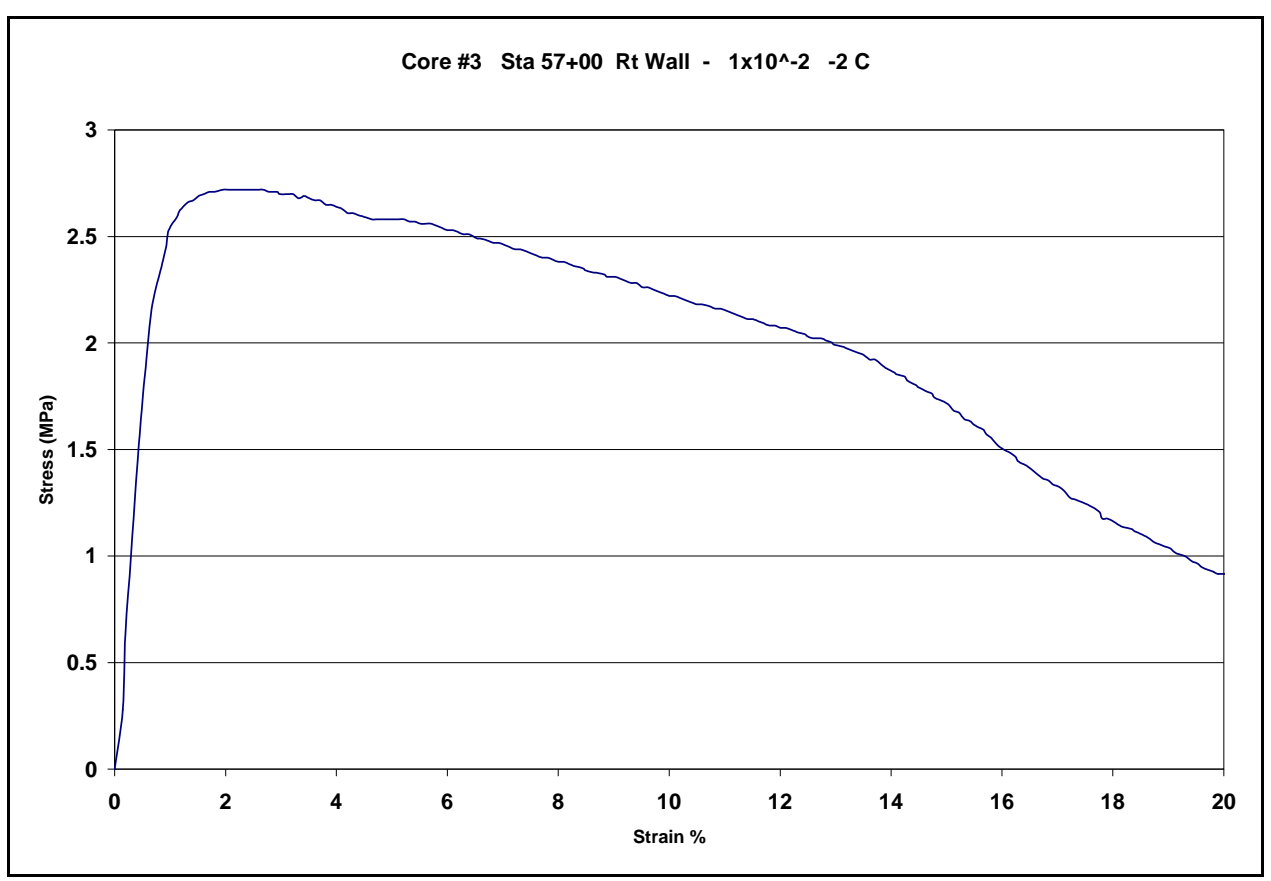

\#3-H Horizontal $-2^{\circ} \mathrm{C}, 1 \times 10^{-2} / \mathrm{s}$.

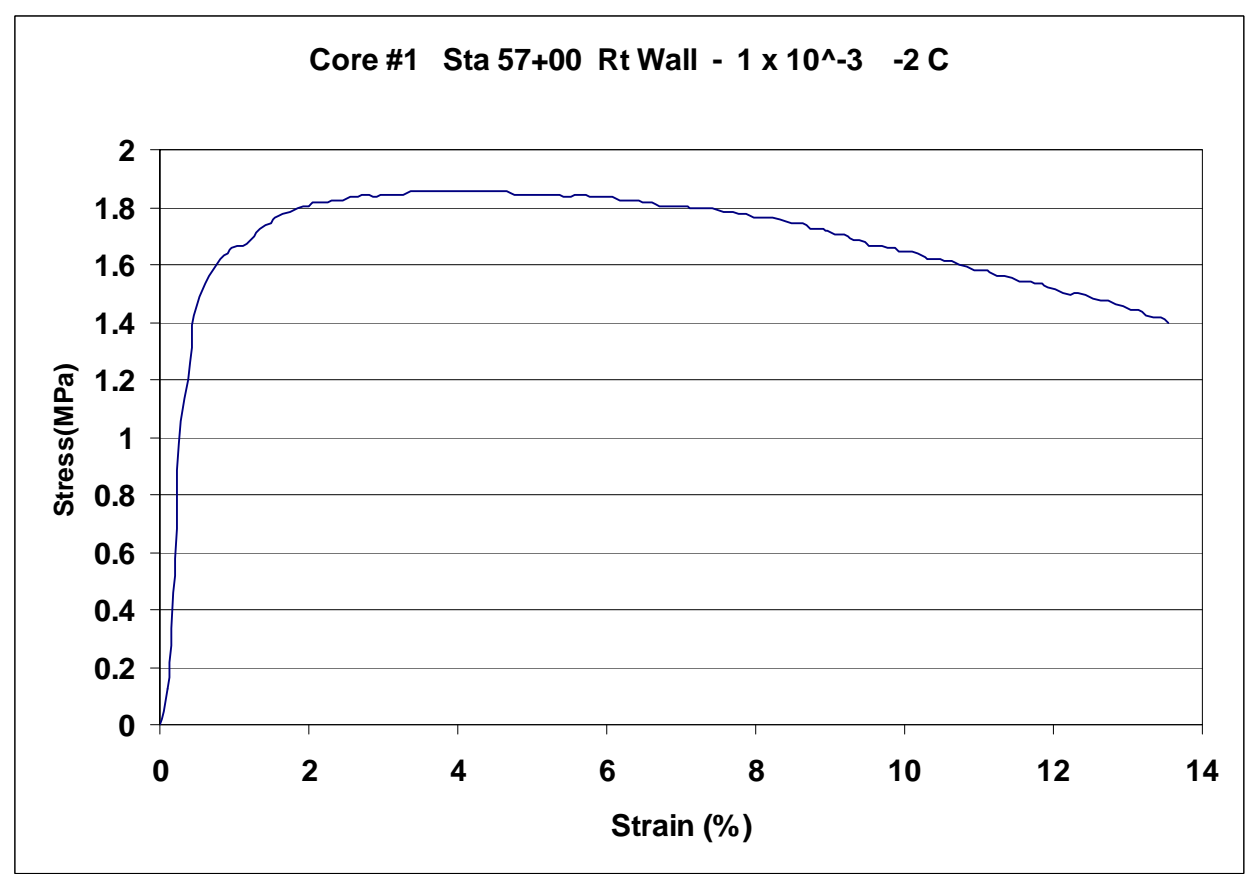

\#1-H Horizontal, $-2^{\circ} \mathrm{C}, 1 \times 10^{-3} / \mathrm{s}$. 


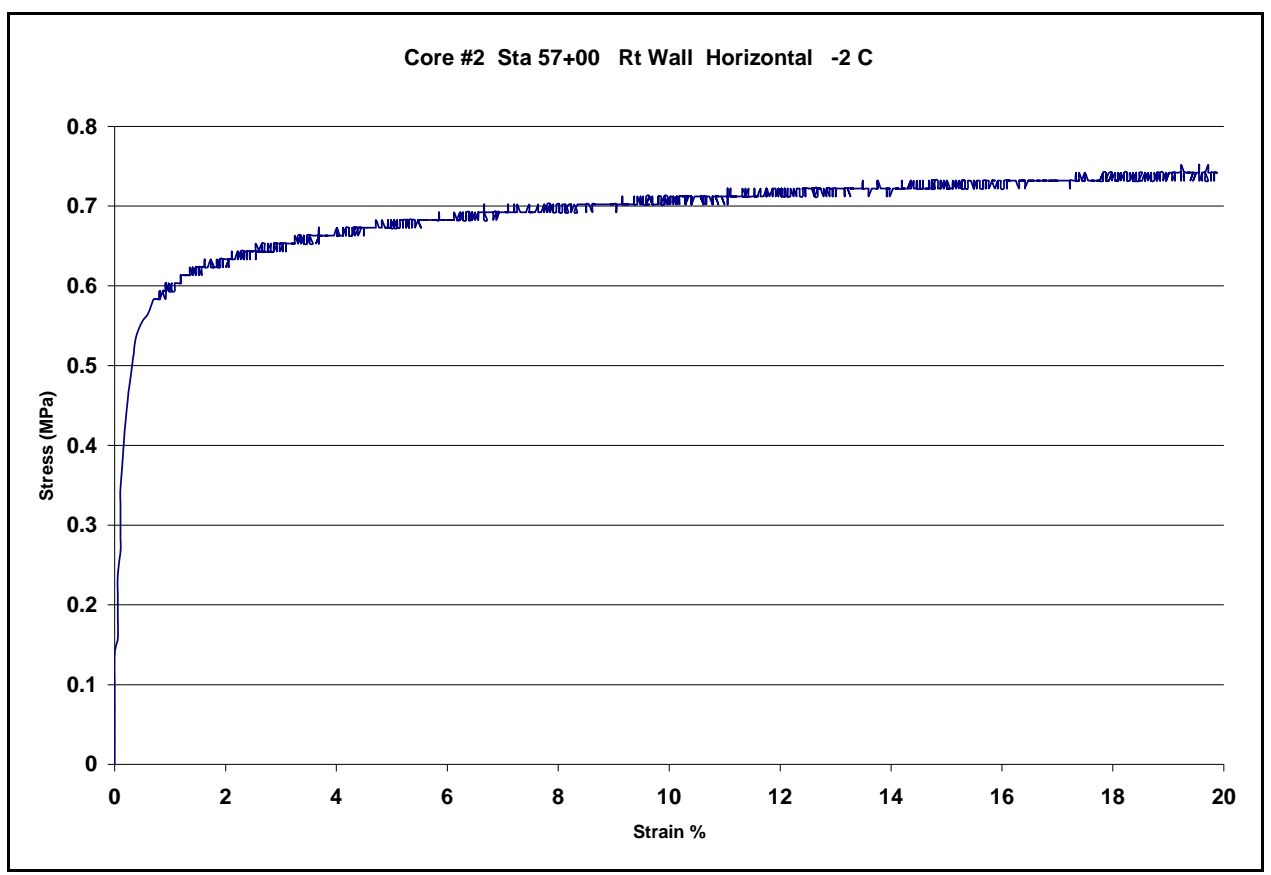

\#2-H Horizontal, $-2^{\circ} \mathrm{C}, 1 \times 10^{-4} / \mathrm{s}$.

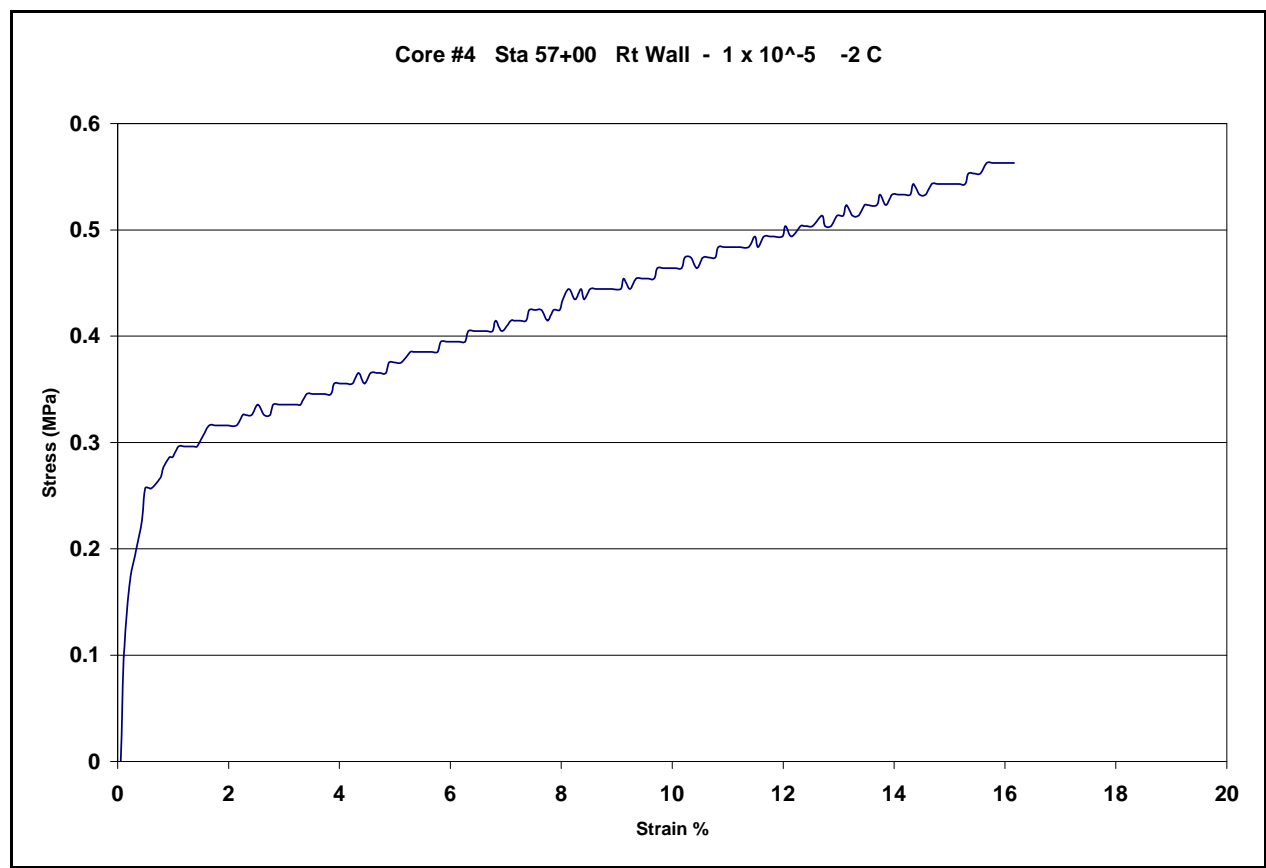

\#4-H Horizontal, $-2^{\circ} \mathrm{C}, 1 \times 10^{-5} / \mathrm{s}$. 


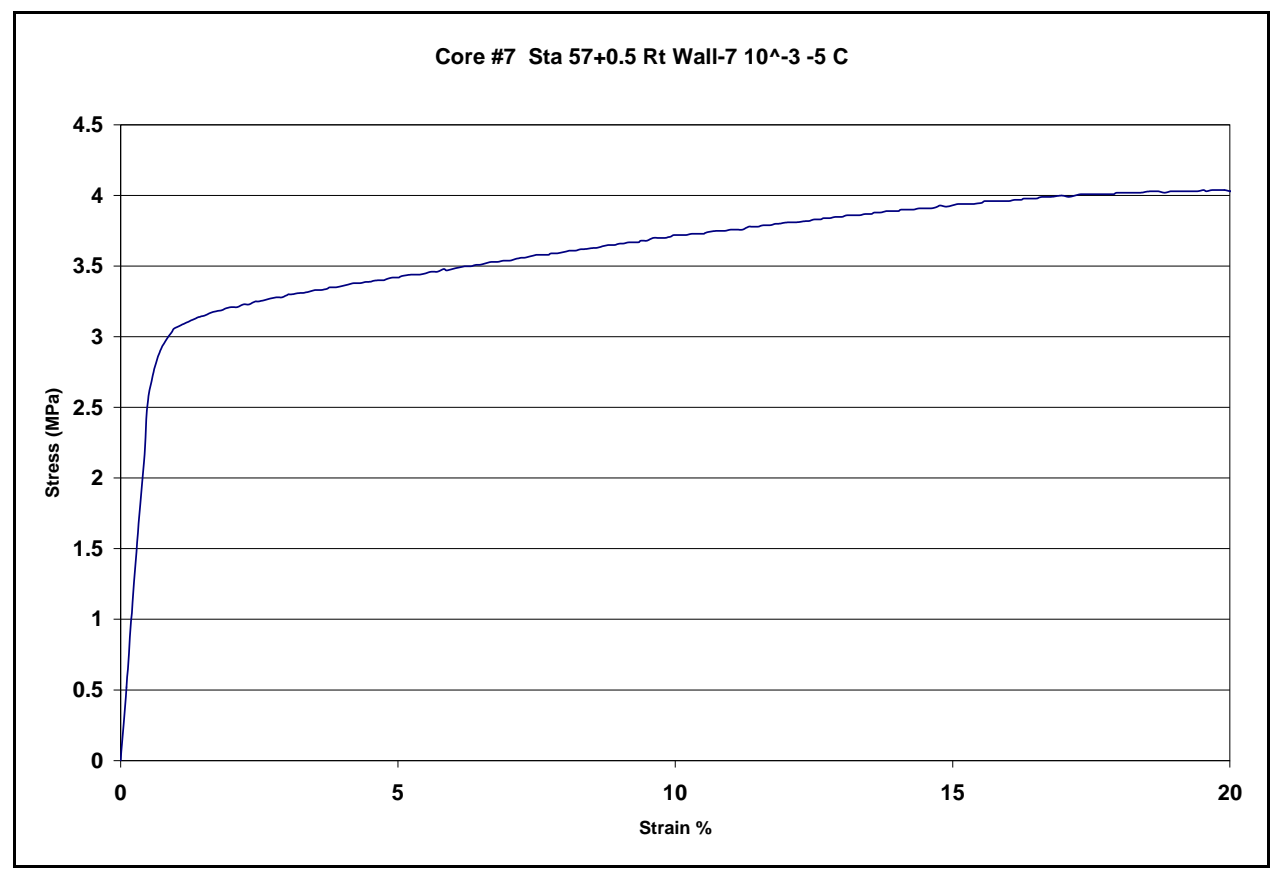

\#7-H Horizontal, $-5^{\circ} \mathrm{C}, 1 \times 10^{-3} / \mathrm{s}$.

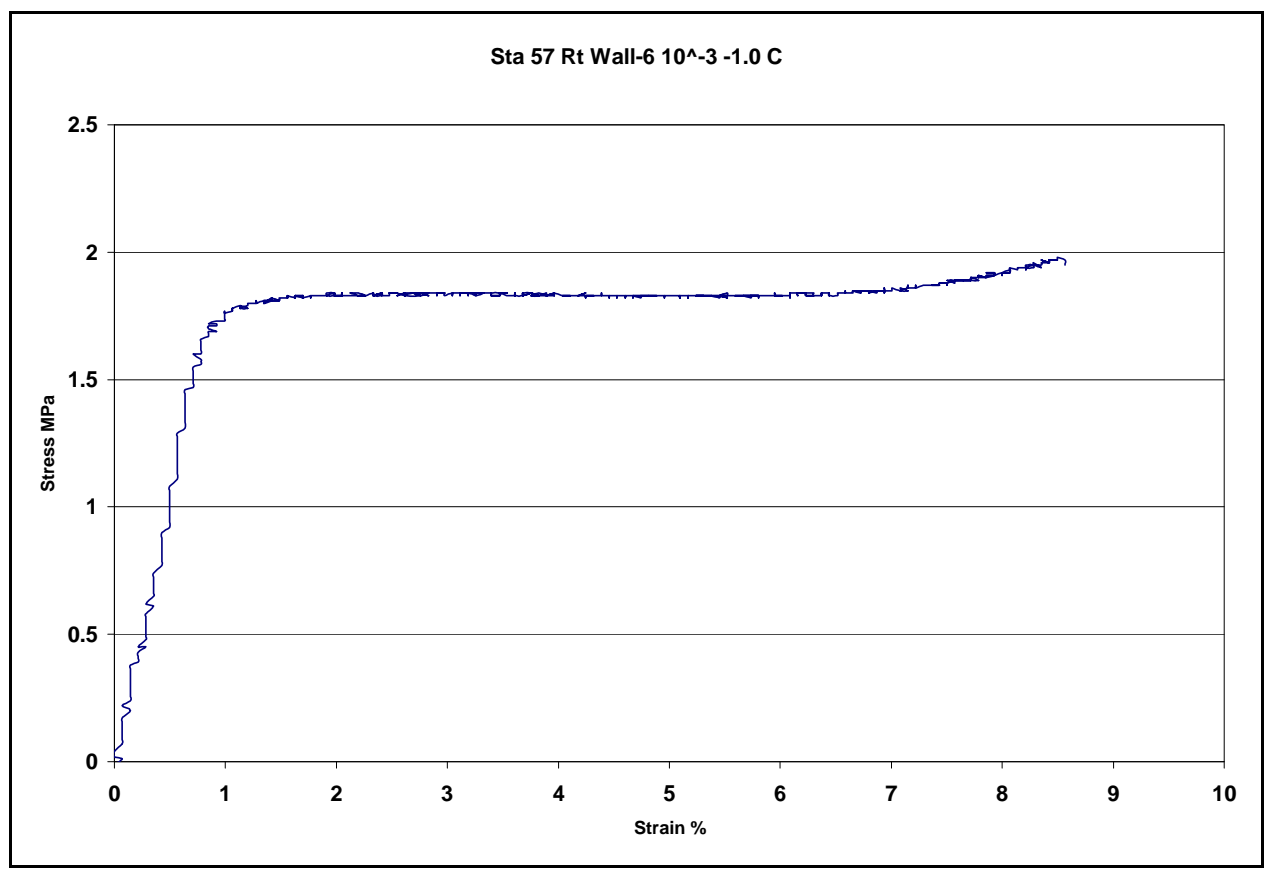

\#6-H Horizontal, $-1.0^{\circ} \mathrm{C}, 1 \times 10^{-3} / \mathrm{s}$. 


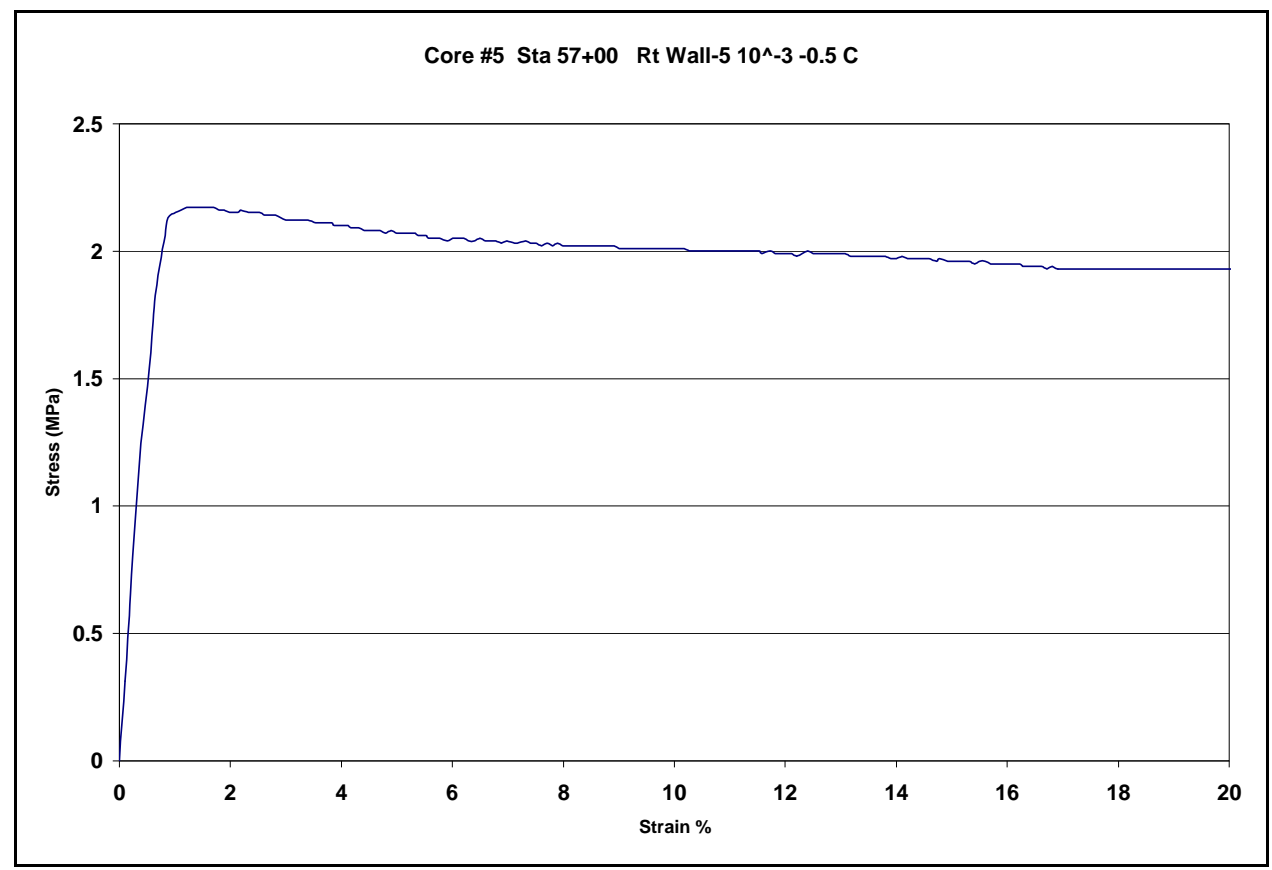

\#5-H Horizontal, $-0.5^{\circ} \mathrm{C}, 1 \times 10^{-3} / \mathrm{s}$.

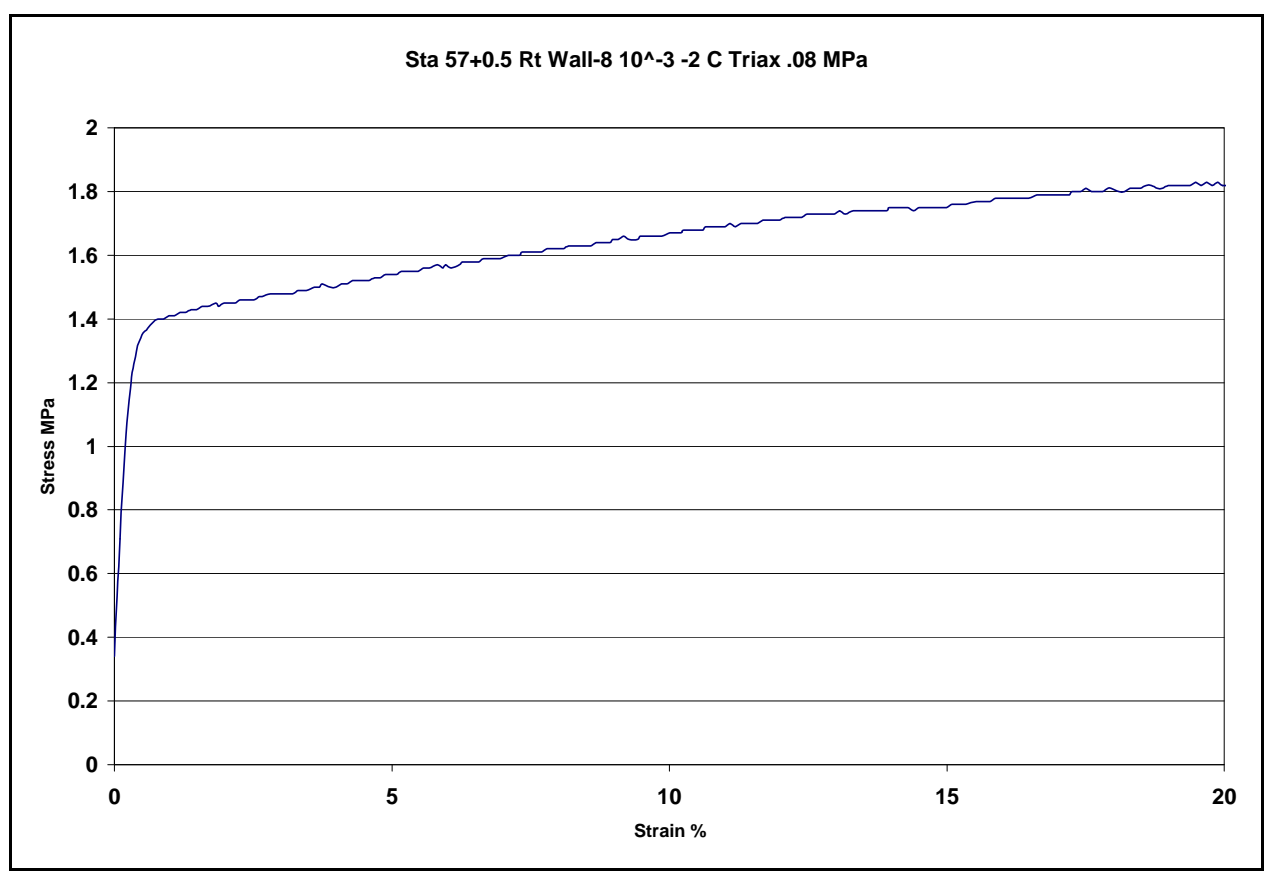

\#8-H Horizontal, $-2.0^{\circ} \mathrm{C}, 1 \times 10^{-3} / \mathrm{s}$, Triaxial at $0.08 \mathrm{MPa}$. 


\section{Appendix B: In-Situ Test Results}

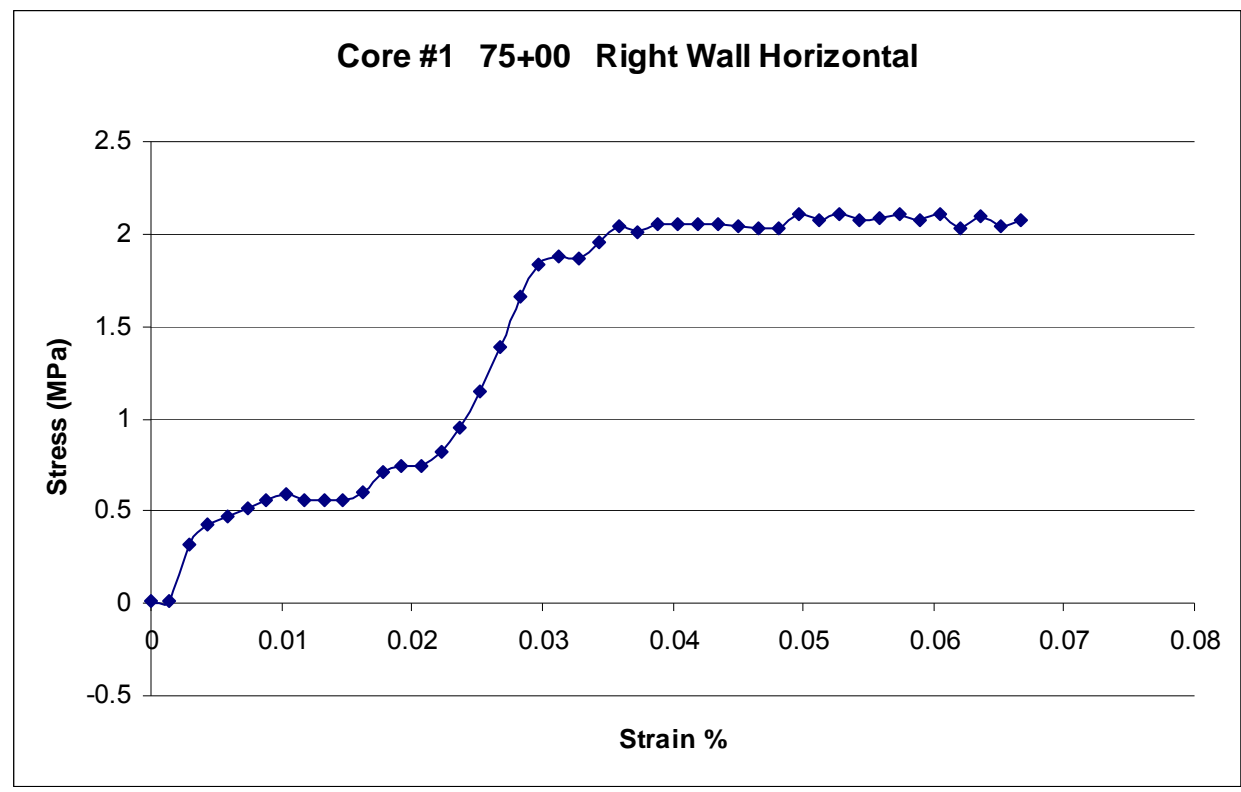

\#1-T Horizontal, $-2.0^{\circ} \mathrm{C}, 1 \times 10^{-3} / \mathrm{s}$.

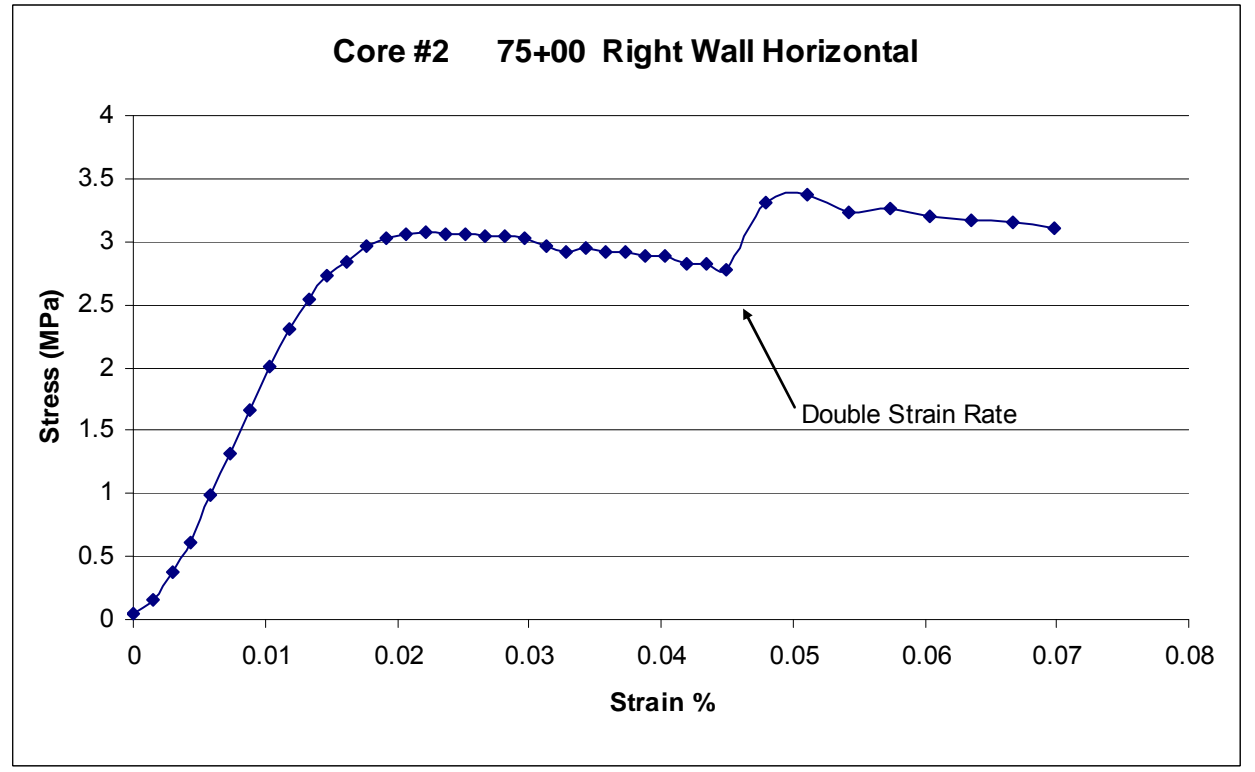

\#2-T Horizontal, $-2.0^{\circ} \mathrm{C}, 1 \times 10^{-3} / \mathrm{s}$. 


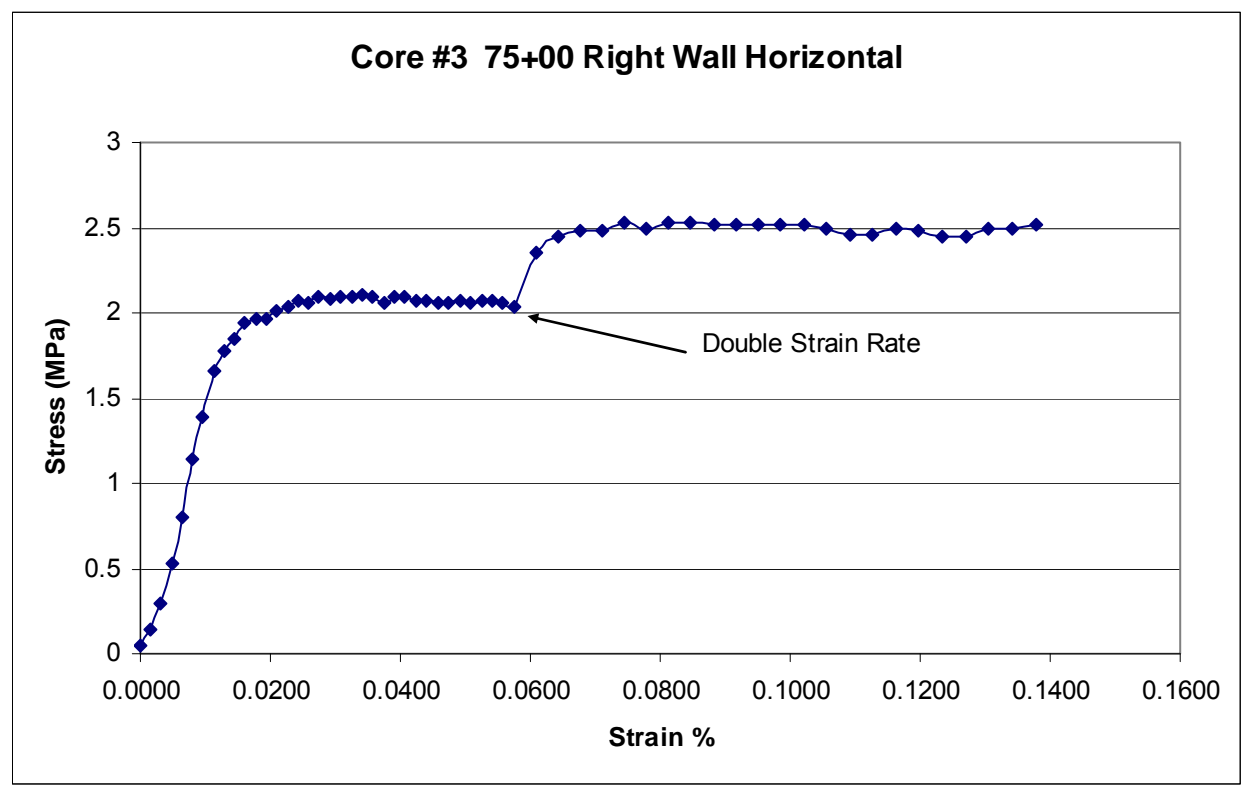

\#3-T Horizontal, $-2.0^{\circ} \mathrm{C}, 1 \times 10^{-3} / \mathrm{s}$.

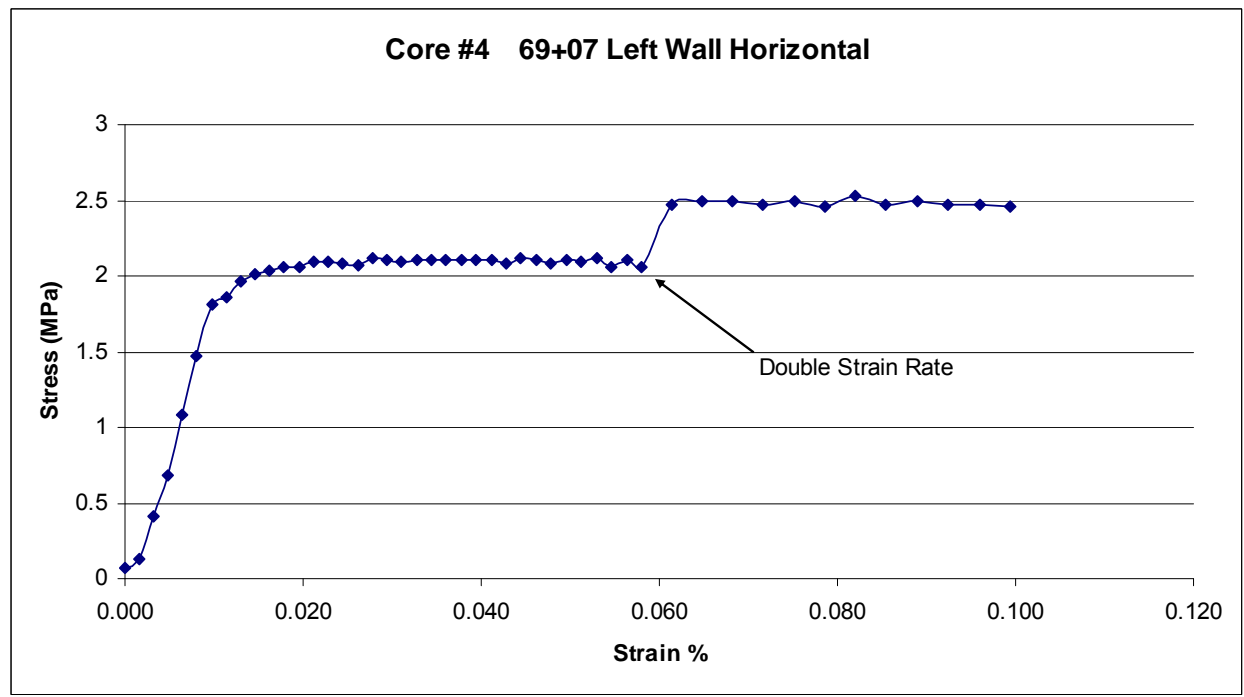

\#4-T Horizontal, $-2.0^{\circ} \mathrm{C}, 1 \times 10^{-3} / \mathrm{s}$. 


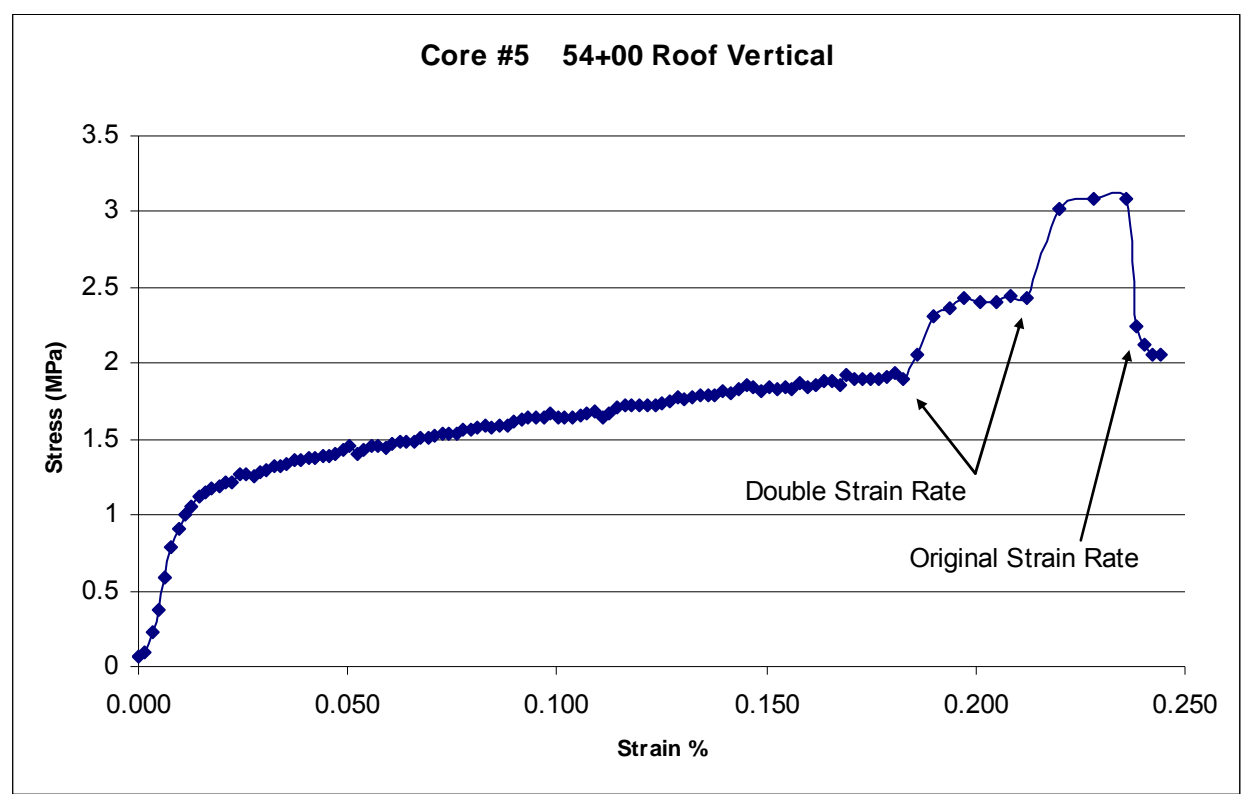

\#5-T Vertical, $-2.0^{\circ} \mathrm{C}, 1 \times 10^{-3} / \mathrm{s}$

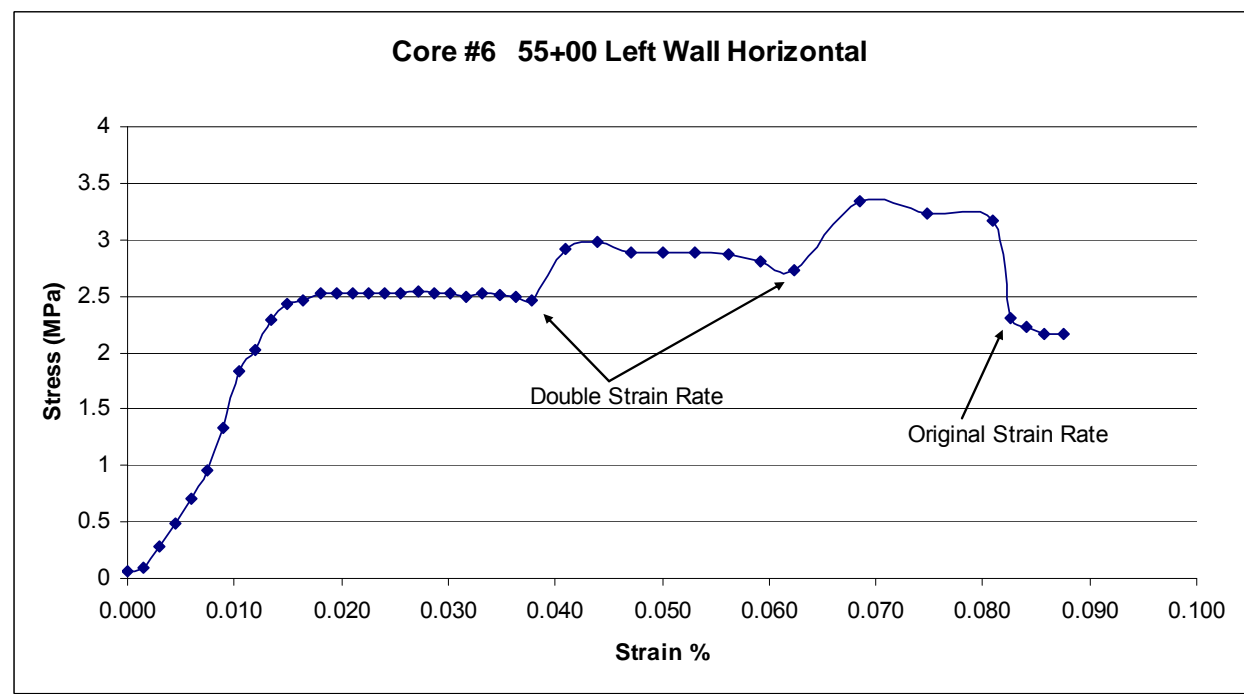

\#6-T Horizontal, $-2.0^{\circ} \mathrm{C}, 1 \times 10^{-3} / \mathrm{s}$. 


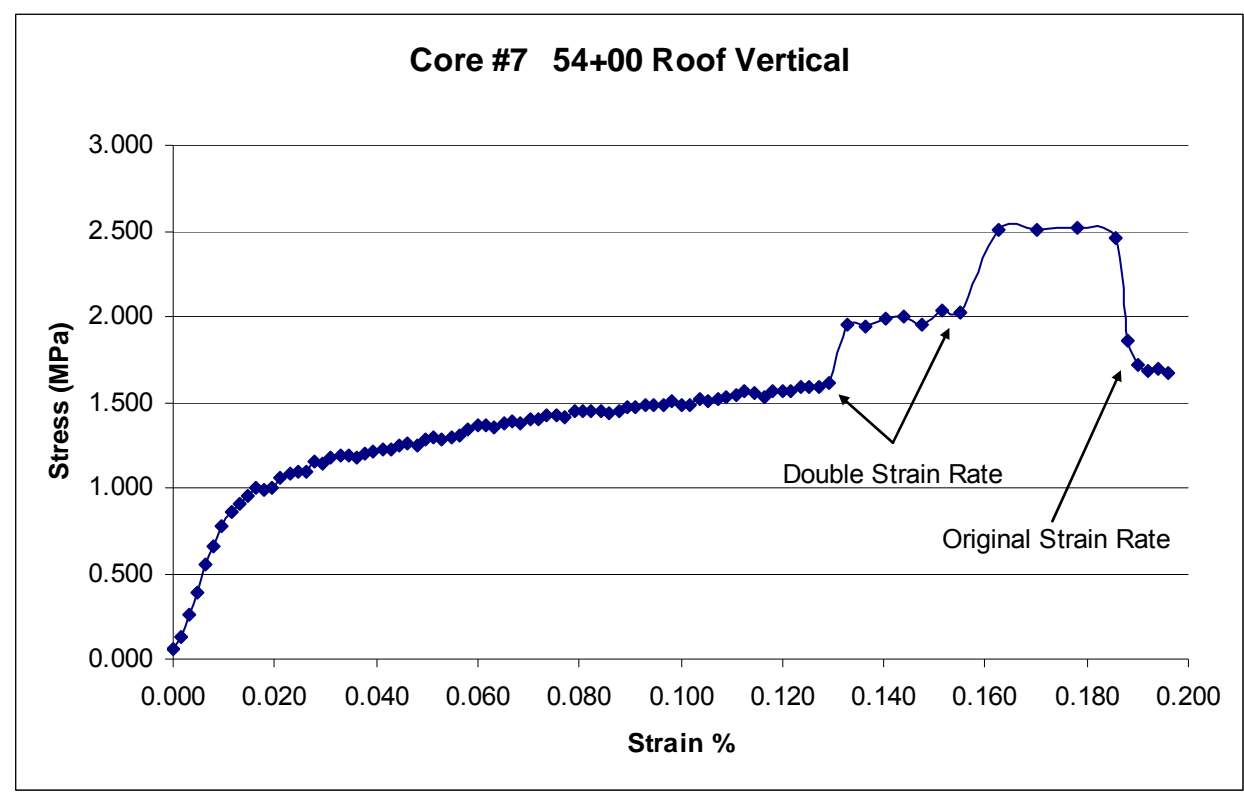

\#7-T Vertical, $-2.0^{\circ} \mathrm{C}, 1 \times 10^{-3} / \mathrm{s}$

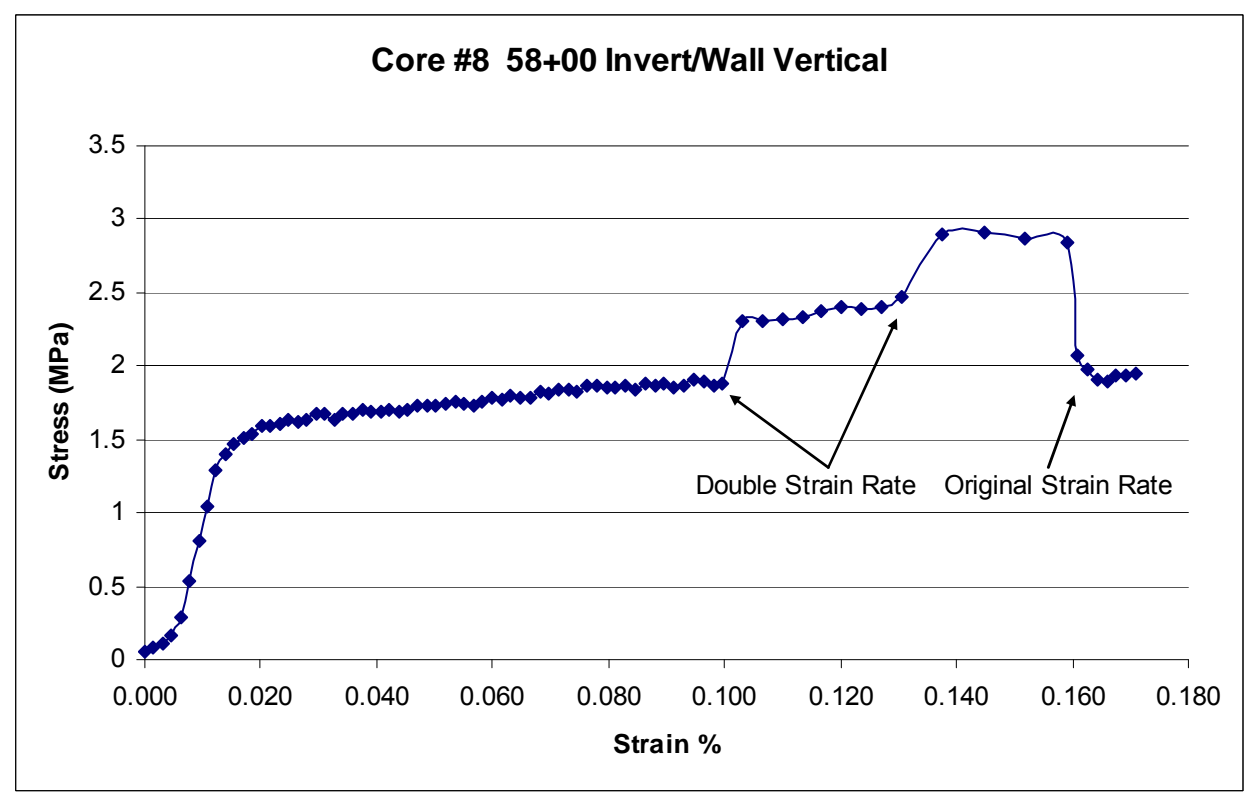

\#8-T Vertical, $-2.0^{\circ} \mathrm{C}, 1 \times 10^{-3} / \mathrm{s}$. 


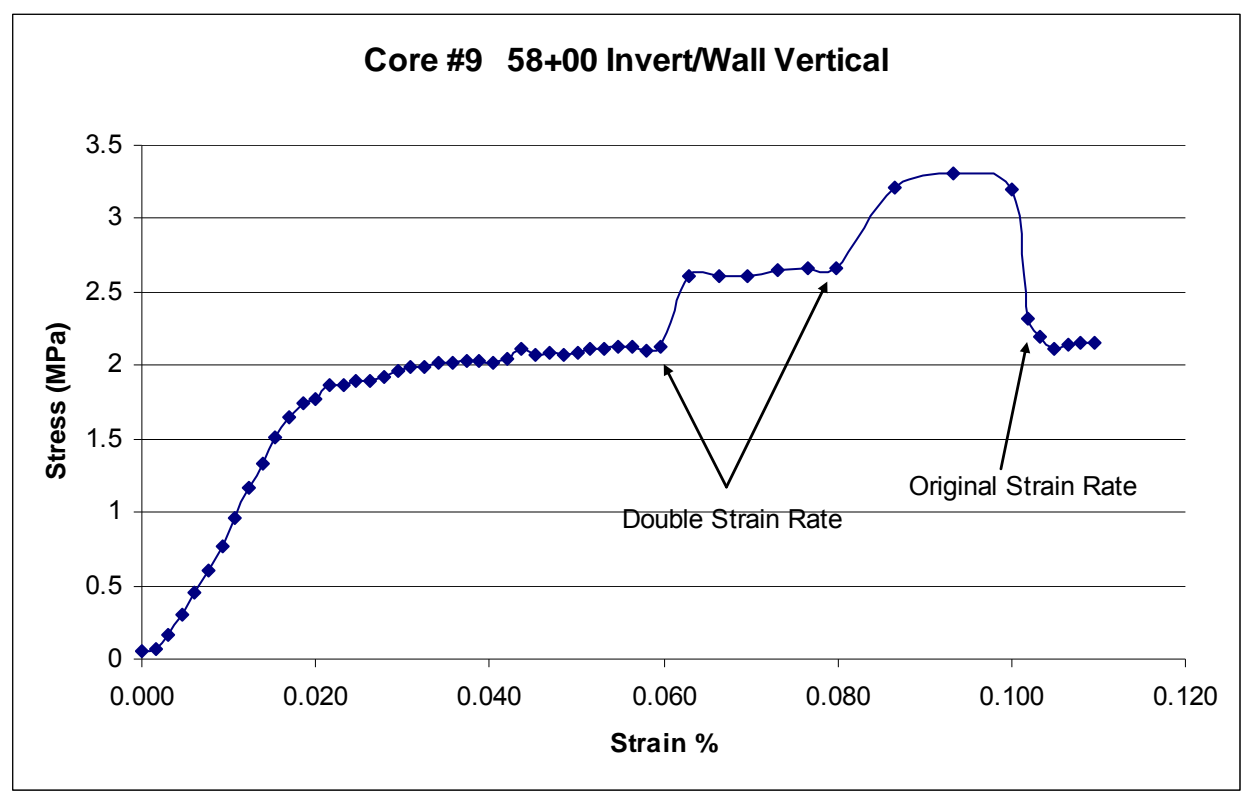

\#9-T Vertical, $-2.0^{\circ} \mathrm{C}, 1 \times 10^{-3} / \mathrm{s}$.

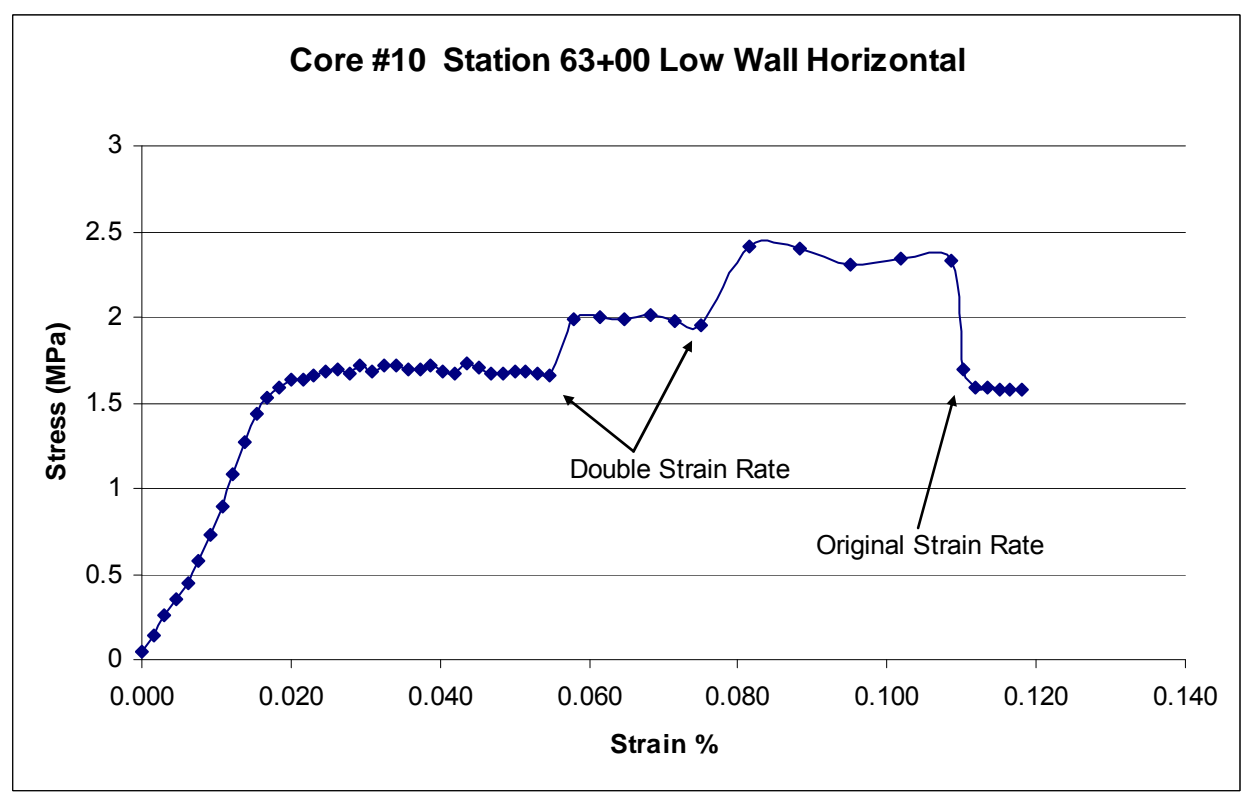

\#10-T Horizontal, $-2.0^{\circ} \mathrm{C}, 1 \times 10^{-3} / \mathrm{s}$. 


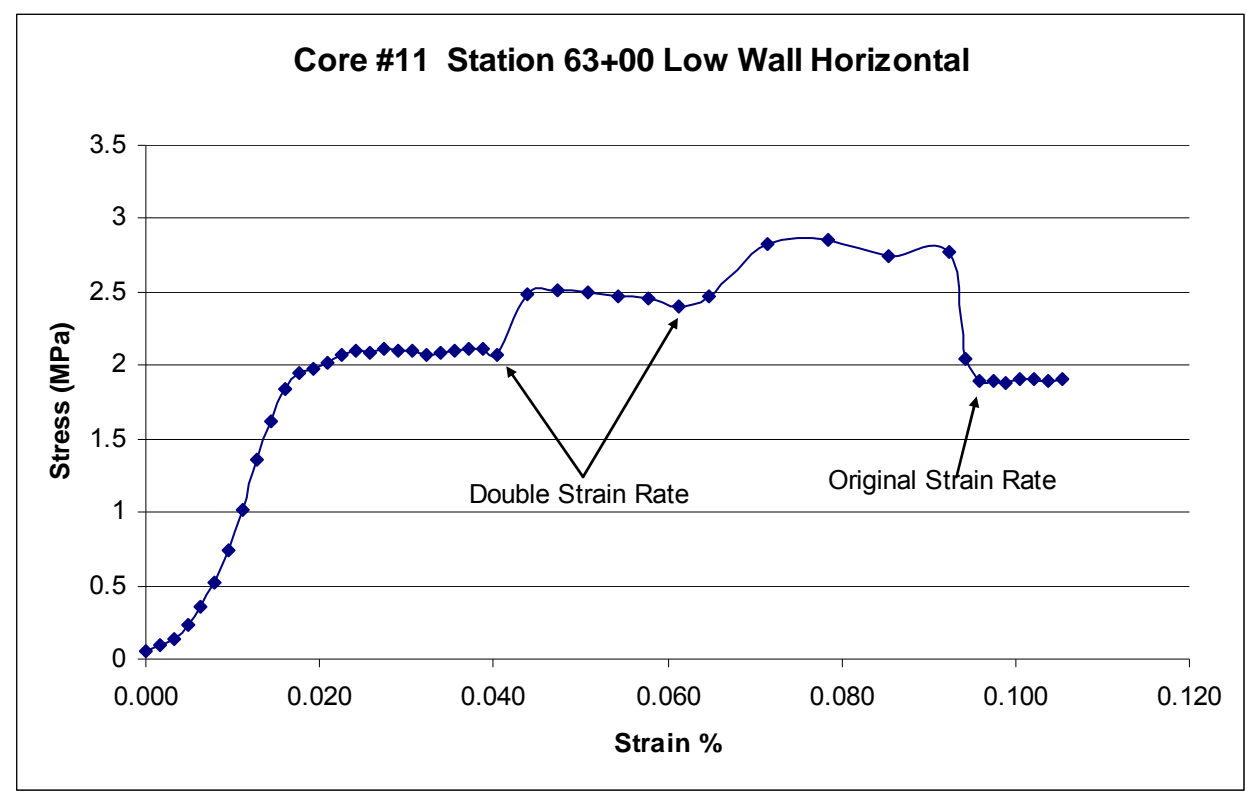

\#11-T Horizontal, $-2.0^{\circ} \mathrm{C}, 1 \times 10^{-3} / \mathrm{s}$.

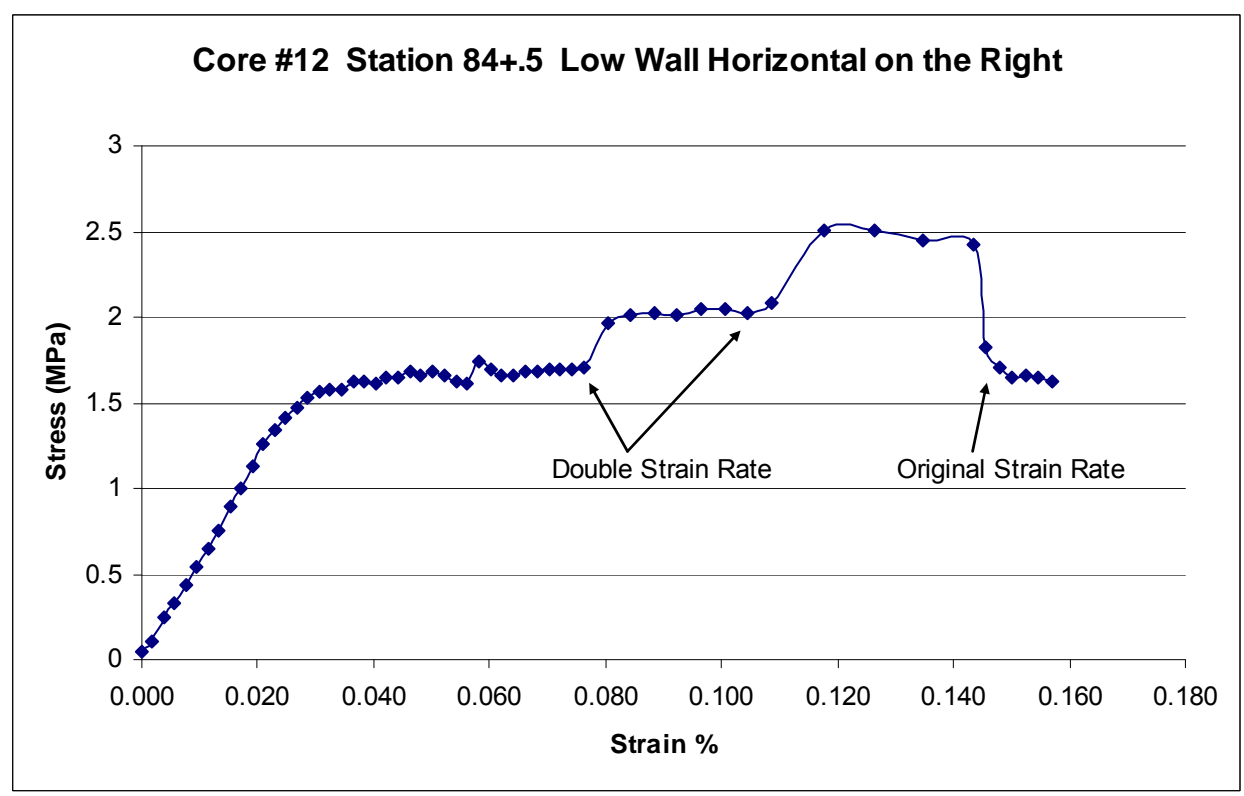

\#12-T Horizontal, $-2.0^{\circ} \mathrm{C}, 1 \times 10^{-3} / \mathrm{s}$. 


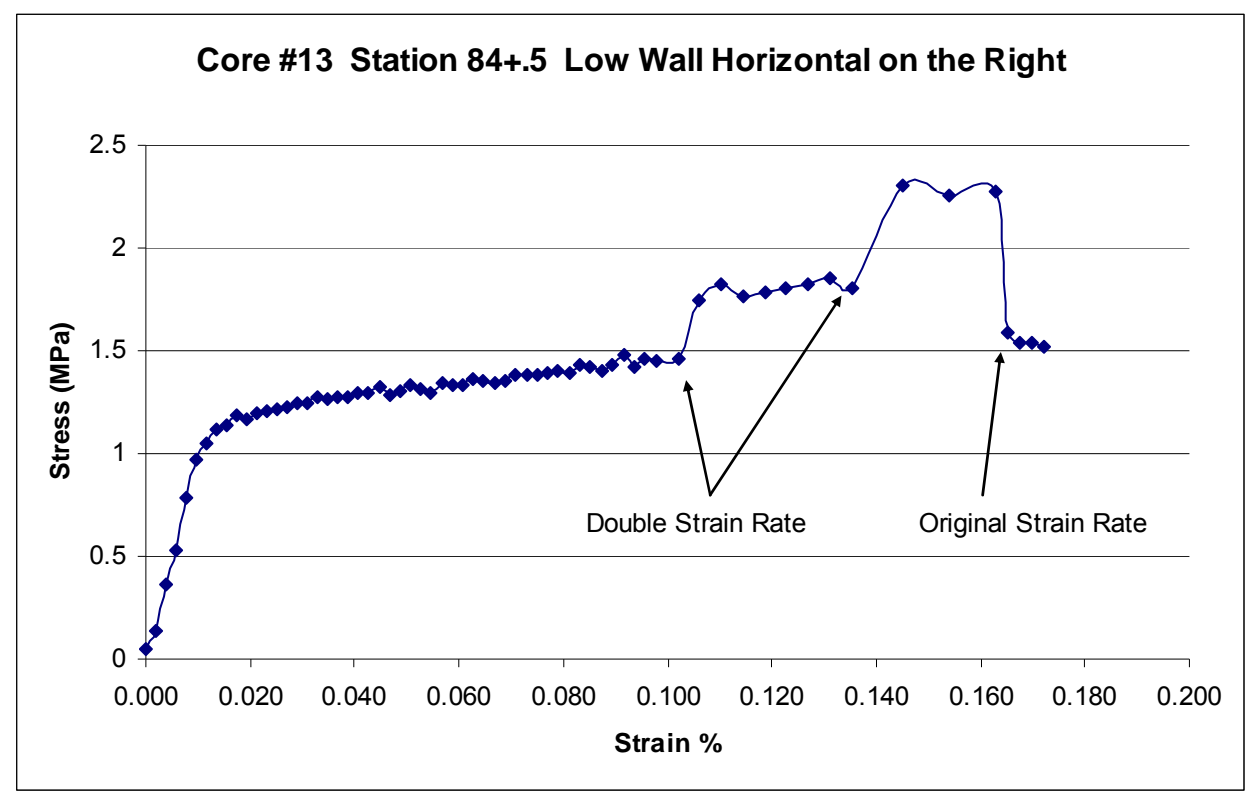

\#13-T Horizontal, $-2.0^{\circ} \mathrm{C}, 1 \times 10^{-3} / \mathrm{s}$.

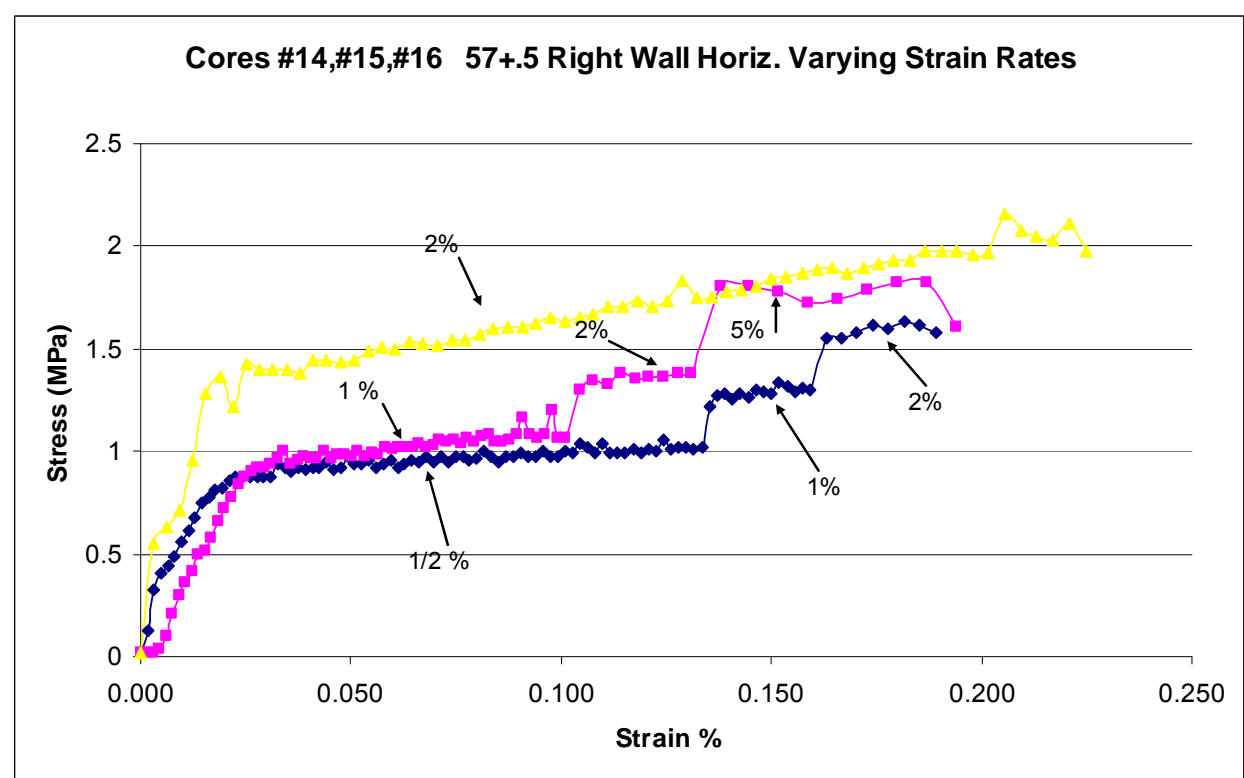

\#14-T, \#15-T, \#16-T Horizontal, $-2.0^{\circ} \mathrm{C}$, varying strain rates. 


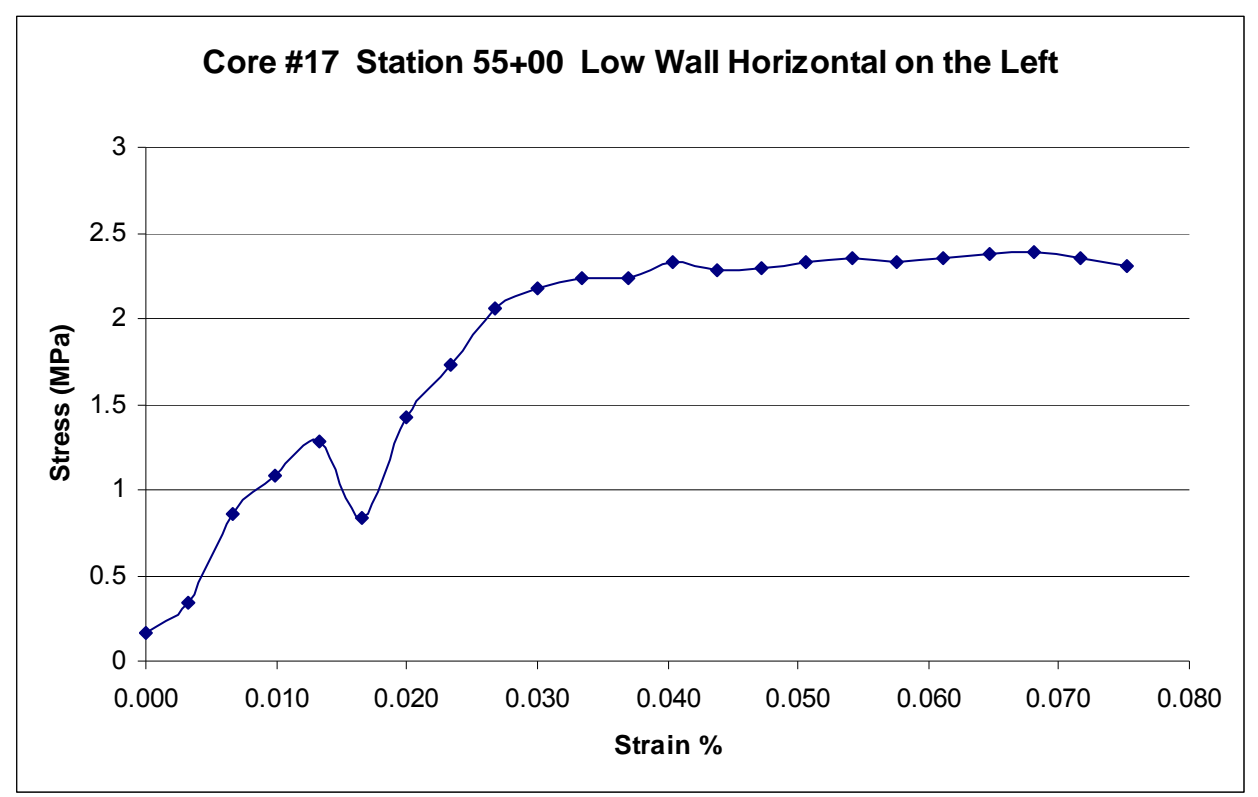

\#17-T Horizontal, $-2.0^{\circ} \mathrm{C}, 2 \times 10^{-3} / \mathrm{s}$. 


\section{APPENDIX C: Calibration of Load Cell}

\begin{tabular}{|c|c|c|c|}
\hline $\begin{array}{c}\text { Load } \\
\text { (lb) }\end{array}$ & $\begin{array}{c}\text { Output } \\
(\mathrm{V})\end{array}$ & Error (\%) & $\begin{array}{c}\text { Using 5 K Sensotec } \\
\text { Calibration Systems Vishay } \\
\text { BA-4 Amplifier settings }\end{array}$ \\
\hline 0 & 000 & & Gain $=8$ \\
\hline 100 & 0.100 & 0.00 & Cal $=20$ \\
\hline 500 & 0.500 & 0.00 & + cal $=-0.541$ \\
\hline 750 & 0.749 & -0.13 & - cal $=0.501$ \\
\hline 1000 & 1.001 & 0.1 & Single-ended output \\
\hline 1500 & 1.499 & -0.07 & Compression only \\
\hline 2000 & 2.002 & 0.1 & \multicolumn{2}{|c}{} \\
\hline
\end{tabular}

A calibration of the Soiltest Press was done to determine the displacement as a function of turns on the crank. This press was used in conjunction with the Revere load cell to obtain in-situ measurements of the load versus strain rate on the 17 samples tested in the tunnel. The calibration was as follows:

\begin{tabular}{|c|c|c|}
\hline $\begin{array}{c}\text { Turns of } \\
\text { crank }\end{array}$ & $\begin{array}{c}\text { Displacement } \\
\text { (in.) }\end{array}$ & Inches/turn \\
\hline 0 & 0 & \\
\hline 1 & 0.0063 & 0.0063 \\
\hline 2 & 0.0138 & 0.0069 \\
\hline 3 & 0.0213 & 0.0071 \\
\hline 4 & 0.0287 & 0.0072 \\
\hline 5 & 0.0367 & 0.0073 \\
\hline 6 & 0.0453 & 0.0076 \\
\hline 7 & 0.0539 & 0.0077 \\
\hline 8 & 0.0626 & 0.0078 \\
\hline 9 & 0.0717 & 0.0080 \\
\hline 10 & 0.0805 & 0.0081 \\
\hline 11 & 0.0896 & 0.0081 \\
\hline 12 & 0.0982 & 0.0082 \\
\hline 13 & 0.1069 & 0.0082 \\
\hline 24 & 0.203 & 0.0085 \\
\hline 30 & 0.2496 & 0.0083 \\
\hline & Average $=$ & 0.0077 \\
\hline
\end{tabular}




\section{APPENDIX D: Creep Station Measurements}

These measurements, taken on 16 May 2006, include only the meter reading of the metal tape and the millimeter reading from the dial gauge. Missing are the sliding scale readings of the centimeter fraction. Subsequent measurements will need to incorporate all three fractions.

The manual for operation of the analog tape extensometer is available at www.slopeindicator.com.

\begin{tabular}{|c|c|}
\hline $\begin{array}{l}\text { Reference point measurement } \\
\text { to reference point }\end{array}$ & Distance $(m+m m)$ \\
\hline $\mathrm{A} 1-\mathrm{A}$ to $\mathrm{A} 1-\mathrm{C}$ & $3.20+1.535$ \\
\hline A1-B to A1-D & $4.45+2.255$ \\
\hline $\mathrm{A} 2-\mathrm{A}$ to $\mathrm{A} 2-\mathrm{C}$ & $3.10+0.565$ \\
\hline$A 2-B$ to $A 2-D$ & $4.70+2.235$ \\
\hline *A3-A to A3-C & $2.70+.0685$ \\
\hline A4-A to A4-C & $2.45+0.00$ \\
\hline A4-B to A4-D & $3.40+3.12$ \\
\hline A5-A to A5-C & $2.25+0.815$ \\
\hline A5-B to A5-D & $4.20+1.430$ \\
\hline A6-A to A6-C & $1.65+3.425$ \\
\hline A6-B to A6-D & $3.50+2.190$ \\
\hline A7-A to A7-C & $1.85+4.550$ \\
\hline A7-B to A7-D & $3.35+2.900$ \\
\hline W1-A to W1-C & $1.70+1.090$ \\
\hline W1-B to W1-D & $4.00+3.705$ \\
\hline W2-A to W2-C & $1.50+1.280$ \\
\hline W2-B to W2-D & $4.20+4.025$ \\
\hline Reference Station at Bulkhead & $3.80+4.870$ \\
\hline \multicolumn{2}{|c|}{$\begin{array}{l}\text { * Creep Reference Location A3 consists only of vertical points. } \\
\text { †easured with Slope Indicator Analog Tape Extensometer Model \# } 51811599 . \\
\text { The first number is meters read from the tape, and the second number is } \\
\text { millimeters read from the dial. }\end{array}$} \\
\hline
\end{tabular}




\section{APPENDIX E: USBM Gravel Room Rock Bolt Elevations}

\begin{tabular}{|c|c|}
\hline Rock Bolt & $\begin{array}{c}\text { Elevation } \\
\text { (m) }\end{array}$ \\
\hline Bolt \#18 & 221.379 \\
\hline Bolt \#21 & 221.607 \\
\hline Bolt \#16 & 221.281 \\
\hline Bolt \#1 & 221.308 \\
\hline \multicolumn{2}{|c|}{ * Bottom of Rock Bolt Rod } \\
\hline
\end{tabular}

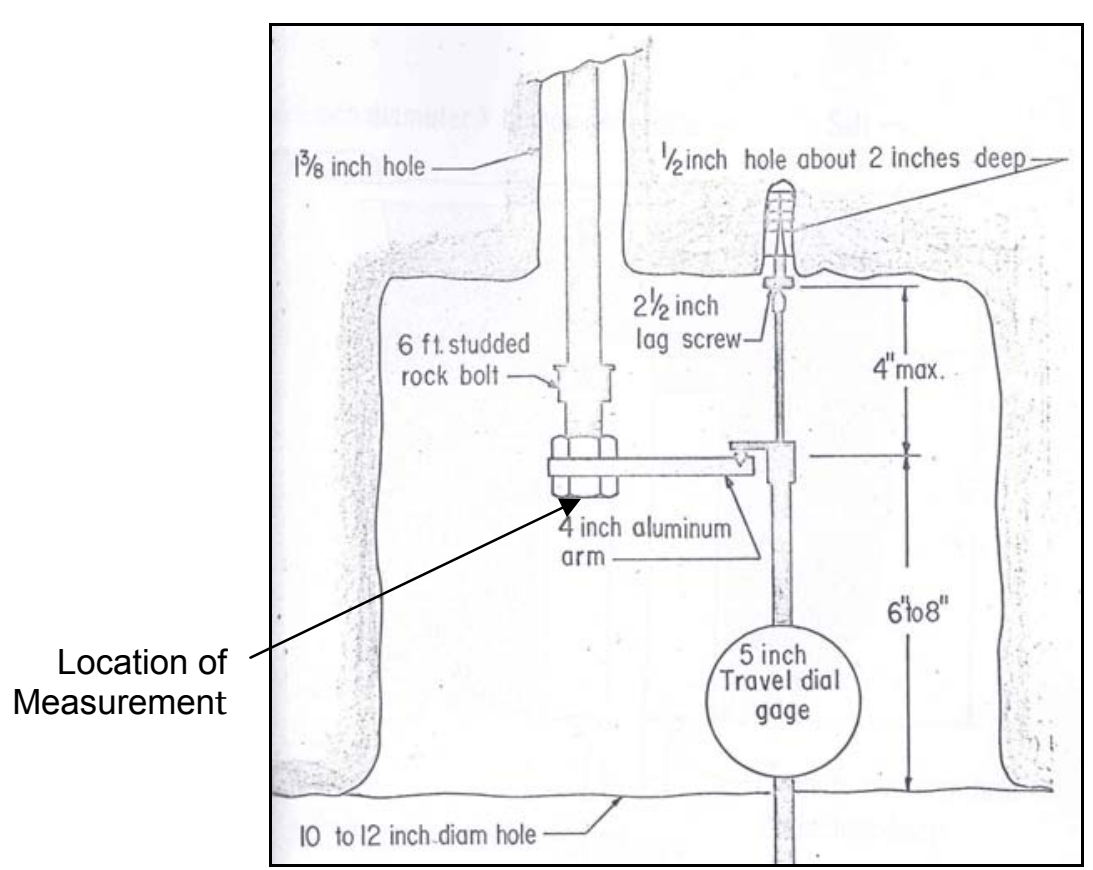

Figure E1. Rock bolt diagram, indicating the location of measurements. 


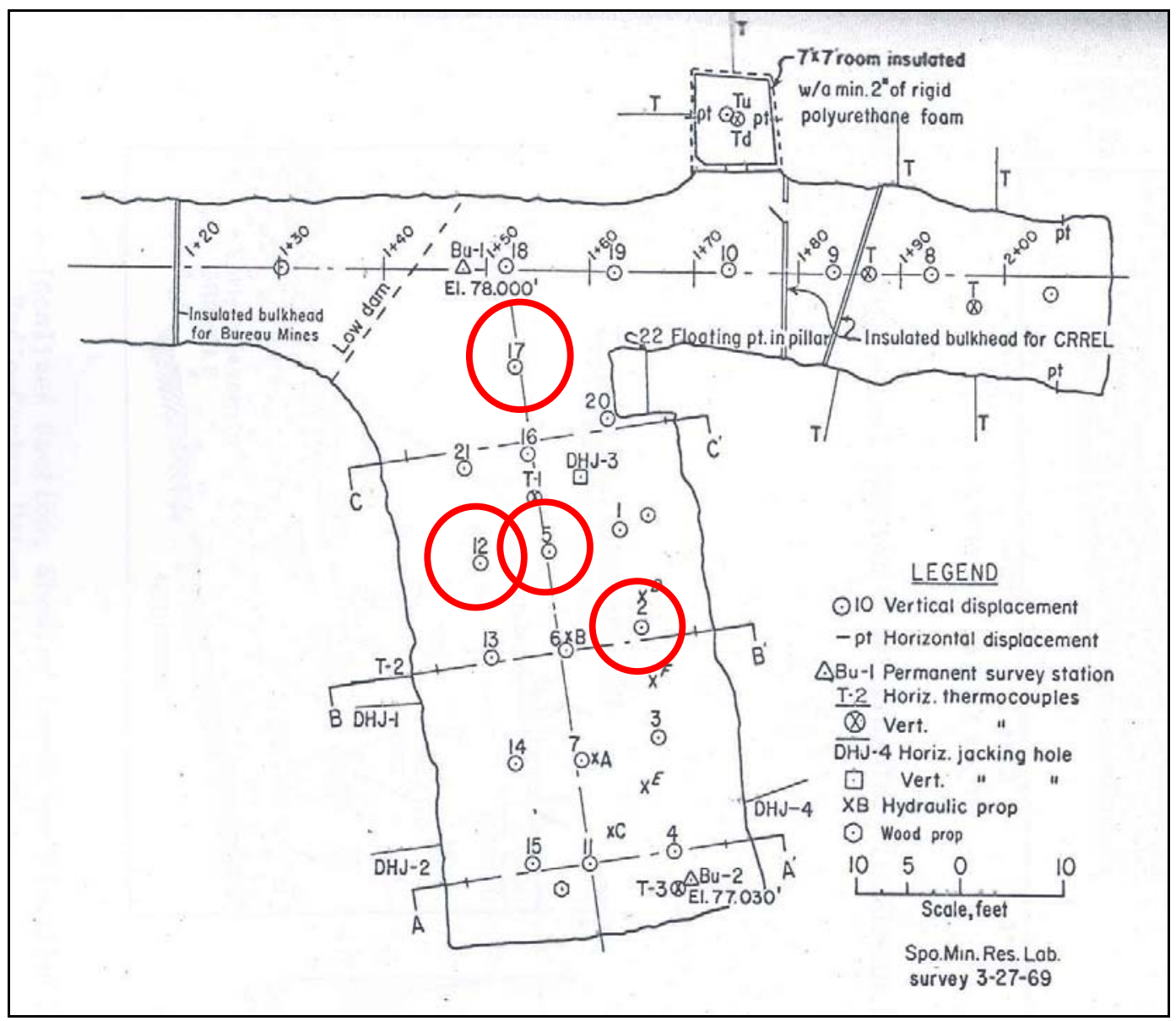

Figure E2. USBM survey of the Gravel Room in 1969. 2006 bolt height measurements are inferred to be those circled. The original data are unavailable. (From Pettibone 1973.) 


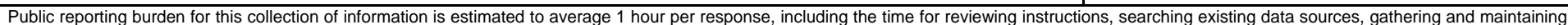

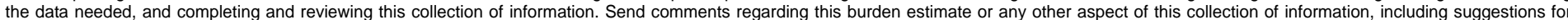

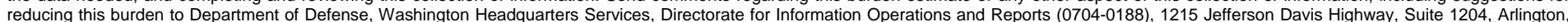

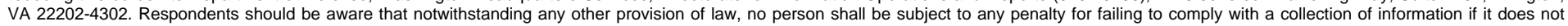
display a currently valid OMB control number. PLEASE DO NOT RETURN YOUR FORM TO THE ABOVE ADDRESS.
1. REPORT DATE (DD-MM-YYYY)
August 2008

\section{Technical Report}

4. TITLE AND SUBTITLE

Evaluation of the CRREL Permafrost Tunnel

6. AUTHOR(S)

Kevin Bjella, Thomas Tantillo, Jason Weale, and James Lever

7. PERFORMING ORGANIZATION NAME(S) AND ADDRESS(ES)

US Army Engineer Research and Development Center

Cold Regions Research and Engineering Laboratory

72 Lyme Road

Hanover, New Hampshire 03755-1290

9. SPONSORING I MONITORING AGENCY NAME(S) AND ADDRESS(ES)

3. DATES COVERED (From - To)

5a. CONTRACT NUMBER

5b. GRANT NUMBER

5c. PROGRAM ELEMENT NUMBER

5d. PROJECT NUMBER

5e. TASK NUMBER

5f. WORK UNIT NUMBER

8. PERFORMING ORGANIZATION REPORT NUMBER

ERDC/CRREL TR-08-11

10. SPONSOR/MONITOR'S ACRONYM(S)

11. SPONSOR/MONITOR'S REPORT NUMBER(S)

\section{DISTRIBUTION I AVAILABILITY STATEMENT}

Approved for public release; distribution is unlimited.

Available from NTIS, Springfield, Virginia 22161.

13. SUPPLEMENTARY NOTES

\section{ABSTRACT}

The Permafrost Tunnel was excavated in frozen silt and consists of a 110-m-long horizontal adit and a 45-m-long winze that extends down to the underlying gravel. Some change has occurred since the excavation was conducted in the mid-1960s, so a team was assembled in the spring of 2006 to assess these changes. Frozen silt deformation was noted in the rear of the adit, and a roof fall of the gravel layer was noted in the room at the bottom of the winze. Both of these were found to be attributable to thermal forcing events and the raising of the overall facility temperature to near-freezing temperatures. Sublimation was also noted throughout the tunnel, but this does not pose a problem for the structural integrity of the facility. The team recommends that the facility temperature be lowered to approximately $-5^{\circ} \mathrm{C}$, which will decrease creep rates and the weakening of lithologic bonds between soil units. Overall, the facility is safe for continued use by researchers and others.

\section{SUBJECT TERMS}

Creep, Excavation in frozen silt, Permafrost, Permafrost Tunnel, Strength of frozen ground

16. SECURITY CLASSIFICATION OF:

a. REPORT

$\mathrm{U}$ b. ABSTRACT

$\mathrm{U}$ c. THIS PAGE
17. LIMITATION OF ABSTRACT

$\mathrm{U}$
18. NUMBER OF PAGES

$\mathrm{U}$

68 19a. NAME OF RESPONSIBLE PERSON

19b. TELEPHONE NUMBER (include area code) 